\title{
Evaluating integrated lighting projects
}

\section{A Procedure to Post-Occupancy Evaluation of Daylight and Electrical Lighting Integrated Projects}

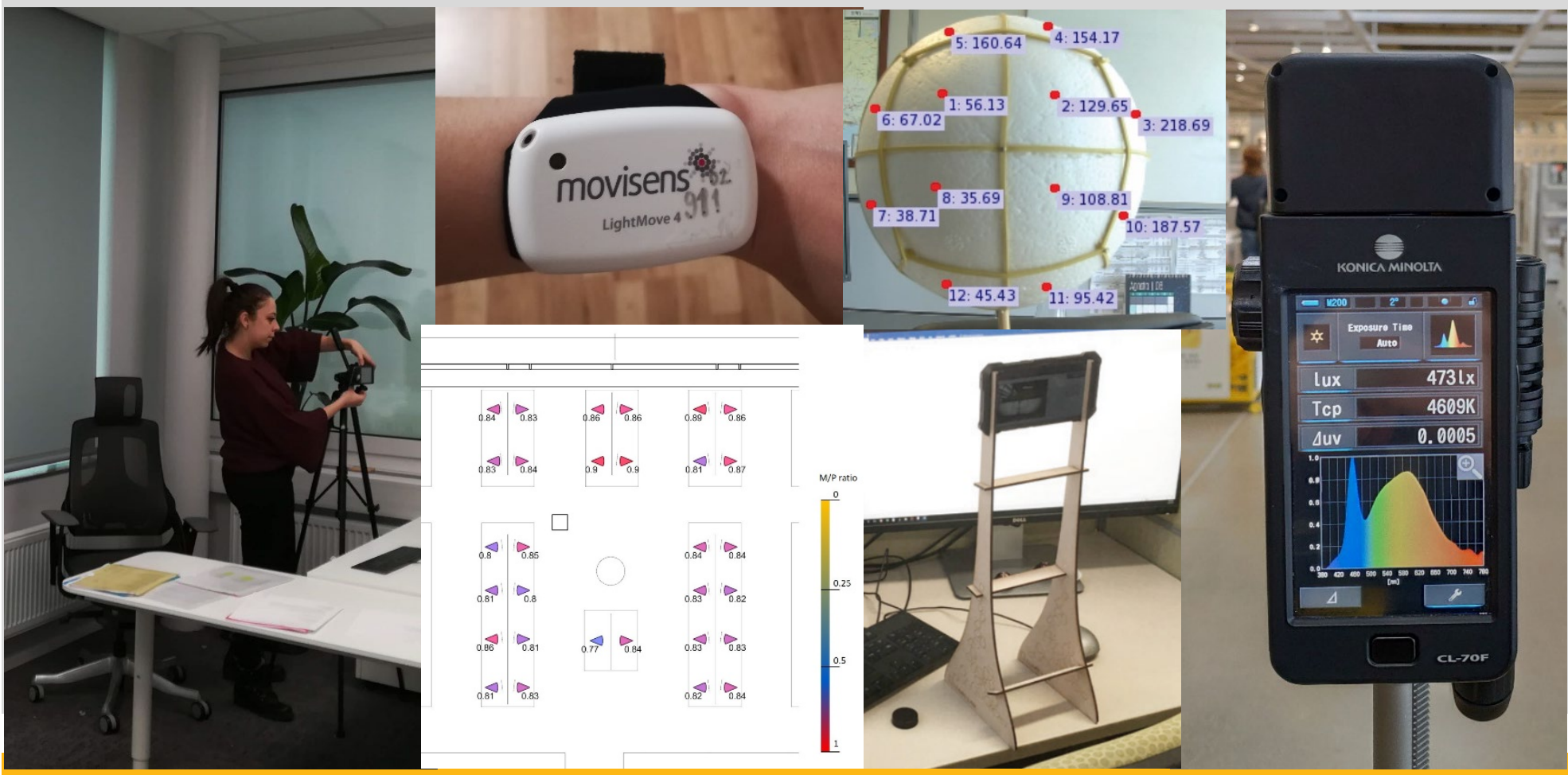

IEA SHC Task 61 / EBC Annex 77: Integrated Solutions for Daylighting and Electric Lighting 


\section{IEA Solar Heating and Cooling Technology Collaboration Programme (IEA SHC)}

The Solar Heating and Cooling Technology Collaboration Programme was founded in 1977 as one of the first multilateral technology initiatives ("Implementing Agreements") of the International Energy Agency. Its mission is "To enhance collective knowledge and application of solar heating and cooling through international collaboration to reach the goal set in the vision of solar thermal energy meeting $50 \%$ of low temperature heating and cooling demand by $2050 . "$

The members of the IEA SHC collaborate on projects (referred to as Tasks) in the field of research, development, demonstration (RD\&D), and test methods for solar thermal energy and solar buildings.

Research topics and the associated Tasks in parenthesis include:

- Solar Space Heating and Water Heating (Tasks 14, 19, 26, 44, 54)

- Solar Cooling (Tasks 25, 38, 48, 53, 65)

- Solar Heat for Industrial or Agricultural Processes (Tasks 29, 33, 49, 62, 64)

- Solar District Heating (Tasks 7, 45, 55)

- Solar Buildings/Architecture/Urban Planning (Tasks 8, 11, 12, 13, 20, 22, 23, 28, 37, 40, 41, 47, 51, 52, 56, 59, 63)

- Solar Thermal \& PV (Tasks 16, 35, 60)

- Daylighting/Lighting (Tasks 21, 31, 50,61)

- Materials/Components for Solar Heating and Cooling (Tasks 2, 3, 6, 10, 18, 27, 39)

- Standards, Certification, and Test Methods (Tasks 14, 24, 34, 43, 57)

- Resource Assessment (Tasks 1, 4, 5, 9, 17, 36, 46)

- Storage of Solar Heat (Tasks 7, 32, 42, 58)

In addition to our Task work, other activities of the IEA SHC include our:

$>$ International Conference on Solar Heating and Cooling for Buildings and Industry

$>$ SHC Solar Academy

$>$ Solar Heat Worldwide annual statics report

$>$ Collaboration with solar thermal trade associations

\section{Country Members}

$\begin{array}{lll}\text { Australia } & \text { France } & \text { South Africa } \\ \text { Austria } & \text { Germany } & \text { Spain } \\ \text { Belgium } & \text { Italy } & \text { Sweden } \\ \text { Canada } & \text { Netherlands } & \text { Switzerland } \\ \text { China } & \text { Norway } & \text { Turkey } \\ \text { Denmark } & \text { Portugal } & \text { United Kingdom } \\ \text { European Commission } & \text { Slovakia } & \end{array}$

\section{Sponsor Members}

European Copper Institute

ECREEE

International Solar Energy Society

RCREEE

CCREEE

RCREEE

EACREEE

SACREEE 
For more information on the IEA SHC work, including many free publications, please visit www.iea-shc.org.

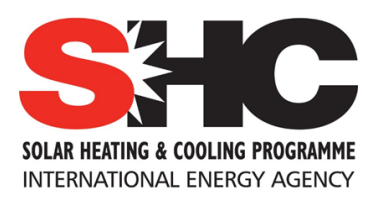

\section{Evaluating integrated lighting projects}

Edited by (in alphabetical order)

AMORIM NAVES DAVID, Cláudia

GARCIA-HANSEN, Veronica

GENTILE, Niko

OSTERHAUS, Werner

PHAM, Kieu

21 September 2021

DOI: 10.18777/ieashc-task61-2021-0006

The contents of this report do not necessarily reflect the viewpoints or policies of the International Energy Agency (IEA) or its member countries, the IEA Solar Heating and Cooling Technology Collaboration Programme (SHC TCP) members or the participating researchers. 
AUTHORS (in alphabetical order)

Sergio ALTOMONTE

Architecture et Climat, LAB-LOCI

Place du Levant 1 / L5.05.04

1348 Louvain-la-Neuve

Belgium

sergio.altomonte@uclouvain.be

Cláudia NAVES DAVID AMORIM

Laboratory of Environmental Control and Energy

Efficiency

LACAM-Faculty of Architecture and Urbanism -

University of Brasília

Campus Universitário Darcy Ribeiro, Ala Norte

70.910-900 Brasília

Distrito Federal Brazil

clamorim@unb.br

Rafael Campamá PIZARRO

Lund University

Box 118

22100 Lund

Sweden

rafael.campama_pizarro@ebd.Ith.se

Donatienne CARMON

Architecture et Climat, LAB-LOCI

Place du Levant 1 / L5.05.04

1348 Louvain-la-Neuve

Belgium

donatiennecarmon@hotmail.com

Giovanni CIAMPI

Department of Architecture and Industrial Design, University of Campania "Luigi Vanvitelli"

via San Lorenzo

81031 Aversa (CE)

Italy

giovanni.ciampi@unicampania.it

Ruben DELVAEYE

Belgian Building Research Institute

Avenue P. Holoffe 211342 Limelette

Belgium

Ruben.delvaeye@bbri.be

Veronica GARCIA-HANSEN

Queensland University of Technology

GPO box 2434

4001 Brisbane

Australia

v.garciahansen@qut.edu.au

Niko GENTILE

Lund University

Box 118

22100 Lund

Sweden

niko.gentile@ebd.Ith.se
David GEISLER-MORODER

Bartenbach $\mathrm{GmbH}$

Rinner Strasse 14

6071 Aldrans

Austria

david.geisler-moroder@bartenbach.com

Myrta GKAINTATZI MASOUTI

Eindhoven University of Technology

Department of the Built Environment

P.O. Box 513

5600 MB Eindhoven

Netherlands

m.gkaintatzi.masouti@tue.nl

Hillevi HEMPHÄLÄ

Lund University

Box 118

22100 Lund

Sweden

hillevi.hemphala@design.Ith.se

Johannes LINDÉN

Lund University

Box 118

22100 Lund

Sweden

johannes.linden@design.Ith.se

Werner OSTERHAUS

Department of Civil and Architectural Engineering -

Design and Construction

Inge Lehmanns Gade 10 building 3210

8000 Aarhus C

Denmark

werner.osterhaus@cae.au.dk

Francisca RODRIGUEZ

Queensland University of Technology

GPO box 2434

4001 Brisbane

Australia

f2.leonard@qut.edu.au

Kieu PHAM

Queensland University of Technology

GPO box 2434

4001 Brisbane

Australia

kieu.pham@qut.edu.au

Clotilde PIERSON

EPFL ENAC IA LIPID

LE 1113 (Bâtiment LE)

Station 18

$\mathrm{CH}-1015$ Lausanne

Switzerland

clotilde.pierson@epfl.ch 


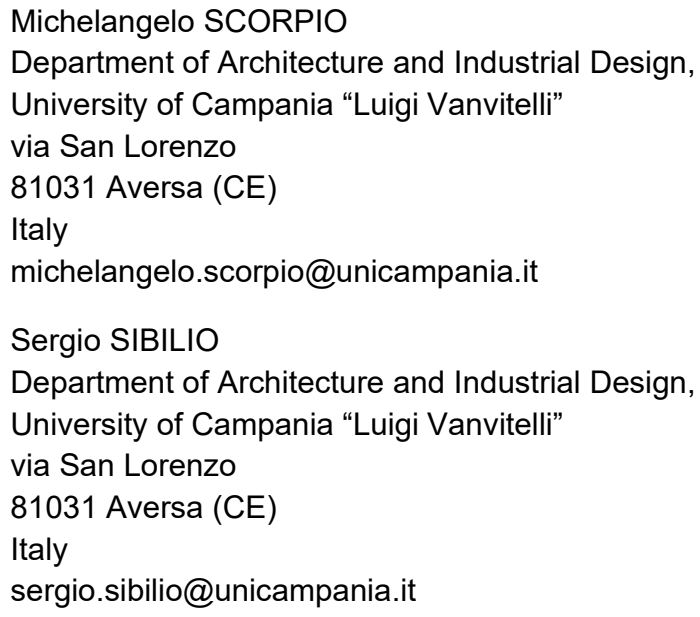

\section{AUTHORS CONTRIBUTION}

- Rafael Campamá Pizarro contributed with conceptual notes, the SWOT analysis approach, and with the beta testing of the framework

- Donatienne Carmon contributed with the section on ALFA simulation software and Spektro analysis for ageing population

- Ruben Delvaeye provided insights on the calculation of energy for lighting and shared publicly a relative Excel sheet based on the EN15193-1:2017

- Myrta Gkaintatzi Masouti contributed with the section on Lark simulation software and the section on wearable devices

- Johannes Lindén and Hillevi Hemphälä contributed with the section on Temporal Light Modulation

- $\quad$ Clotilde Pierson contributed with the step-by-step guide to produce HDR images with DSLR cameras

- Francisca Rodriguez provided contributed with the section on view out

All the other authors equally contributed to the concept, development, writing and revision of this report.

Pimkamol Mattsson and Thorbjörn Laike (Lund University) are acknowledged for providing insights on the lighting diary and the PILQ questionnaire.

Elif Ceren Yılmaz and Rawan Abdulhaq are acknowledged for having provided useful insights on wearable devices and ALFA simulation software.

David Geisler-Moroder (Bartenbach $\mathrm{GmbH}$ ) is acknowledged for sharing the semantic differential scale used at Bartenbach. 


\section{KEYWORDS}

Indoor lighting, post-occupancy evaluations, monitoring, measurements, integrated lighting, electric lighting, daylighting, light quality, user assessment, energy use, non-visual effects.

\section{ACKNOWLEDGEMENTS}

The authors thank their respective funding agencies for supporting their work:

- The Swedish Energy Agency EELYS programme, project 45165-1

- the Danish Energy Agency EUDP programme, project 64017-05110

- the Brazilian National Council of Scientific and Technological Development - CNPq

- The Australian Research Council (ARC) Linkage Scheme in collaboration with AECOM and Light Naturally, project LP150100179

- The Australian Renewable Energy Agency (ARENA), project RE017

- SST - UCLouvain

- the Federal Ministry for Climate Action, Environment, Energy, Mobility, Innovation and Technology (BMK) through the IEA Research Cooperation program managed by the Austrian Research Promotion Agency FFG (project 864136) 


\title{
PREFACE
}

Lighting accounts for approximately $15 \%$ of the global electric energy consumption and $5 \%$ of greenhouse gas emissions. Growing economies, higher user demands for quality lighting and rebound effects as a result of low priced and more versatile electric lighting lead to an absolute increase of lighting energy consumption. More light is used, often less consciously.

The electric lighting market as well the façade, daylighting and building automation sectors have seen significant technological developments in the past decade. However, these sectors still act mainly independent of each other, missing out on the energy saving potential achievable with better technology and market integration. The integration benefits are two-fold, it is beneficial in providing better user-centred lighting of indoor spaces, and it can contribute significantly to the reduction of worldwide electricity consumptions and C02-emissions, which is in line with several different governmental energy efficiency and sustainability targets.

IEA SHC Task 61 / EBC Annex 77 "Integrated Solutions for daylighting and electric lighting - From Component to system efficiency" therefore aims to support and foster the better integration of electric lighting and daylighting systems including lighting controls with a focus on the non-residential sector. This includes the following activities:

- Review the relationship between user perspective (needs/acceptance) and energy in the emerging age of "smart and connected lighting" for a relevant repertory of buildings.

- Consolidate findings in use cases and "personas" reflecting the behaviour of typical users.

- Based on a review of specifications concerning lighting quality, non-visual effects as well as ease of design, installation and use, provision of recommendations for energy regulations and building performance certificates.

- Assess and increase robustness of integrated daylight and electric lighting approaches technically, ecologically, and economically.

- Demonstrate and verify or reject concepts in lab studies and real use cases based on performance validation protocols.

- Develop integral photometric, user comfort and energy rating models (spectral, hourly) as pre-normative work linked to relevant bodies: CIE, CEN, ISO. Initialize standardization.

- Provide decision and design guidelines incorporating virtual reality sessions. Integrate approaches into widespread lighting design software.

- Combine competencies: Bring companies from electric lighting and façade together in workshops and specific projects. Hereby support allocation of added value of integrated solutions in the market.

To achieve this goal, the work plan of IEA SHC Task 61 / EBC Annex 77 is organized according to the following four main subtasks, which are interconnected by a joint working group:

- $\quad$ Subtask A:

- Subtask B:

- Subtask C:

- Subtask D:

- Joint Working Group:

\author{
User perspective and requirements \\ Integration and optimization of daylight and electric lighting \\ Design support for practitioners (Tools, Standards, Guidelines) \\ Lab and field study performance tracking \\ Evaluation tool \& VR Decision Guide
}

Subtask $D$ demonstrates and assesses, and either verify or reject, currently available and typically applied concepts for daylighting and electric lighting design and their integration to better understand how various integrated lighting systems and their control mechanisms behave with respect to important parameters (e.g., energy use, thermal and visual environment, maintenance, adaptability to new requirements, etc.) and how building users respond to them. Work includes a comprehensive literature review of relevant research materials (in close collaboration with Subtask A.1), targeted medium-term experiments in living laboratories, supplemented by short-term investigations of specific concepts or ideas in controlled research laboratory environments, as well as performance tracking through "real" field studies in recently completed or retrofitted buildings across selected building types in several of the participating countries. Case studies were selected in close collaboration with other Subtasks.

Subtask D project areas:

- D.1. Literature Survey: Quantifying Potential Energy Savings

- D.2. Monitoring Protocol

- D.3. Case Studies: Living Laboratories and Real Buildings

- $\quad$ D.4. Lessons Learned - Guidance to Decision Makers 


\section{EXECUTIVE SUMMARY}

This report presents tools for post-occupancy evaluation (POE) to evaluate indoor lighting of commissioned projects ('case studies') under a common framework. In this report, POE includes technical environmental assessment (TEA) and observer-based environmental assessment (OBEA). The framework proposed in this report evaluates four key aspects of the case study:

1. Energy use (electrical lighting systems),

2. Visual effects (Indoor lighting environment/photometry)

3. Non-visual effects (circadian potential), and

4. The user (subjective/surveys and observations)

The report targets industry professionals, building designers, lighting designers, building managers, researchers and/or owners wishing to evaluate projects where lighting is supplied by a combination of electrical lighting, daylighting systems (e.g., fenestrations) and assisted technologies (e.g., smart sensors). The framework in this report makes available methods and procedures related to the evaluation of integrated lighting performance in residential and non-residential buildings and its impact on users, and it summarises and categorize methods and procedures in an accessible and industry-oriented language.

The content of this document is based on methods and procedures used by participating experts in IEA SHC Task 61 for monitoring twenty-five worldwide integrated daylighting and electric lighting case studies. Since integrated lighting projects are different in type and scopes, the methods and procedures included in the framework do not follow a rigid protocol. Practitioners should use the framework to define the scope of POE monitoring in terms of the aims of the project, context, and resources available. The document is thus a toolbox for planning and executing the monitoring of their integrated lighting projects. 


\section{Contents}

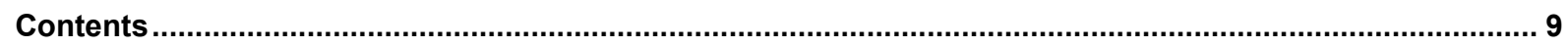

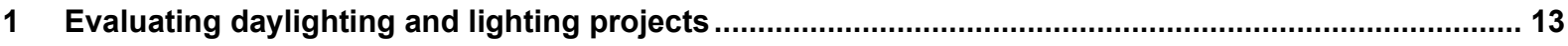

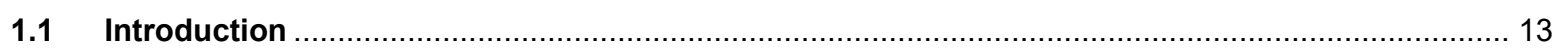

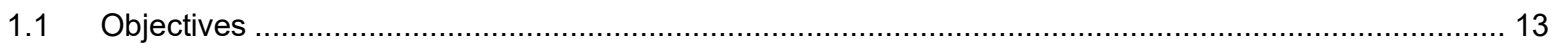

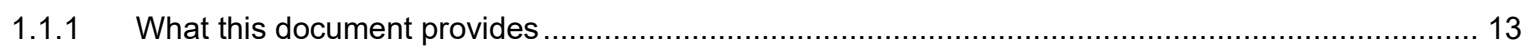

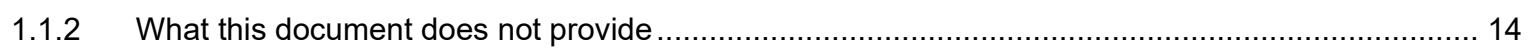

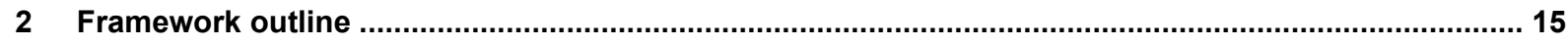

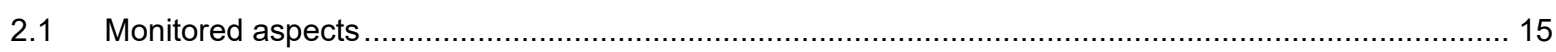

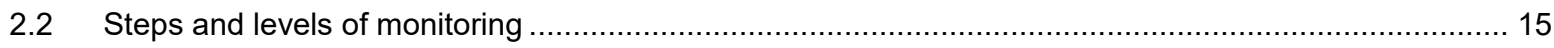

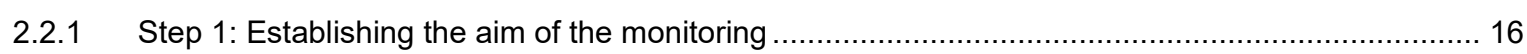

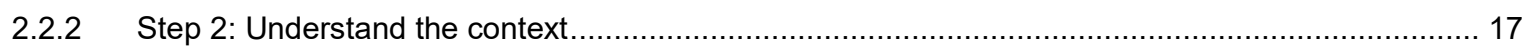

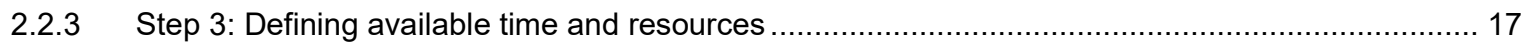

2.2.4 Step 4: Developing the monitoring scope........................................................................... 21

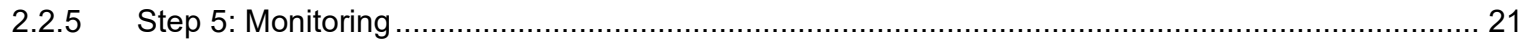

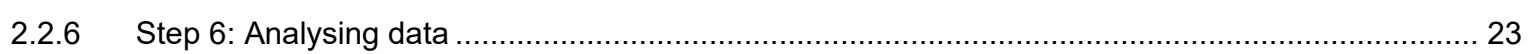

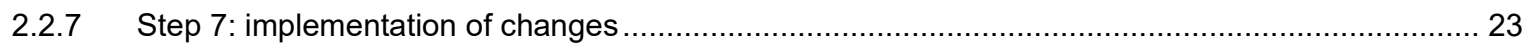

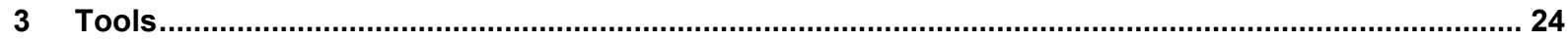

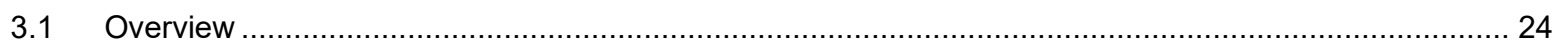

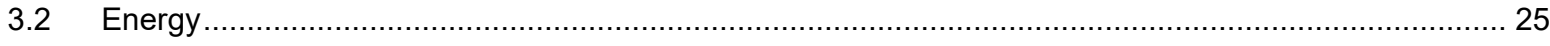

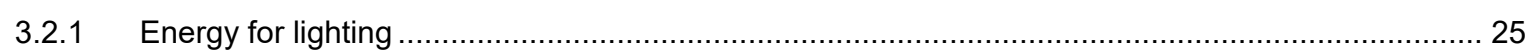

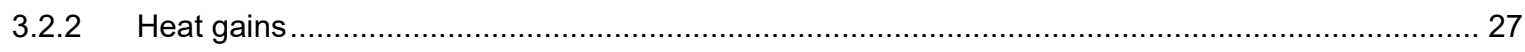

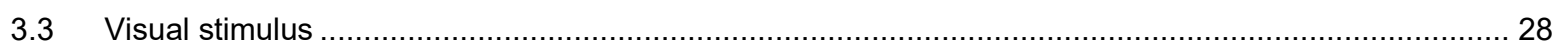

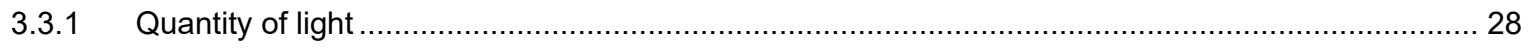

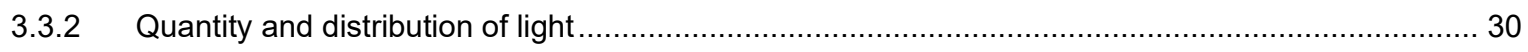

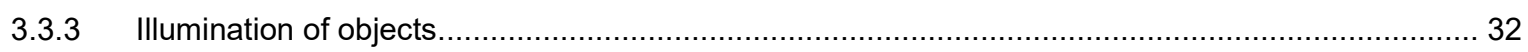

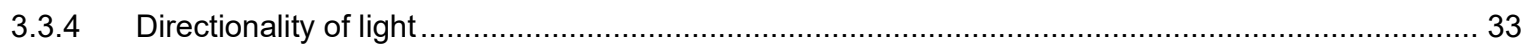

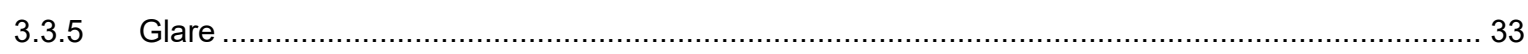

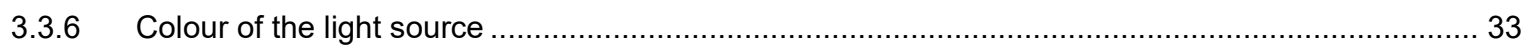

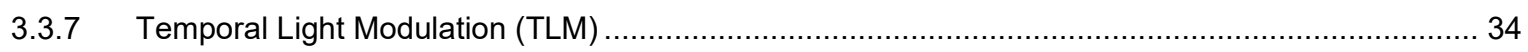

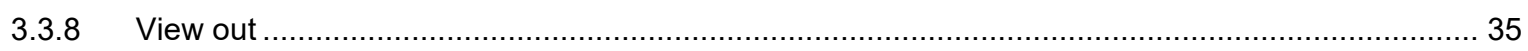

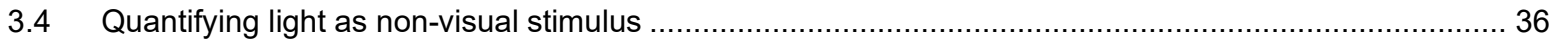

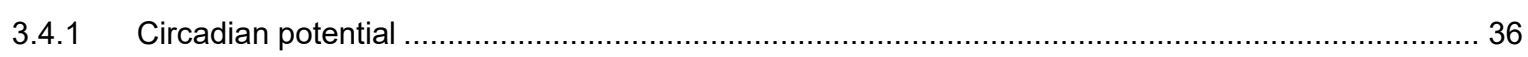

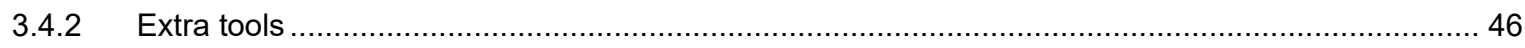

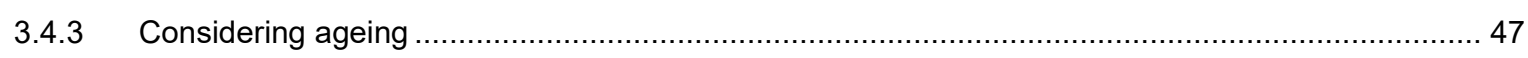

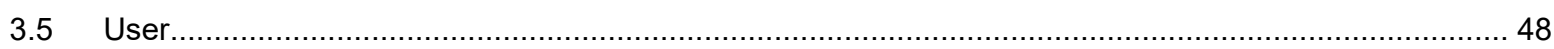

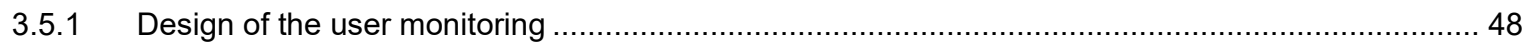

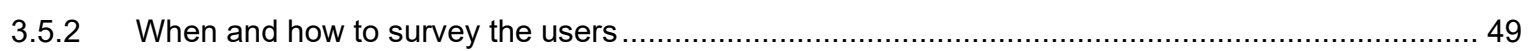




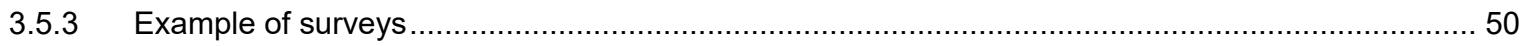

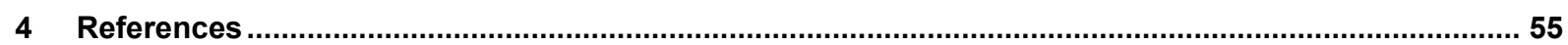

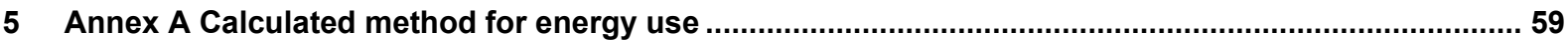

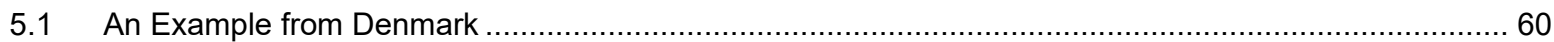

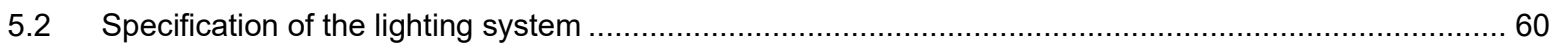

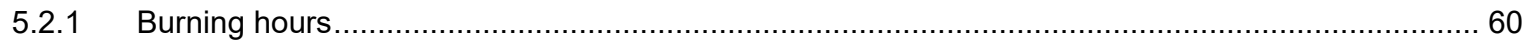

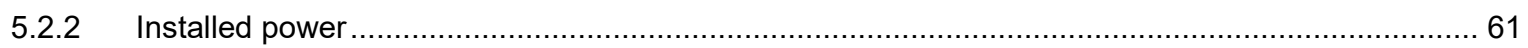

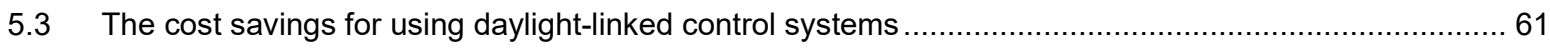

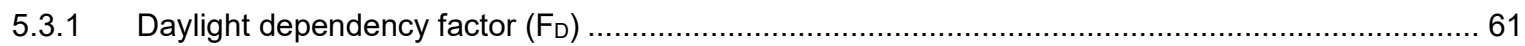

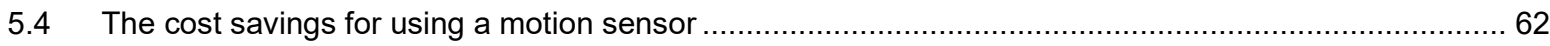

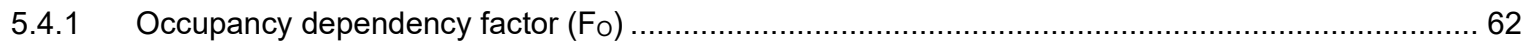

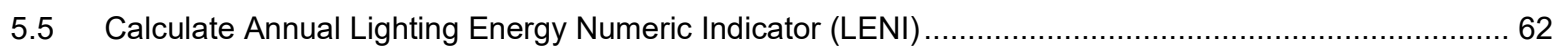

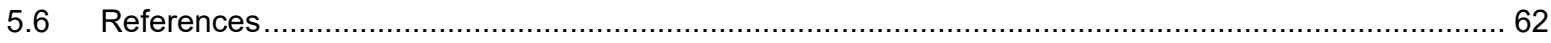

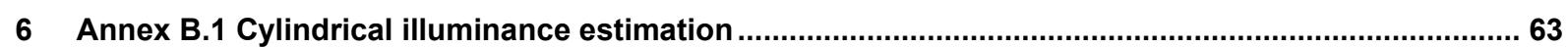

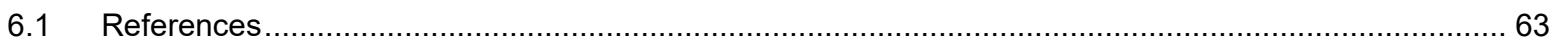

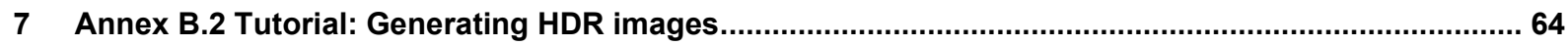

7.1 Step-by-step calibration using an automatic merging algorithm ................................................. 64

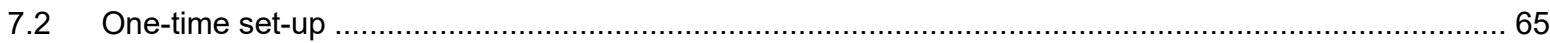

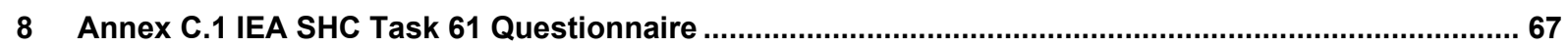

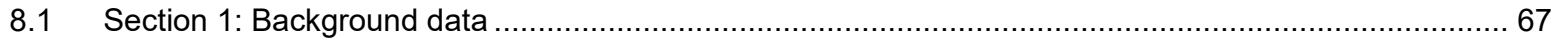

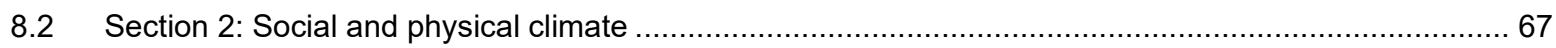

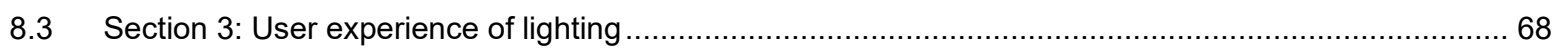

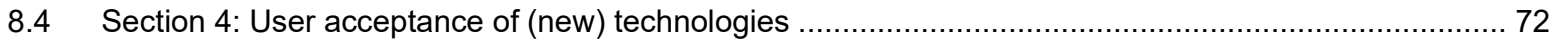

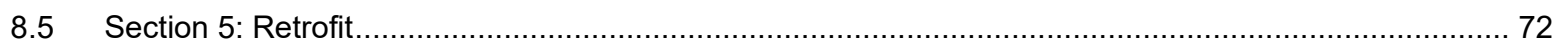

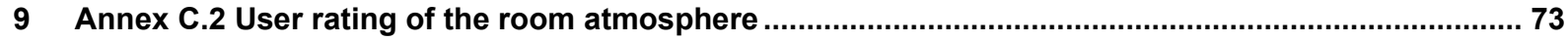

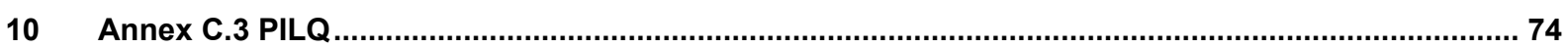

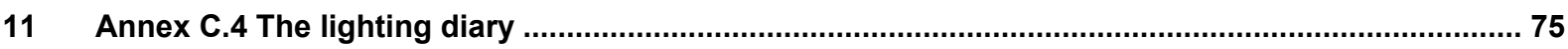

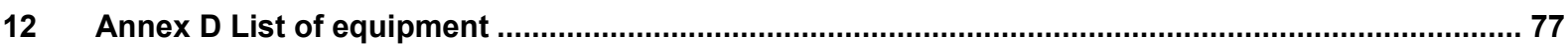




\section{SYMBOLS}

A

aview,space

bglazing

Cdaylighting

Celectricity

Clighting

Cmaintenance

Coperation

Cretro

CRI Ra

d

Doperation

droom

E

$E$ (max)

E(-max)

Eng

$\mathrm{E}_{\mathrm{s}}$

Esurround task

Etask

$E_{v}$

Evertical eye

Evgs

Ewp

$\mathrm{F}_{\mathrm{C}}$

$\mathrm{F}_{\mathrm{cc}}$

FD

Fo

foc

L

$L_{(p)}$

Lb

Lceiling

Lergo

Lpano

Ls

Ltask

Lwalls

$\mathrm{p}$

$\mathrm{P}$

$\mathrm{P}_{\mathrm{ci}}$

$\mathrm{Pei}_{\mathrm{e}}$
Total useful floor area of the building (m2)

Width of the view (m)

Total of the width of the transparent glazing of all windows $(\mathrm{m})$

Total cost of daylighting systems $\left(€ / \mathrm{m}^{2}\right)$

Cost of electricity in the area where the building is located ( $€ / \mathrm{kWh}$ )

Total cost of retrofitted electric lighting system $\left(€ / \mathrm{m}^{2}\right)$

Maintenance cost, $\left(€ / \mathrm{m}^{2}\right)$

Operation costs $\left(€ / \mathrm{m}^{2}\right)$

Total cost of the retrofit project $\left(€ / \mathrm{m}^{2}\right)$

Colour rendering index

Longer dimension of the calculation area $(\mathrm{m})$

Annual operation time (hours/year)

Depth of space $(\mathrm{m})$

Illuminance (lux)

Highest illuminance at the surface of a diffuse sphere (lux)

Illuminance measured at the opposite side of the diffuse sphere (lux)

Exterior horizontal global illuminance (lux)

Scalar illuminance (lux)

Horizontal illuminance surrounding the task (lux)

Horizontal illuminance on task (lux) or otherwise the workplane height measured at 0.75 or $0.85 \mathrm{~m}$ from the finish floor level

Vector illuminance (lux)

Vertical illuminance on the eye (lux)

Vertical sky illuminance on façade (lux)

Horizontal illuminance at work plane height (lux)

Constant illuminance factor

Efficiency factor of the constant illuminance control

Daylight dependency factor

Occupancy dependency factor

Luminance ratio between the exterior vertical sky illuminance and the exterior horizontal global illuminance

Luminance of luminaire in the direction of the observer's eye $\left(\mathrm{cd} / \mathrm{m}^{2}\right)$

Luminance of point on perfectly diffusing white sphere $\left(\mathrm{cd} / \mathrm{m}^{2}\right)$

Background luminance $\left(\mathrm{cd} / \mathrm{m}^{2}\right)$

Luminance of the ceiling $\left(\mathrm{cd} / \mathrm{m}^{2}\right)$

Luminance surrounding the task in the ergorama $\left(\mathrm{cd} / \mathrm{m}^{2}\right)$

Luminance surrounding the task in the panorama $\left(\mathrm{cd} / \mathrm{m}^{2}\right)$

Luminance of a glare source $\left(\mathrm{cd} / \mathrm{m}^{2}\right)$

Luminance of task $\left(\mathrm{cd} / \mathrm{m}^{2}\right)$

Luminance of the walls $\left(\mathrm{cd} / \mathrm{m}^{2}\right)$

Maximum grid cell size $(\mathrm{m})$

Guth's position index

Standby power for the luminaire controls (W)

Luminaire emergency battery charging power (W) 


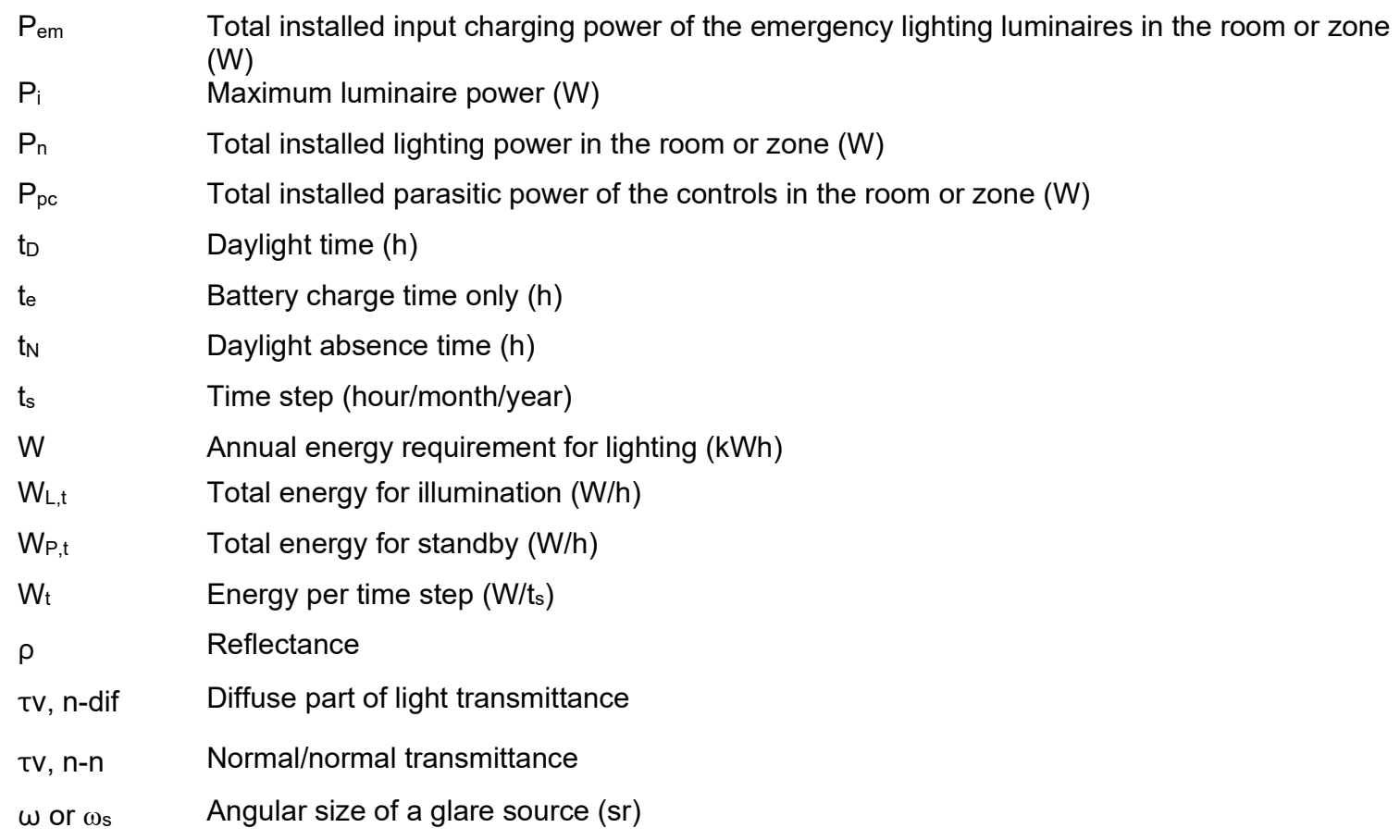




\section{Evaluating daylighting and lighting projects}

\subsection{Introduction}

This report presents a framework and tools to create post-occupancy evaluations (POE) to evaluate indoor daylighting and electric lighting projects for residential and non-residential buildings ('case studies'). POE can be defined as "a platform for the systematic study of buildings once occupied, so that lessons may be learned that will improve their current conditions and guide the design of future buildings". The POE can also be defined as the process for documenting stakeholders' reports about ways that building features and qualities support their work and well-being in various conditions (Preiser et al., 2015). POE draws on an extensive quantitative and qualitative toolkit: physical measurements and monitoring, as well as subjective and interactional methods. In this report, POE includes technical environmental assessment (TEA) and observer-based environmental assessment (OBEA), as the quality of environmental features, such as lighting, can be assessed by both (Meir et al., 2009). TEA is referred to as a "place centred" and "objective" because it involves tools and measures (metrics) to produce a reading of environmental quality and the OBEA is usually termed "person-centred" and "subjective" since it relies on self-report tools through which people express perceptions, observations, and impressions, i.e. it employs human perception to define the environmental quality (Gifford, 2007).

The report targets industry professionals, building designers, lighting designers, building managers, researchers and/or owners and provides a framework to evaluate integrated solutions, where lighting is supplied by a combination of electrical lighting, daylight-linked control systems (i.e. solar blinds, openings, etc.,) and assisted technologies (e.g., smart sensors). The framework addresses aspects of energy, visual stimulus (indoor lighting environment), non-visual stimulus (circadian potential), and users. The content of the framework proposed here is progressive and complementary to the IEA SHC Task 50 D.3 Monitoring protocol for lighting and daylighting retrofit report (Dubois et al., 2016; Gentile et al., 2016) when alternative or new methods are to achieve time and resource contingent objectives in the evaluation. It includes guidance for evaluating the operational performance of daylighting and electrical lighting components in the context of a building space. Lighting researchers will likely require a different level of detail and additional options for monitoring than practitioners in lighting or the built environment. Approval of the conception, design, execution, and operation of integrated lighting solutions from relevant stakeholders is advised before hand-over.

\subsection{Objectives}

The objective of this document is to provide a common framework to monitor four key aspects of integrated lighting solutions (energy, visual stimulus, non-visual stimulus, and user) such that:

- Methods of monitoring are accessible and practical for industry-led evaluations,

- Alternative methods can address time, cost, and resource availability,

- Includes attributes which would be suitable for the assessment of actual operational performance with respect to the verification of requirements stipulated by current or future building performance codes and building rating schemes

\subsubsection{What this document provides}

The framework provided in this document is targeted towards industry professionals, such as lighting designers, building designers and researchers, building owners or managers, and occupants to:

1. Make available methods and procedures related to evaluate the performance of integrated lighting in buildings and its impact on users and,

2. Summarise and categorize methods and procedures in an accessible and industry-oriented language.

The framework is intended for on-site measurements prior and/or post-occupancy in selected spaces.

Computational simulations are also included and they can be used as corollary to:

1. Compare on-site measurements

2. Complement the field data

3. Evaluate solutions when access to buildings may not be possible (e.g. due to Covid-19). 


\subsubsection{What this document does not provide}

This report does not compare the performance or results against other case studies that have context-related features and goals unique to that case study - unless both case studies are identical or exceptionally similar. Comparisons are only made with established benchmarks within each of the four aspects.

Whilst this document aims to provide a comprehensive monitoring protocol, the monitoring team will still need to determine the most suitable methods and tools to monitor each of the four key aspects based on time, cost, and resource availability (e.g., access to site and equipment). 


\section{Framework outline}

\subsection{Monitored aspects}

In context to indoor lighting, lighting quality should be assessed in terms of its performance for vision at a high degree of comfort and promotion of health, well-being, and lighting satisfaction. Whilst it is difficult to directly measure lighting quality in post-occupied settings (Kruisselbrink et al., 2018), the protocol outlines methods to indicate aspects of lighting quality in four key areas:

1. Energy use (electrical lighting systems),

2. Visual stimulus (Indoor lighting environment /photometry)

3. Non-visual stimulus (circadian potential), and

4. The user (subjective/surveys and observations)

\subsection{Steps and levels of monitoring}

To evaluate the four aspects of lighting quality related to integrated solutions for daylighting and electrical lighting, we present a framework to aid practitioners in determining the best approach to monitoring. This framework has seven steps, including setting up aims for the monitoring and understanding the context, developing a monitoring scope, executing the monitoring (data collection), evaluation (data analysis) and implementation of changes. A schematic diagram of the framework it is presented in Figure 1. 


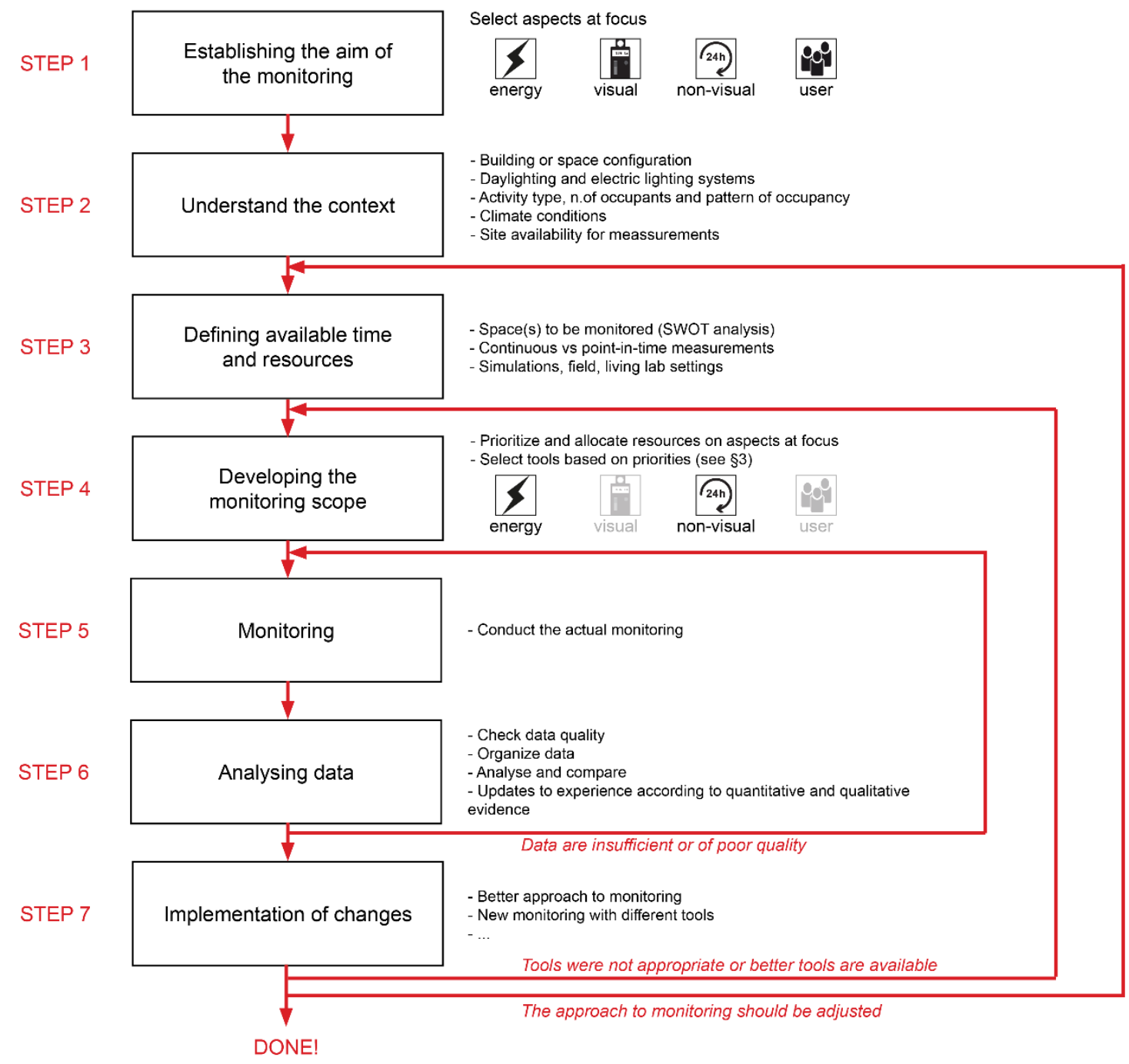

Figure 1. Overview of the monitoring protocol to evaluate the performance and quality of integrated lighting solutions in aspects of energy, visual effects, user, and non-visual effects.

\subsubsection{Step 1: Establishing the aim of the monitoring}

It is important to establish the focus of the monitoring and identify what strategies to use for evaluation. The strategies of integration presented in this protocol are based on the IEA Task 50 matrix of retrofit solutions (Aktuna et al., 2016), and the IEA SHC Task 61 Subtask D Report "Integrating daylighting and lighting in practice - Lessons learned from international case studies". The evaluation of the integration could focus on integration of daylighting, evaluating the façade design and or shading systems, and/or electrical lighting integration, and lighting controls, or the effectives of the design of the lighting/shading interface (Table 1).

Table 1. Categories to setting monitoring goal.

\begin{tabular}{|l|l|}
\hline Aspects of the monitoring & Strategies of integration \\
\hline Energy use & Daylighting Integration (facades design/blinds and shading) \\
Visual stimulus & Electrical lighting solutions and lighting controls \\
Non-visual stimulus & Design interfaces (Automated / manual / mixed) \\
The user - occupant preferences and behaviour & \\
\hline
\end{tabular}




\subsubsection{Step 2: Understand the context}

It is important to establish what type of space is evaluated and how much access is required for monitoring. In principle, this should be a space fitted with daylighting and electrical lighting systems in areas where activities are carried out (e.g. workstations in office buildings, patient rooms in hospitals, populated spaces in shopping centres, etc.). In conjunction, the time of day is an important factor in the monitoring framework, to capture potential issues during hours of occupancy.

For some case studies, the space may need to be divided into different zones. As an example, large open plan offices have distinct lighting characteristics along the building perimeter versus the core area where electrical lighting would be most dominant. In this scenario, it would be easier to monitor both zones separately, to identify performance issues characteristic of dominant light sources. In some cases, it can be useful to monitor more than a space to show e.g. performance under different daylight conditions due to orientation and spatial configurations. The selection of the space will depend also on the context, building and occupancy characteristics, the aspects which are the subject of investigation, as well as on pragmatic issues like accessibility and capacity of operation. A preliminary site investigation is required to gather important information about the type of space that is monitored. Table 2 can be used as a checklist to document context specific conditions during the site investigation.

It can be useful to organize meetings with the building managers or similar figures at this stage. The meetings will provide more insights on the ordinary use of the space and the daily functioning of the integrated lighting systems, supporting the development of an efficient and goal-based monitoring.

Table 2. Checklist to document the details of the building to inform the monitoring procedure.

\begin{tabular}{|c|c|}
\hline Checklist & Description (example) \\
\hline Climate & Tropical \\
\hline Building type & Commercial office building \\
\hline Activity type & Computer-based activities \\
\hline \multicolumn{2}{|l|}{ Space features } \\
\hline Type & Open plan office \\
\hline Solar Orientation & North-east \\
\hline Total occupancy & 15 \\
\hline Total floor area & $200 m^{2}$ \\
\hline $\begin{array}{l}\text { Daylighting system } \\
\text { (fenestration) }\end{array}$ & Glazed non-openable windows with manually adjusting shading controls \\
\hline Lighting system & Recessed luminaires, with occupancy controls \\
\hline Luminaire type & 4000K 23 Wattage LED \\
\hline Number of luminaires & 12 \\
\hline \multicolumn{2}{|l|}{ Period of monitoring } \\
\hline Month & June $21^{\text {st }}$ to May $21^{\text {st }}$ (summer solstice period) \\
\hline Day of the week & Monday to Friday \\
\hline Time period & 9:00AM to 5:00PM \\
\hline Total days & 21 \\
\hline Approval & Building manager \\
\hline
\end{tabular}

\subsubsection{Step 3: Defining available time and resources}

Preliminary site investigations identify the available resources (e.g., equipment, human resources, etc.,), accessibility to the space, equipment set-up, and the complexity of the integrated lighting installation. When the constraints are established, the monitoring approach is determined as either:

1. Point-in-time: single measurements taken intermittently at different times of the day using portable instruments under different sky conditions, typically: 
○ Daytime clear sky (ideally close ( \pm 1 week) to an equinox and solstice(s)),

Daytime overcast,

- Night-time (electrical lighting only) or,

2. Continuous and/or point-in-time: longitudinal measurements are continuously logged across an extended period (e.g., week, month, or year), in combination with point-in-time measurements and other assessments such as surveys to compare objective and subjective measurements

Point-in-time measurements characterise conditions at a glance (snapshot). When taken at significant periods of the day, such that the sun angle is at its lowest and/or highest during occupancy hours (e.g. 9:00AM, 12:00PM and 3:00PM), it can indicate performance issues at that time of day only. It is usually sufficient to perform the assessment at two (2) extreme task positions in the space, one with predominantly daylighting (e.g. close to side windows) and the other with predominantly electrical lighting (e.g. deeper in the room). Measurements at solstices are less important if the building is located close to the equator. Intermediate sky days can also be checked, depending on the goal of monitoring (e.g. to test the performance of daylight-linked control systems). With intermediate or clear sky, the measurements should be repeated at least twice per day, during the morning and the afternoon; this is increasingly critical for spaces with sidelight openings facing east or west and located far from the Equator.

Continuous measurements are comprehensive and accurate in characterising the overall performance of the integrated lighting installation. This is because, lighting variations and durations are captured across the day(s) which can identify specific periods when performance issues occur. Moreover, when it is coupled with other pointin-time assessments (e.g. user responses about glare), associations are made that can lead to post-retrofitting solutions. Similarly, longitudinal measurements should be taken at least at extreme task positions or areas of known issues across a one-day working period at a minimum, but ideally across a one-week period or more during significant times of the year.

The monitoring team may also consider running complementary computer daylight and electric lighting simulations using the point-in-time measurements as verification. This approach should be considered when the space cannot be easily accessed. For example, it has been adopted for monitoring some of the case studies in this IEA SHC Task 61, when the Covid-19 pandemic resulted in a strict lockdown of several of the investigated buildings. A list of advantages and disadvantages of different approaches to monitoring is provided in Table 3.

As general recommendation, the measurements should cover a wide array of situations for both daylighting and electric lighting. The monitoring team should plan thoroughly the monitoring so that it will cover both ordinary (daylight factors; electric lighting system in default settings; ...) and extreme operating conditions (glare risk at susceptible times and positions; daylight dimming of electric lighting system under intermediate sky; ...).

Table 3. A summary of the advantages and disadvantages of the different approaches for monitoring.

\begin{tabular}{|c|c|c|c|}
\hline Approach & Method & Advantages & Disadvantages \\
\hline Simulation & Computational & $\begin{array}{l}\text { - } \quad \text { Not labour or time intensive } \\
\text { - } \quad \text { Unsimited simulation iterations to } \\
\text { improve results } \\
\text { - } \quad \text { Option for point-in-time or longitudinal } \\
\text { Energy, photometry, circadian } \\
\text { simulation results can be compared to } \\
\text { field results later for verification }\end{array}$ & $\begin{array}{ll}\text { - } & \text { Metrics are simplified and still } \\
\text { - } & \text { Revolving } \\
\text { Requires expert knowledge for } \\
\text { diagnostics } \\
\text { Building model inaccuracy can lead } \\
\text { to misleading results } \\
\text { - To date, software tools cannot fully } \\
\text { integrate advanced daylighting and } \\
\text { electric lighting simulations }\end{array}$ \\
\hline $\begin{array}{c}\text { Field } \\
\text { (real-life } \\
\text { settings) }\end{array}$ & Point-in-time & $\begin{array}{l}\text { - Snapshot of daylighting and electrical } \\
\text { systems used in real settings at most } \\
\text { critical points of the day } \\
\text { Identifies real issues occurring in real } \\
\text { settings } \\
\text { - Anecdotal observations on-site provide } \\
\text { better context to any issues and } \\
\text { successes } \\
\text { Informal discussions with building } \\
\text { occupants and managers for better } \\
\text { insight and feedback } \\
\text { Baseline benchmarks are established } \\
\text { and comparable to certified metrics }\end{array}$ & $\begin{array}{l}\text { - } \quad \begin{array}{l}\text { On-site access may delay field } \\
\text { monitoring (e.g. approval to } \\
\text { conduct study, work schedules and } \\
\text { availability) } \\
\text { Requires expert knowledge to plan } \\
\text { significant time, location, and type } \\
\text { of measurements } \\
\text { Insufficient knowledge of } \\
\text { equipment quality and accuracy } \\
\text { can lead to misleading results } \\
\text { Equipment availability (including } \\
\text { cost of procurement) can delay field } \\
\text { monitoring } \\
\text { Poor planning may invalidate } \\
\text { measurements (e.g. if } \\
\text { measurements are not }\end{array} \\
\end{array}$ \\
\hline
\end{tabular}




\begin{tabular}{|c|c|c|c|}
\hline Approach & Method & Advantages & Disadvantages \\
\hline & & & $\begin{array}{l}\text { standardised and taken at the } \\
\text { same location) } \\
\text { Only provides a snapshot of } \\
\text { daylighting and electrical lighting } \\
\text { performance }\end{array}$ \\
\hline & $\begin{array}{l}\text { Longitudinal } \\
\text { In-situ sensors }\end{array}$ & $\begin{array}{l}\text { - Continuous monitoring provides } \\
\text { detailed information of performance } \\
\text { issues and successes } \\
\text { Issues are identified that can lead to } \\
\text { improved solutions } \\
\text { - } \quad \text { Baseline benchmarks can be } \\
\text { established and compared to other } \\
\text { metrics } \\
\text { - } \quad \begin{array}{l}\text { Results can be compared to simulated } \\
\text { results for verification }\end{array} \\
\text { - } \begin{array}{l}\text { Ad-hoc methods can be used to adjust } \\
\text { measurements }\end{array}\end{array}$ & $\begin{array}{l}\text { - } \quad \text { Poor planning may invalidate } \\
\text { measurements (e.g. if } \\
\text { measurements are not systematic } \\
\text { and standardised) } \\
\text { - } \\
\text { Risks to equipment damage } \\
\text { Insufficient knowledge of } \\
\text { equipment quality and accuracy } \\
\text { can lead to misleading results }\end{array}$ \\
\hline & $\begin{array}{l}\text { Longitudinal } \\
\text { and point-in- } \\
\text { time } \\
\text { Mixed } \\
\text { methods }\end{array}$ & 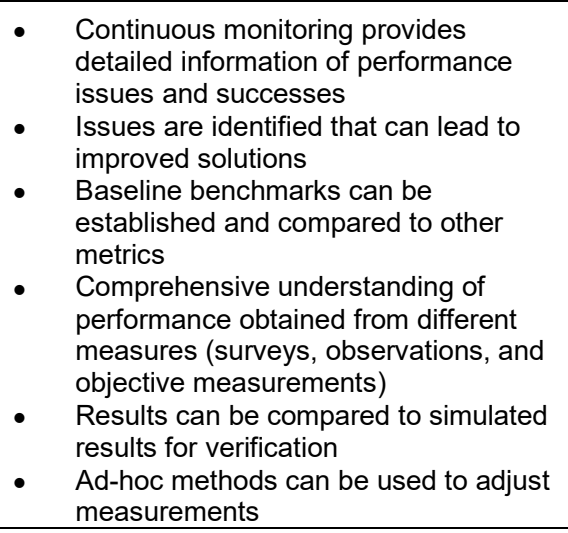 & $\begin{array}{l}\text { - } \quad \text { Can be expensive in terms of time } \\
\text { and resources } \\
\text { Poor planning may invalidate } \\
\text { measurements (e.g. if } \\
\text { measurements are not systematic } \\
\text { and standardised) } \\
\text { - } \quad \text { Risks to equipment damage } \\
\text { Insufficient knowledge of } \\
\text { equipment quality and accuracy } \\
\text { can lead to misleading results }\end{array}$ \\
\hline $\begin{array}{l}\text { Field } \\
\text { (Controlled } \\
\text { /semi- } \\
\text { controlled) }\end{array}$ & Test cells & $\begin{array}{l}\text { - Evaluates performance of daylighting } \\
\text { and electrical lighting systems } \\
\text { - Testing of different solutions and } \\
\text { strategies } \\
\text { - More control of monitoring conditions to } \\
\text { identify issues and successes }\end{array}$ & $\begin{array}{l}\text { - } \quad \text { Cost of equipment and set-up may } \\
\text { not be feasible } \\
\text { Results can change when } \\
\text { strategies/systems are used in real } \\
\text { conditions (e.g. human factors) }\end{array}$ \\
\hline $\begin{array}{l}\text { Living } \\
\text { laboratories }\end{array}$ & $\begin{array}{l}\text { Living } \\
\text { laboratories }\end{array}$ & $\begin{array}{l}\text { - } \quad \text { Action-based monitoring allows for } \\
\text { different solutions and strategies } \\
\text { - Solutions can be compared and } \\
\text { analysed to understand issues and } \\
\text { successes } \\
\text { - } \quad \text { Direct feedback from occupants } \\
\end{array}$ & $\begin{array}{ll}\text { - } & \text { Cost of equipment and set-up may } \\
\text { not be feasible } \\
\text { - Interference on normal work routine } \\
\text { can be disruptive }\end{array}$ \\
\hline
\end{tabular}

Strengths - Weaknesses - Opportunities - Threats (SWOT) analysis matrices can be used first to support the selection of the space and the approach to monitoring. An example of SWOT analysis for the monitoring of an integrated lighting project is shown in Table 4.

Table 4. Example of SWOT analysis supporting the selection of the space to be monitored and the approach to monitoring. The SWOT analysis refers to the IKEA Kaarst case study in IEA SHC Task 61 Subtask D Report "Integrating daylighting and lighting in practice - Lessons learned from international case studies". Areas in bold were eventually monitored. Source: Campama Pizarro (2019).

\begin{tabular}{|c|c|c|c|c|}
\hline Daylit Areas & Strengths & Weaknesses & Opportunities & Threats \\
\hline 01. Living Room & $\begin{array}{c}\text { South and West } \\
\text { windows, high-priced } \\
\text { products. Colour } \\
1 \text { Window } \\
6.2 * 2.4 \mathrm{~m} \\
1 \text { Glazed Door } \\
2.8 * 2.8 \mathrm{~m}\end{array}$ & $\begin{array}{c}\text { Modest size of } \\
\text { windows. Risk of } \\
\text { frontal Glare. }\end{array}$ & $\begin{array}{c}\text { First exhibition area. } \\
\text { Ask about plans, such } \\
\text { as expected visit time. }\end{array}$ & $\begin{array}{c}\text { Transition zone to the } \\
\text { rest of the showroom, } \\
\text { many customers are not } \\
\text { interested in the product } \\
\text { range and they will skip } \\
\text { it }\end{array}$ \\
\hline
\end{tabular}




\begin{tabular}{|c|c|c|c|c|}
\hline Daylit Areas & Strengths & Weaknesses & Opportunities & Threats \\
\hline $\begin{array}{l}\text { 02. Kitchen } \\
\begin{array}{l}1 \text { Window } \\
14^{*} 2.8 \mathrm{~m}\end{array}\end{array}$ & $\begin{array}{l}\text { North facing windows } \\
\text { integrated in the interior } \\
\text { kitchen scenery. }\end{array}$ & $\begin{array}{c}\text { No Daylight integration } \\
\text { on the electrical lighting } \\
\text { circuit. }\end{array}$ & $\begin{array}{c}\text { Customer can feel like } \\
\text { in his own kitchen, } \\
\text { suitable to investigate } \\
\text { effect on sales. }\end{array}$ & $\begin{array}{c}\text { Window area is obstructed } \\
\text { from the main customer } \\
\text { path. }\end{array}$ \\
\hline $\begin{array}{l}\text { 03. Bedroom } \\
1 \text { Window } \\
12 \text { * } 2.8 \mathrm{~m}\end{array}$ & $\begin{array}{l}\text { North facing full height } \\
\text { windows integrated in the } \\
\text { interior bedroom scenery. }\end{array}$ & $\begin{array}{c}\text { The area will be } \\
\text { undergoing remodelling } \\
\text { during the study, so it } \\
\text { should be avoided. }\end{array}$ & $\begin{array}{l}\text { Customer can feel like } \\
\text { in his own bedroom, } \\
\text { could be suitable to } \\
\text { investigate if it is } \\
\text { positive for sales. }\end{array}$ & $\begin{array}{c}\text { The effects of light may } \\
\text { not } \\
\text { relevant, colour rendering } \\
\text { more tied to bed linen. }\end{array}$ \\
\hline $\begin{array}{l}\text { 04. Children } \\
1 \text { Window } \\
4 * 1.8 \mathrm{~m}\end{array}$ & $\begin{array}{l}\text { Only exposition zone with } \\
\text { East facing windows. }\end{array}$ & $\begin{array}{c}\text { No Daylight integration } \\
\text { on the electrical lighting } \\
\text { circuit. }\end{array}$ & $\begin{array}{l}\text { Low-priced, colourful } \\
\text { products, light can have } \\
\text { an important role. }\end{array}$ & $\begin{array}{c}\text { The glazed area may go } \\
\text { unnoticed during peak } \\
\text { hours due to location and } \\
\text { size. }\end{array}$ \\
\hline $\begin{array}{l}\text { 05. Cookshop } \\
2 \text { Window } \\
6.2 * 2.8 \mathrm{~m}\end{array}$ & $\begin{array}{l}\text { South facing window with } \\
\text { visual contact towards } \\
\text { street level. }\end{array}$ & $\begin{array}{l}\text { Lighting control system } \\
\text { circuit not properly } \\
\text { sized, creating too high } \\
\text { contrast in the area. }\end{array}$ & $\begin{array}{l}\text { To investigate the } \\
\text { observer-based } \\
\text { assessment of these } \\
\text { lighting conditions. }\end{array}$ & $\begin{array}{c}\text { Customers may easily } \\
\text { bypass the area due to } \\
\text { different shortcuts } \\
\text { previously present. }\end{array}$ \\
\hline $\begin{array}{l}\text { 06. Textiles } \\
1 \text { Window } \\
4.7^{*} 2.8 \mathrm{~m}\end{array}$ & $\begin{array}{c}\text { Goods present in the area } \\
\text { particularly related to } \\
\text { daylight and glare } \\
\text { protection. }\end{array}$ & $\begin{array}{c}\text { The system is cancelled } \\
\text { due to faulty integration } \\
\text { of the sensor. }\end{array}$ & $\begin{array}{c}\text { Direct interaction } \\
\text { between people and } \\
\text { adjustment of daylight } \\
\text { intensity }\end{array}$ & $\begin{array}{l}\text { Customer can modify } \\
\text { lighting conditions of the } \\
\text { zone moving the curtains. }\end{array}$ \\
\hline $\begin{array}{l}\text { 07. Home Decoration } \\
1 \text { Window } \\
16 \text { * } 2.4 \mathrm{~m} \\
1 \text { Glazed Door } \\
2.8 \text { * } 2.8 \mathrm{~m} \\
\end{array}$ & $\begin{array}{l}\text { Fully glazed West and } \\
\text { North façade in the area. } \\
\text { Circadian fixtures } \\
\text { installed. }\end{array}$ & $\begin{array}{c}\text { Highly exposed to } \\
\text { direct solar radiation } \\
\text { during peak times. } \\
\text { Interior sun shading. }\end{array}$ & $\begin{array}{c}\text { Low-priced and } \\
\text { greenery products, } \\
\text { where light could play } \\
\text { a major role. }\end{array}$ & $\begin{array}{l}\text { Customers can be } \\
\text { disturbed by sunlight. }\end{array}$ \\
\hline $\begin{array}{l}\text { 08. Home Ranging } \\
\begin{array}{l}1 \text { Glazed Door } \\
2.8^{*} 2.8 \mathrm{~m} \\
1 \text { Window } \\
13.7^{*} 2.4 \mathrm{~m} \\
\end{array}\end{array}$ & $\begin{array}{l}\text { North windows no } \\
\text { exposed to glare issues. } \\
\text { Products range tend to } \\
\text { have a neutral incidence. }\end{array}$ & $\begin{array}{c}\text { Uniformly coloured low- } \\
\text { priced products where } \\
\text { the quality of light is not } \\
\text { as relevant. }\end{array}$ & $\begin{array}{l}\text { Last exhibition area in } \\
\text { the store. }\end{array}$ & $\begin{array}{l}\text { Area of entrance to the } \\
\text { self-serve, so it might be } \\
\text { difficult to catch the } \\
\text { attention of customers. }\end{array}$ \\
\hline $\begin{array}{l}\text { 09. Self-Service } \\
6 \text { Windows } \\
10 * 2.8 \mathrm{~m} \\
\text { Skylights } \\
45^{\circ} \text { tilt. North }\end{array}$ & $\begin{array}{l}\text { Zone with abundant } \\
\text { Daylight from Skylights } \\
\text { and Windows. }\end{array}$ & $\begin{array}{l}\text { Extensive passage } \\
\text { and stock area, hard } \\
\text { to define a } \\
\text { representative study } \\
\text { subzone. }\end{array}$ & $\begin{array}{c}\text { High daylight } \\
\text { intensity. High } \\
\text { connection to the } \\
\text { exterior. }\end{array}$ & $\begin{array}{l}\text { Customers may be } \\
\text { focused in finding } \\
\text { goods rather than } \\
\text { appreciating scenery. }\end{array}$ \\
\hline 10. Exit & $\begin{array}{l}\text { Linear skylight in the } \\
\text { background driving } \\
\text { daylight into the area. } \\
\text { Circadian fixtures. }\end{array}$ & $\begin{array}{c}\text { There is no integration } \\
\text { of Daylight with lighting } \\
\text { system. }\end{array}$ & $\begin{array}{c}\text { Last area In the store. } \\
\text { Possible to ask total } \\
\text { time spent and overall } \\
\text { shopping experience. }\end{array}$ & $\begin{array}{l}\text { Clients may wish to leave } \\
\text { after completing their visit. }\end{array}$ \\
\hline
\end{tabular}




\subsubsection{Step 4: Developing the monitoring scope}

The monitoring should be performed for each of the four key aspects (Figure 2), choosing appropriate tools.

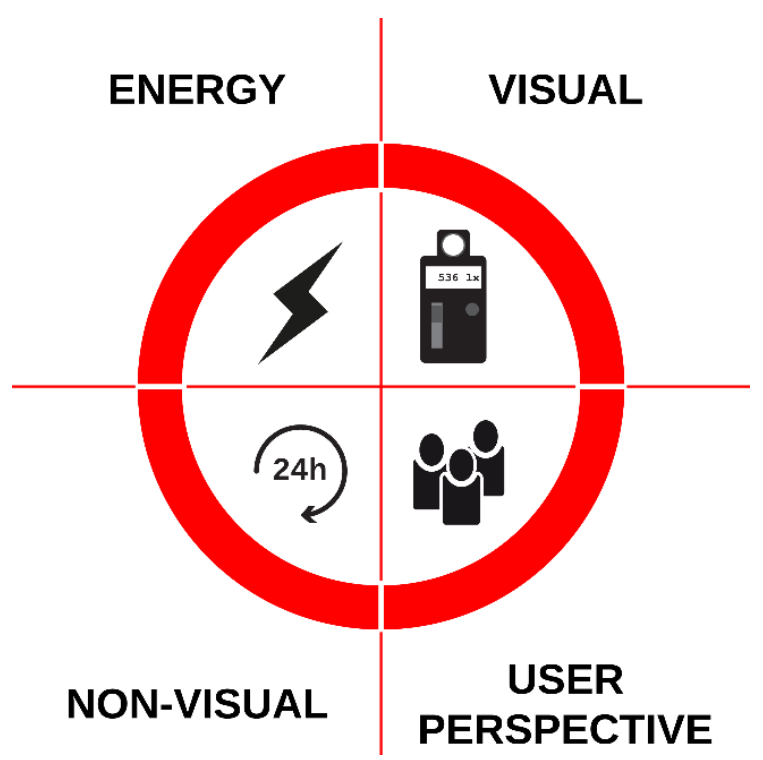

Figure 2. The four key aspects included in this framework.

In developing a monitoring scope, it is important first to prioritize the aspect on focus, the level of desired monitoring (basic to comprehensive) for each of the other aspects, and effort (including time and resources available). An impact effort prioritization matrix can be used first (Figure 3).

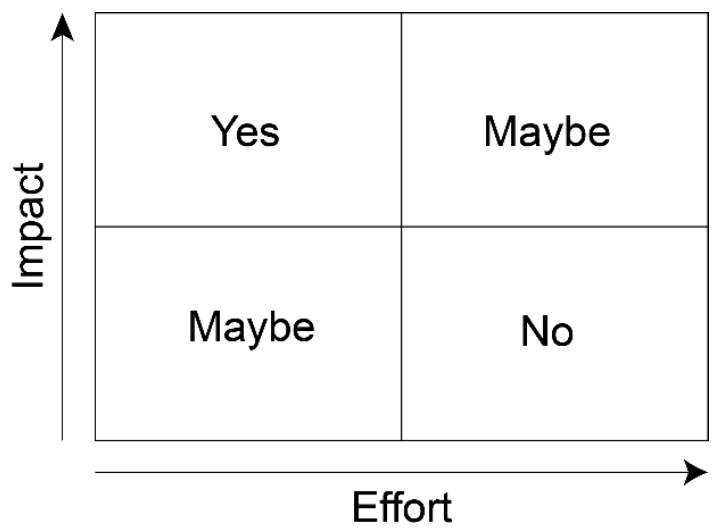

Figure 3. Impact-effort prioritization matrix.

The outcomes of Step $1-3$ will help completing the impact-effort prioritization matrix. Successively, the monitoring team decides on tools for monitoring. A selection of monitoring tools is presented in the following chapter of this document ( $(3)$. The monitoring tools require the equipment are listed in Annex D List of equipment.

\subsubsection{Step 5: Monitoring}

The actual monitoring follows the preparatory phase (Step $1-4)$. Monitoring in real buildings can be difficult and prone to unexpected events. In addition, real case study buildings might be accessible only for limited time. It is important that nothing is left to chance. Therefore, the monitoring team is strongly advised to:

- $\quad$ prepare a list of risks which may hinder or fail the monitoring; the risks should be listed alongside a plan for risks mitigation.

- $\quad$ prepare a detailed checklist before the monitoring (Table 5). 
Table 5. Example of detailed checklist for the monitoring.

\begin{tabular}{|c|c|c|c|}
\hline When? & \multicolumn{3}{|c|}{ What? } \\
\hline Two months before & $\begin{array}{l}\square \\
\square \\
\square \\
\square \\
\square \\
\square \\
\square\end{array}$ & \multicolumn{2}{|c|}{$\begin{array}{l}\text { Check calibration certificate of instruments. Eventually send for calibration. } \\
\text { Check battery level of instruments } \\
\text { Book potential monitoring days with building manager (book 3-4 days as } \\
\text { weather might not be ok) } \\
\text { Ask manager to inform employees about the monitoring } \\
\text { Book colleagues for on-site support } \\
\ldots\end{array}$} \\
\hline Two weeks before & $\begin{array}{l}\square \\
\square \\
\square \\
\square \\
\square \\
\square \\
\square\end{array}$ & \multicolumn{2}{|c|}{$\begin{array}{l}\text { Check again battery level of instruments } \\
\text { Send reminder to building manager } \\
\text { Send email to office employees presenting myself, explaining monitoring, } \\
\text { scope, required effort, ... } \\
\text { Check long term weather forecast. Think eventually to alternative scenarios } \\
\text { (can we book an alternative monitoring day on the short term?) } \\
\text { Send reminder to colleagues for support on-site } \\
\text { Book transportation } \\
\ldots\end{array}$} \\
\hline The day before & & $\begin{array}{l}\text { Chec } \\
\text { Chec } \\
\text { Print } \\
\text { Pack }\end{array}$ & $\begin{array}{l}\text { ather forecast and eventually reschedule monitoring } \\
\text { cess information } \\
\text { ey forms } \\
\text { ruments } \\
2 \text { pcs illuminance meter hand-held } \\
4 \text { pcs illuminance meter standalone loggers } \\
\text { Luminance camera } \\
\text { HDR camera } \\
\text { Polistirene sphere } \\
3 \text { pcs tripods } \\
\text { Tape meter } \\
\text { Laser meter } \\
\text { Bubble level } \\
\text { Tape } \\
\text {.. }\end{array}$ \\
\hline Monitoring day & $\square$ & \multicolumn{2}{|c|}{$\begin{array}{ll}\text { Employee arrivals } \\
\circ & \text { Welcome and presentation } \\
\circ & \text { Colleague goes outdoor at 9:30 with handheld illuminance meter } \\
\circ & \text { Test phone connection with colleague } \\
\circ & \text { At 10:00 start grid measurements with illuminance meters. Keep } \\
& \text { communication with colleague for simultaneous outdoor/indoor } \\
& \text { measurement } \\
& \circ \\
& \ldots\end{array}$} \\
\hline After monitoring & $\begin{array}{l}\square \\
\square \\
\square \\
\square \\
\square\end{array}$ & \multicolumn{2}{|c|}{$\begin{array}{l}\text { Check that all the surveys are filled } \\
\text { Check that all the instruments are packed back } \\
\text { Call building manager to communicate end of monitoring } \\
\text { Fast check on data quality } \\
\ldots\end{array}$} \\
\hline
\end{tabular}




\subsubsection{Step 6: Analysing data}

Upon completion of monitoring, the procedure to analyse the results should occur across four stages to derive to meaningful and reliable results.

\section{Check data quality}

The quality of data collected during monitoring should be validated by the monitoring team. Only reliable dataset must be considered for further analysis. If the monitoring was planned in detail and the monitoring team considered a risk analysis for the monitoring, there are high chances that the data are of good quality. However, if data are of low quality, the monitoring team should consider a new monitoring. Typical causes of low quality for the data are: instrumental (e.g. dataloggers who unexpectedly failed during measurements); operational due to the surveyor (e.g. a light sensor which was accidentally shaded); or operational due to operating conditions (e.g. changing cloud covering during measurement of daylight factors).

The experience of the monitoring team is fundamental at this stage as, in many cases, it might be difficult to determine the quality of data.

\section{Organize data}

The quantity of data collected in monitoring can be overwhelming. In addition, many details are noted by the monitoring team during the monitoring day; these are very important for the correct interpretation of data. It is important to organize the data in an understandable form as soon as possible. The monitoring team should not limit this process to the creation of a plain clean dataset. Notes, reflections, observations should also be added in annex to the dataset. As general principle, the data should be organized such that an external person would be able to read and interpret the data just as any of the surveyors in the monitoring team.

\section{Analyse and compare}

The analysis of the dataset depends on the type of data that have been collected. Specific indications on how to analyse different type of data are provided elsewhere in this document.

In general, the analysis should follow standard procedures and the results should be comparable to existing benchmarks. This way, it will be easier to communicate the results of the monitoring in a familiar and understandable manner.

The analysis should also be rigorous. For example, it is important that data treated statistically satisfy the hypothesis of the specific statistical test (e.g. normality test) and that the statistical population is such that statistical significance is reached. For qualitative data, it is important that both the collected data and their interpretation is not biased by the beliefs of the surveyor; thus, the analysis and interpretation of qualitative data should be conducted by more than one person.

\section{Updates to experience according to quantitative and qualitative evidence}

The analysis of data would provide insights both on the monitored integrated lighting project, but also on the monitoring procedure itself. Most likely, the monitoring team will identify room for improvement of the procedure. The monitoring team should meet and discuss thoroughly strength and weaknesses of the monitoring procedure and propose adjustments.

\subsubsection{Step 7: implementation of changes}

The monitoring is sharpened thanks to previous experience. The adjustments are introduced for a new round of monitoring. Normally, the adjustments may concern the approach to monitoring (Step 3) or the tools used (Step 4). For adjustments concerning the approach to monitoring, additional monitoring may be necessary. For adjustment concerning tools, it is often possible to slightly revise the planned monitoring with minor repercussions on the allocated time and resources. 


\section{Tools}

\subsection{Overview}

This chapter outlines the tools (procedures) to monitor the four key aspects of the indoor lighting environment and the relevant indicators for evaluating case studies. Table 6 is a summary of the tools to evaluate each of the four key aspects. The monitoring team should read the table as toolbox where appropriate tools can be selected upon definition of the monitoring scope ( $\$ 2.2 .4$ ). Each of the four aspects considered in this framework are provided with focus criteria, and each criterion can be assessed with one or more of the proposed tools.

Table 6. Aspects, focus, and tools considered in this framework for the evaluation of integrated daylight and electric lighting design.

\begin{tabular}{|c|c|c|c|}
\hline Aspect & Focus & Metric/indicators & Tools/equipment \\
\hline \multirow[t]{4}{*}{ Energy } & \multirow{3}{*}{ Electrical lighting } & $\mathrm{kWh} / \mathrm{m}^{2} \cdot \mathrm{yr}$ & $\begin{array}{l}\text { - Direct metering } \\
\text { - Smart metering }\end{array}$ \\
\hline & & $\begin{array}{l}\text { Lighting Energy Numerical Indicator } \\
\text { (LENI) }\end{array}$ & $\begin{array}{l}\text { Comprehensive calculated method } \\
\text { EN15193-1 }\end{array}$ \\
\hline & & Usage patterns in lux (qualitative) & Illuminance meter \\
\hline & Heat gains* & Weighting factors & $\begin{array}{l}\text { Qualitative categorisation of daylighting } \\
\text { components using benchmarks }\end{array}$ \\
\hline \multirow{14}{*}{$\begin{array}{l}\text { Visual } \\
\text { stimulus }\end{array}$} & \multirow[t]{2}{*}{ Quantity of light } & Workplane illumination & \multirow{4}{*}{$\begin{array}{l}\text { Grid-based measurements with } \\
\text { illuminance meters } \\
\text { (upcoming) Ceiling mounted luminance } \\
\text { mapping via High Dynamic Range (HDR) } \\
\text { imaging }\end{array}$} \\
\hline & & Daylight Factor (DF) & \\
\hline & \multirow{3}{*}{$\begin{array}{l}\text { Quantity and } \\
\text { distribution of light }\end{array}$} & Uniformity Ratio & \\
\hline & & $\begin{array}{l}\text { Climate-based annual daylighting } \\
\text { metrics }\end{array}$ & \\
\hline & & Luminance ratios & $\begin{array}{l}\text { - Luminance mapping via High Dynamic } \\
\text { Range (HDR) imaging } \\
\text { - Luminance meter } \\
\text { - Measured reflectance and } \\
\text { transmittance or database repository }\end{array}$ \\
\hline & $\begin{array}{l}\text { Illumination of } \\
\text { objects }\end{array}$ & Cylindrical illuminance & $\begin{array}{l}\text { - Illuminance meter } \\
\text { - Low-cost sensors }\end{array}$ \\
\hline & Directionality of light & Vector-to-scalar luminance ratio & $\begin{array}{l}\text { Luminance mapping via High Dynamic } \\
\text { Range (HDR) imaging }\end{array}$ \\
\hline & \multirow{2}{*}{ Glare } & Daylight Glare Probability (DGP) & $\begin{array}{l}\text { Luminance mapping via High Dynamic } \\
\text { Range (HDR) imaging }\end{array}$ \\
\hline & & Unified Glare Ratio (UGR) & \\
\hline & \multirow[t]{2}{*}{$\begin{array}{l}\text { Colour of light } \\
\text { sources }\end{array}$} & Correlated Colour Temperature (CCT) & $\begin{array}{l}\text { Luminaire datasheets } \\
\text { Spectrometer } \\
\text { Luminance mapping }\end{array}$ \\
\hline & & CRI Ra & Spectrometer, datasheets \\
\hline & $\begin{array}{l}\text { Temporal Light } \\
\text { Modulation (TLM) }\end{array}$ & PstLM, SVM (for electric light sources) & $\begin{array}{l}\text { Datasheets } \\
\text { Flicker tester }\end{array}$ \\
\hline & View out & Access to view (low, medium, high) & Comprehensive method EN17037 \\
\hline & Circadian potential & $E M L, M / P$ & Lucas' toolbox ${ }^{* *}$, ALFA and Lark software \\
\hline
\end{tabular}




\begin{tabular}{|c|c|c|c|}
\hline Aspect & Focus & Metric/indicators & Tools/equipment \\
\hline \multirow{3}{*}{$\begin{array}{l}\text { Non-visual } \\
\text { stimulus }\end{array}$} & & M-EDI & CIE S 026 a-opic toolbox** \\
\hline & & CS & CS Calculator**, Lark software \\
\hline & $\begin{array}{l}\text { Individual light intake } \\
\text { (both visual and } \\
\text { non-visual) }\end{array}$ & $\begin{array}{l}\text { Pattern of light intake at individual } \\
\text { level }\end{array}$ & Wearable light sensors ${ }^{\star * *}$ \\
\hline User & $\begin{array}{l}\text { Perception } \\
\text { Acceptance } \\
\text { Satisfaction } \\
\text { Beahviour }\end{array}$ & - & 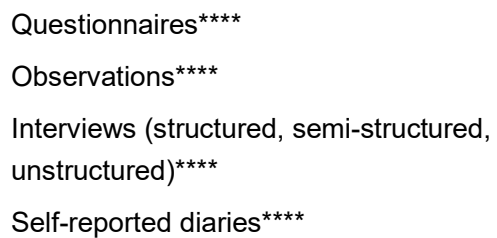 \\
\hline
\end{tabular}

* : heat gains are not central in this monitoring framework

** : tools requiring either a spectrometer or an illuminance meter

${ }^{* * *}$ : typically equipped with RGB-IR sensors. New wearables with integrated spectrometer are rapidly appearing on the market and they might be suitable for measuring circadian potential at the individual level.

**** : these are general tools. Some specific tools for the focus are provided in $\S 3.5$.

\subsection{Energy}

\subsubsection{Energy for lighting}

The energy use of the electrical lighting system is the total energy intensity per unit area for illumination. It accounts for the total energy to operate luminaires (including luminaires for emergency lighting) and control systems (e.g. occupancy sensors, dimmable ballasts etc.,) inclusive of the total energy from parasitic loads (i.e. standby power), and the impact of the space function (occupancy, daylighting, maintenance) as well as, the operational patterns (occupancy and activity).

Evaluation of the energy performance of the lighting system should aim to obtain the true value of the total energy use per year [kWh/year], to compare benchmark values specific to the building and activity type provided in Table M.1 of the EN15193-2:2017 standard (CEN, 2017a). For countries outside of the EU, it is important to conform to localized benchmarks to compare performance against national standards and then endeavour to compare with the EU benchmarks as auxiliary for a global comparison.

The procedure to obtain the total energy of the electrical lighting system is either measured or calculated. To prepare, it would be advisable to itemise the lighting installation features to determine which method is possible. Table 7 can be used as a checklist to determine what is possible. 
Table 7. Checklist of the lighting system installation to determine which method to use to obtain the yearly total energy use with prevailing information.

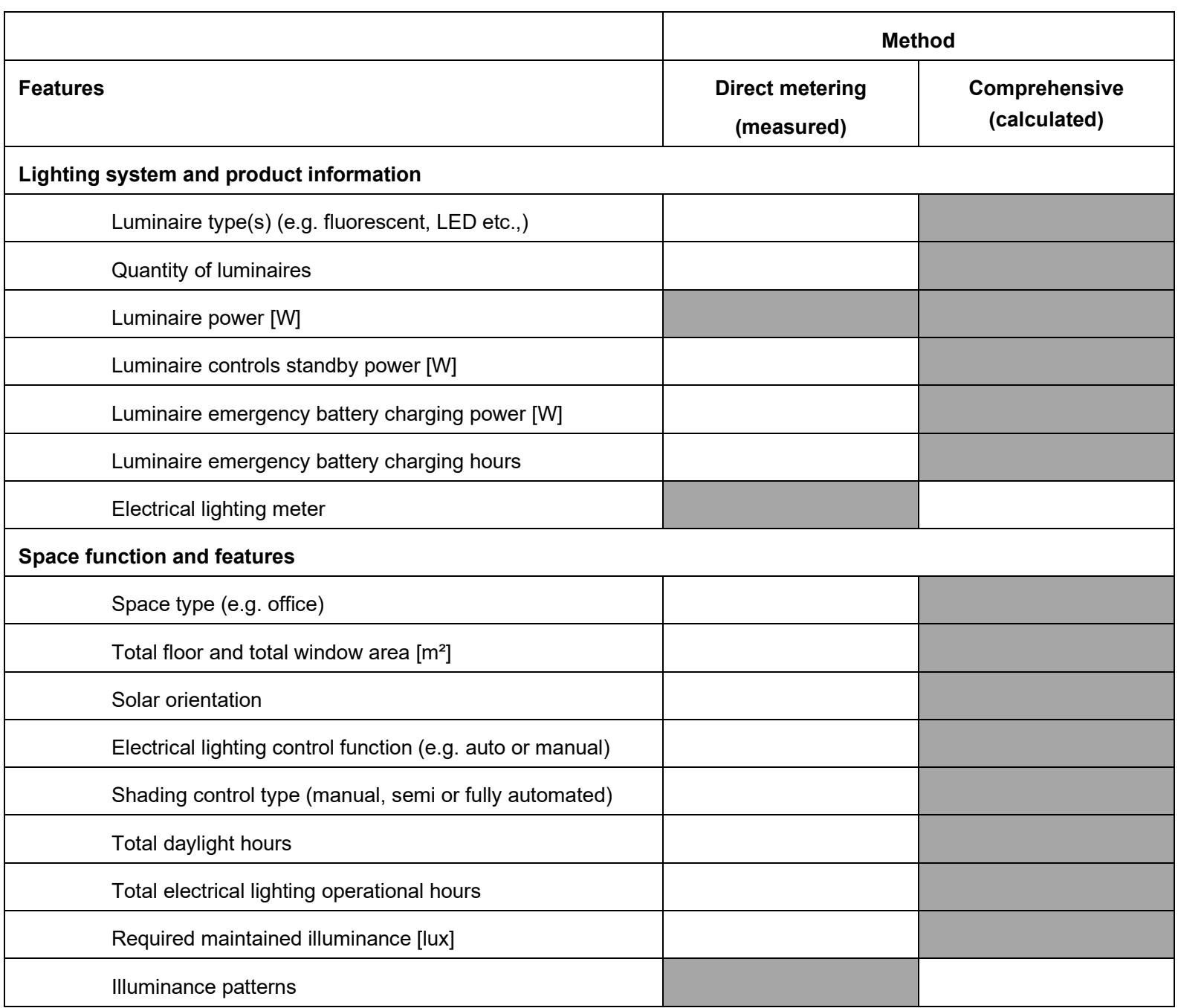

The measured method (direct metering) gives the true or most accurate total energy use of the lighting system. This is possible when lighting circuits are clearly segregated from other electrical services and readily extracted from an Energy Management System (EMS) or meter. Alternatively, connecting a digital voltmeter to luminaires or the energy meter can yield the same results.

The calculated method offers a comprehensive framework to approximate the total energy use such that the Lighting Energy Numerical Indicator (LENI) is obtained to compare benchmark values in $\mathrm{kWh} /\left(\mathrm{m}^{2} \mathrm{y}\right)$. The LENI is the ratio of the annual energy use $(\mathrm{kWh})$ of the total useful floor area $\left(\mathrm{m}^{2}\right)$ based on the knowledge of the lighting system such as:

- $\quad$ The type and number of luminaires: maximum luminaire power $\left(\mathrm{P}_{\mathrm{i}}\right)[\mathrm{W}]$;

- $\quad$ Luminaire control standby power $\left(\mathrm{P}_{\mathrm{ci}}\right)[\mathrm{W}]$;

- $\quad$ Luminaire emergency battery charging power $\left(\mathrm{P}_{\mathrm{ei}}\right)[\mathrm{W}]$;

- Occupancy dependency factor $\left(\mathrm{F}_{\mathrm{O}}\right)$;

- Daylight dependency factor $\left(\mathrm{F}_{\mathrm{D}}\right)$ and;

- Constant illuminance factor $\left(\mathrm{F}_{\mathrm{c}}\right)$.

The LENI benchmark values are provided in Table M.1 of EN15193-2:2017. As an example, the current LENI benchmark for a highly efficient lighting scheme in a single occupant office is $6.00 \mathrm{kWh} / \mathrm{m}^{2} \mathrm{y}$. Estimation should include the power consumed by control systems remote from the luminaire ${ }^{1}$. The full calculation is provided in

\footnotetext{
${ }^{1}$ In regards to standby, the standard EN15193-1:2017 states that "This estimation does not include the power consumed by control systems remote from the luminaire and not drawing power from the luminaire" (§6.4.3.7, Note 2 of EN15193-1:2017) (CEN, 2017)
} 
EN1519301:2017 (CEN, 2017a) and EN15193-2:2017 (CEN, 2017b). An MS Excel toolbox by Delvaeye (2017) is an open-source spreadsheet for using the comprehensive method by adding details in the spreadsheet (Annex $A$ Calculated method for energy use). If the comprehensive method is selected, it can be used to verify the true energy use when direct metering is available.

The monitoring team may explore alternative methods to log the actual usage patterns of lighting, for example by using stand-alone illuminance loggers next to the fixture (see IKEA Kaarst case study) or using the actual lighting schedules, see Annex A An Example from Denmark.

\subsubsection{Alternative metering methods: smart meters}

An alternative is installing smart meters to the existing energy boards to log energy data. Today several companies offer data storage, query, analysis, and visualization on the electricity metering from smart meters. The queries and analysis services are of particular interests for lighting; machine learning techniques can recognize usage patterns of electricity and identify loads (Zeifman \& Roth, 2011), that is disaggregating the total electricity use into specific final uses (e.g. lighting) (Wang et al., 2018)

\subsubsection{Heat gains}

Daylighting carries solar heat gains, which can affect the energy balance for heating and cooling when it is transmitted through the window glass. In turn, it can create overheating issues if shading systems are not enough to protect occupants from thermal discomfort when sitting near windows.

Whilst the monitoring protocol does not address thermal comfort, daylighting components can be evaluated to consider the potential energy contributions under 'thermal considerations' using weighting factors provided by Knoop (2016). Specifically, this aspect of the monitoring protocol evaluates the energy contributions of the window system in terms of the heat transmittance (g-value), heat changing properties (e.g. shading systems, thermochromics etc.), light-to-thermal ratio (LSG) and, the secondary internal heat transfer (qi-value). When these values are obtained, weighting factors to determine the energy savings potential can be made as shown in Table 8.

Please note that electric lighting would also affect heating and cooling demand, depending on type and position of the light source, as well as type of space conditioning, even with LEDs (Liu et al., 2017). This protocol does not consider internal gains from electric lighting, but surveyors are welcome to add such information if available. 
Table 8. Thermal considerations for evaluating heating and cooling contributions from daylighting.

\begin{tabular}{|c|c|c|c|c|c|}
\hline & $\begin{array}{l}\text { Much worse } \\
\text { than baseline }\end{array}$ & $\begin{array}{c}\text { Worse than } \\
\text { baseline }\end{array}$ & $\begin{array}{l}\text { Similar to baseline } \\
\text { or not applicable }\end{array}$ & $\begin{array}{l}\text { Better than } \\
\text { baseline }\end{array}$ & $\begin{array}{l}\text { Much better } \\
\text { than baseline }\end{array}$ \\
\hline $\begin{array}{l}\text { Energy savings } \\
\text { potential }\end{array}$ & Less than $-\mathbf{3 0} \%$ & $\begin{array}{c}-30 \% \leq \text { energy } \\
\text { savings potential } \\
<-10 \%\end{array}$ & $\begin{array}{c}-10 \% \leq \text { energy } \\
\text { savings potential } \leq \\
10 \%\end{array}$ & $\begin{array}{c}10 \% \leq \text { energy } \\
\text { savings } \\
\text { potential } \leq 30 \%\end{array}$ & $\begin{array}{c}\text { Energy savings } \\
\text { potential } \geq \\
30 \%\end{array}$ \\
\hline $\begin{array}{c}\text { Thermal } \\
\text { considerations } \\
\text { (Minimum g- } \\
\text { value) }\end{array}$ & $\begin{array}{c}\quad \mathbf{g} \geq \mathbf{0 . 5} \\
(\text { EN14501 Class } \\
0) \\
\text { High solar gain/ } \\
\text { large window } \\
\text { plane }\end{array}$ & $\begin{array}{c}\mathbf{0 . 3 5} \leq \mathbf{g}<\mathbf{0 . 5} \\
(\text { EN14501 Class } \\
\text { 1) } \\
\text { Increased solar } \\
\text { gain/ slightly larger } \\
\text { window plane }\end{array}$ & $\begin{array}{c}\mathbf{0 . 1 5} \leq \mathbf{g}<\mathbf{0 . 3 5} \\
(\text { EN14501 Class 2) } \\
\text { Similar to baseline }\end{array}$ & $\begin{array}{c}\mathbf{0 . 1 0} \leq \mathbf{g}<\mathbf{0 . 1 5} \\
(\mathrm{EN} 14501 \text { Class } \\
\text { 3) } \\
\text { Reduced solar } \\
\text { heat gain/ } \\
\text { slightly smaller } \\
\text { window plane }\end{array}$ & $\begin{array}{c}\quad \mathbf{g}<\mathbf{0 . 1} \\
(\mathrm{EN14501} \text { Class } \\
\text { 2) } \\
\text { Highly reduced } \\
\text { solar heat gain / } \\
\text { small window } \\
\text { plane }\end{array}$ \\
\hline $\begin{array}{l}\text { Variable thermal } \\
\text { considerations } \\
\text { (Maximum g- } \\
\text { value variation) }\end{array}$ & No & & $\begin{array}{c}\text { Variation of g-value } \\
\text { more than } 0.15\end{array}$ & & $\begin{array}{c}\text { Variation of } g- \\
\text { value more than } \\
0.30\end{array}$ \\
\hline $\begin{array}{l}\text { Light to thermal } \\
\text { ratio (LSG) }\end{array}$ & $\begin{array}{c}\tau v / g \text { reduces by } \\
>30 \%\end{array}$ & $\begin{array}{c}\tau v / g \text { reduces by } \\
\quad>10 \%\end{array}$ & $\begin{array}{l}\text { Similar to baseline } \\
\qquad( \pm 10 \%)\end{array}$ & $\begin{array}{c}\tau v / g \text { increases } \\
\quad \text { by }>10 \%\end{array}$ & $\begin{array}{c}\tau v / g \text { increases } \\
\text { by }>30 \%\end{array}$ \\
\hline $\begin{array}{c}\text { Surface } \\
\text { temperatures/ } \\
\text { secondary heat } \\
\text { transfer } \\
\text { (qi = ge -te; } \\
\text { EN14501) }\end{array}$ & $\begin{array}{c}\text { Very high } \\
\text { difference } \\
\text { between room } \\
\text { and surface } \\
\text { temperature } \\
\text { qi } \geq 0.3 \\
\text { (EN14501 Class } \\
0)\end{array}$ & $\begin{array}{c}\text { High difference } \\
\text { between room and } \\
\text { surface } \\
\text { temperature } \\
0.10 \leq \text { qi < } 0.3 \\
\text { (EN14501 Class } \\
\text { 1) }\end{array}$ & $\begin{array}{l}\text { Similar to baseline } \\
\quad 0.10 \leq \text { qi }<0.2 \\
(\text { EN14501 Class } 2)\end{array}$ & $\begin{array}{c}\text { Small difference } \\
\text { between room } \\
\text { and surface } \\
\text { temperature } \\
0.03 \leq \text { qi < } 0.1 \\
\text { (EN14501 Class } \\
\text { 3) }\end{array}$ & $\begin{array}{c}\text { Very small } \\
\text { difference } \\
\text { between room } \\
\text { and surface } \\
\text { temperature } \\
\text { qi } \leq 0.03 \\
\text { (EN14501 Class } \\
4)\end{array}$ \\
\hline
\end{tabular}

\subsection{Visual stimulus}

Lighting quality is difficult to define (Veitch \& Newsham, 1998) but can be evaluated in context to 'lighting that can allow excellent vision while providing high comfort' (Kruisselbrink et al., 2018). In this section of the protocol, we cover the aspect of the visual stimulus across eight lighting quality criteria for daylight sources, electrical light sources and when both daylight and electrical light sources are in operation (Table 6). This is an extended guide from the work of Dubois et al. (2016) and \{Gentile, $2016 \# 4$ \}, where the primary focus is to complement and add additional guidance on existing and alternative procedures.

The selection of tools to use in the case study will depend on the availability of resources (e.g. equipment) and the prevailing time afforded to the monitoring team. Where there are significant limitations to carry out the evaluations, the monitoring team should only focus on the criteria that will answer the aim and objectives for monitoring.

\subsubsection{Quantity of light}

This section outlines the tools to measure the quantity and distribution of daylight and electrical light sources using illuminance and luminance metrics/indicators.

For illuminance-based tools, ideally measurements should be taken when light source types are isolated, to determine its contribution to the performance of the integrated lighting system. A simple approach is to measure the lux values (with an illuminance meter) from the electrical lights when no daylighting is present (i.e. night-time) and to subtract this with the lux values with electrical lighting and daylighting present. The resulting value is the daylighting contributions in lux. It is important to take measurements at the same location, height (workplane height) and orientation (horizontal plane) to ensure reliability of results. 


\subsubsection{Grid-based measurements}

The quantity and distribution of daylight and electrical light sources are typically measured in illuminance using grid systems. This approach characterises patterns of illumination in the space and its relationship to spatial conditions. The arrangement of the grid should closely conform to the standards specified in EN12464-1:2019 and EN17037:2017, such that the formation of the grid encompasses the entire task area, the immediate surrounding area, and the background area. Ideally, the grid cells should be squared, with the length to width ratio of $p$ (cells) being within 0.5 and 2 , with the maximum grid determined by the following formula:

$$
p=0,2 \cdot 5^{\log _{10}(\mathrm{~d})}
$$

prEN 12464-1:2019

Where $d$ is the longer dimension of the area and $p$ is the resulting distance between two nodes of the grid. If the longer to shorter side ratio of the area is equal or higher than 2 , then $d$ becomes the shorter dimension of the area. The grid should be distanced 0.5 from the wall. The distance between the points of the grid depends on the area; the grid is tighter on and around task areas.

The practicalities of devising a grid system under operational conditions can be very limited because of physical obstructions (e.g. furniture and occupants). A pragmatic approach is to measure only relevant locations in which task activities are carried out (e.g. workstations) by placing the illuminance meter on the table, such that the diffuser of the meter is facing the ceiling to measure the workplane illuminance $\left(E_{\text {task }}\right)$. Ideally, it is preferable to use multiple meters to simultaneously capture measurements. However, in most cases it is more practical to systematically measure each location in intervals. When this is the case, each point should be measured as close as possible to characterise point-in-time measurements at a specific time of day. When it is not possible to place the meter on a table, a tripod can be used to mount the meter at $0.85 \mathrm{~m}$ and positioned at close to the task area as practical. However, this type of approach does not allow for a straightforward calculation of e.g. average Daylight Factor.

New approaches using low-cost sensors to enable continuous and wireless measurements in field have also been investigated (Pham et al., Manuscript in submitted, 2021). Whilst the photometric accuracy is still in infancy, this approach is useful for preliminary results to support further investigation when potential performance issues are indicated and can be verified with calibrated illuminance meters.

Workplane illumination

A standard approach to evaluate the performance of daylight and electrical light sources, is to measure the quantity of illumination on the workplane (task surfaces). The target illuminance provided by electric lighting is defined by EN12464-1. Typically, 500 lux should be guaranteed for point on the task area in ordinary offices. This can be measured in the evening (when daylighting is not present). If the electric lighting system is provided with dimming, the monitoring should include a set of measurements for a reasonable number of dimming steps.

\section{Daylight Factor}

The Daylight Factor (DF) is the ratio between indoor and outdoor illuminance. It is a well-documented indicator in standards and certification schemes to provide initial characterisation of the quantity of daylighting in space under the CIE Overcast Sky. Theoretically, it is independent of the geographical location, time of day, and solar orientation of the space, and is the sum of three components: direct illuminance (if the sky is visible at that point), outdoor reflections and indoor reflections from surfaces. Realistically, it would not be possible to verify a perfect overcast sky, hence, point-in-time measurements should be captured at 9am, 12pm and 3pm to represent critical solar azimuth angles ${ }^{2}$.

To proceed with measurements, establish a grid-system in the room at workplane height ( $\left.E_{\text {task }}\right)(0.75$ or $0.85 \mathrm{~m})$ and record lux values at each point (or simultaneously if possible) under overcast sky conditions. Simultaneously, record the outdoor horizontal illuminance (ideally on the roof or on the ground in an area with minimal vertical obstruction such as neighbouring buildings that can cause overshadowing). If lux values fluctuate, wait until recordings are stabilized and accept the most persistent value. The DF is the average (DF mean) of all points divided by the outdoor horizontal illuminance (expressed as a percentage \%). Generally, a DF of $2 \%$ is the

\footnotetext{
${ }^{2}$ In theory, only one measurement is required when the ideal CIE overcast sky is present. In practice, this is difficult to verify. The ideal $\mathrm{CIE}$ overcast sky shows a constant ratio of 0.396 between the screened vertical illuminance, i.e. screened from ground reflection, and the global horizontal illuminance. Values between 0.36 and 0.44 are usually considered acceptable, but they might also be difficult to verify is some geographical locations.
} 
minimum requirement prescribed in most standards. The European Daylight Standard EN17037:2018 introduces target DF depending on geographical location and space use. Alternative to the arithmetic mean, the median (DF median) may allow for statistical comparisons of different spaces (CEN, 2018). Where grid-points are not possible, the DF can still be calculated using a single point in the room, preferably in the centre of the room.

Whilst the DF continues as a standard indicator to quantify daylighting, it has been well documented that its characterisation of daylighting performance is outdated [reference] and not realistic of other contextual conditions (geography, sky conditions, time of day and, solar orientation) which would influence the results.

Measuring horizontal illuminance with a ceiling mounted luminance camera In recent years, researchers have recognized the potential of using digital photography to investigate lighting conditions (Inanici, 2006; Jakubiec et al., 2016a; Pierson et al., 2017). High Dynamic Range (HDR) images make it possible to generate luminance maps that can be used for exploring lighting scenarios in building interiors. HDR images are created by combining several Low Dynamic Range (LDR) images taken with different exposures (Robertson et al., 1999). Their advantage is that they are able to capture a wide range of light, permitting the representation of very dark and very bright areas in the same image, without significant loss of detail.

Image-based luminance maps can be used to identify sources of glare (Wienold \& Christoffersen, 2005) and provide a broader representation of lighting in a space compared to spot luminance measurements. Moreover, they present the user's point of view, which offers an insight that cannot be obtained for example by grid illuminance measurements. The device would preferably create luminance maps corresponding to the visual field of a user, but ceiling based measurements can offer reasonable accuracy (Kruisselbrink et al., 2020).

Researchers interested in generating luminance maps can choose between commercially available calibrated luminance cameras, available software that converts HDR images into luminance maps or systematic camera calibration. However, high equipment cost can be a limitation for several light measuring applications. This makes the use of low-cost luminance cameras convenient for long-term measurements in buildings, where there is a risk of equipment damage or even theft.

In this context, a Raspberry $\mathrm{Pi}(\mathrm{RPi})$ computer equipped with a camera module and a $180^{\circ}$ fisheye lens can be utilized. A Raspberry $\mathrm{Pi}$ is a single board computer used for several tasks, such as simple programming, robotics and photography. A main advantage of using this device for the purpose of luminance measurement is that it offers significant possibilities in terms of automation of an image capturing sequence and post-processing. This characteristic makes it very handy for monitoring case studies for long periods, where the device can be placed in a fixed location and continuously generate luminance maps for several weeks.

A recent study describes the calibration of the RPi camera and the automation of the luminance map generation process (Baumann et al., 2021).

\subsubsection{Quantity and distribution of light}

Uniformity ratios

The Uniformity ratio determine the uniformity of light source distribution in the space. The illuminance uniformity can be distracting and have a 'transient adaptation' effect that can be visually uncomfortable from sudden changes in illumination. The illuminance uniformity, $\mathrm{U}_{\mathrm{o}}$, of the task area is measured on the horizontal plane, $\mathrm{E}_{\text {task }}$, and is determined as the ratio between the minimum and average or the average and maximum $\mathrm{E}_{\text {task }}$. At a minimum, the illuminance distribution in task areas should provide a uniformity, $U_{0}$, of no less than the values prescribed in tables 6.3 in EN12464-1:2019. These values may be different for other countries outside of the EU ${ }^{3}$.

Climate-Based Daylight Metrics

Climate-based Daylight Metrics (CBDM) are time-series based indicators of the quantity and distribution of available daylighting in the space. Daylight Autonomy (DA), continuous Daylight Autonomy (cDA), Spatial Daylight Autonomy (SDA), and the Useful Daylight Illuminance (UDI) are easier to simulate computationally in programs such as Rhinoceros using the Ladybug tools (Ladybug Tools LLC, 2021).

Specifically, the Useful Daylight Illuminance (UDI) (Nabil \& Mardaljevic, 2006) is an alternative to the DF because it accounts for the geographical location, sky conditions, time of day and solar orientation. Daylight illuminance within 100 to 300 lux is considered enough illumination with or without electrical lighting. Values within 300 to

\footnotetext{
${ }^{3}$ For example, in Australia, provision of illuminance uniformity is in accordance to AS1680.1 of the Australian Standards.
} 
3,000 lux are desirable for at least $80 \%$ of the time during occupancy hours (Mardaljevic et al., 2012). The monitoring team may explore the possibility to run a CBDM simulation calibrated with a field DF measurement.

Recent development in technology may allow for field measurements of climate-based metrics. These can be possible e.g. with ubiquitous use of wireless illuminance loggers, or with a ceiling-placed calibrated HDR camera (see method Measuring horizontal illuminance with a ceiling mounted luminance camera presented above). These approaches are promising, but the technology is currently not mature enough for large scale disclosure of devices.

\section{Surface luminance}

The luminance of surfaces is required to evaluate contrast. The luminance of the main vertical surfaces should be measured. This should be done at least with a luminance spot meter, or, preferably, via luminance mapping.

Measure luminance of the main surfaces with a spot luminance meter. Choose the spot in a critical way; for example, one to three spots may be enough to characterize a uniformly lit wall. If strong shades are casted on the surfaces, select more points. Always take a picture of your field of view; superimpose the spot measurement of luminance on the picture. Spot measurements of luminance are performed for side walls, at eye level for both sitting $(1.2 \mathrm{~m})$ and standing $(1.6 \mathrm{~m})$ positions. The spot measurement should be repeated for electric lighting (each setting provided by the system) and daylighting (different sky conditions), and a mix of the two. Values above $100 \mathrm{~cd} / \mathrm{m}^{2}$ are generally preferable in offices.

\section{Luminance ratios}

The distribution of light in the field of view is fundamental for good visibility. Spot measurement of luminance at task will assure that contrast ratios guarantee a comfortable luminous environment. A detailed procedure for the determination of luminance ratios for task areas is provided in T50 D.3 5.2.2.1 page 37 (Dubois et al., 2016).

Reflectance and transmittance

Reflectance of diffusive surface: reference plate method

The approximate diffuse reflectance of Lambertian surfaces may be measured with a luminance spot meter and a plate of known reflectance $\left(R_{\text {plate }}\right)$. The luminance of the surface $\left(L_{\text {surface }}\right)$ and of the plate $\left(L_{\text {plate }}\right)$ is measured under identical lighting conditions. The reflectance of the surface $\left(R_{\text {surface }}\right)$ is derived with

$R_{\text {surface }}=\left(L_{\text {surface }} \cdot R_{\text {plate }}\right) / L_{\text {plate }}$

It is suggested to repeat the measurement several times and average the results, as the method can be affected by a number of operational issues (shadows, movement of luminance meters, changing lighting conditions, ...).

Reflectance of real surfaces: material databases

The reflectance of non-Lambertian materials is provided in open databases. The web application "Colour picker" by Jaloxa (www.jaloxa.eu/resources/radiance/colour picker/index.shtml) provides reflectance (and Radiance definitions) of materials based on their colour, roughness, and specularity. The colour can be selected by choosing from different colour ordering systems. Roughness and specularity are selected autonomously by the user, adding arbitrariness to the process.

The website Spectral Material Database by Jakubiec (2016) provides a collection of measured spectral reflectance (and transmittance) of materials (Design for Climate \& Comfort Lab, 2021). The user can select the material closest to the one to be defined and retrieve the relative spectral proprieties. The definitions in the Spectral Material Database can be used in both traditional and circadian lighting Radiance-based simulations.

\section{Transmittance}

The transmittance of transparent surface with direct transmission may be estimated using two luxmeters. The first luxmeter should be placed on the outer surface of the surface, the second on the inner surface. The sensors should be directed towards the same direction and they should not shade each other. The transmittance is given by the ratio between the outdoor and indoor illuminance. This method provides only an approximate value of transmittance and it is affected by operational issues. It is suggested to repeat the procedure several times and to average the results. Radiance-based simulations adopt transmissivity (tn); if the transmittance (Tn) is used for Radiance simulations, the conversion can be done via the formula:

$\operatorname{Tn}=\left(\operatorname{sqrt}\left(0.8402528435+0.0072522239 \cdot \mathrm{Tn}^{2}\right)-0.9166530661\right) / 0.0036261119 / \mathrm{Tn}$

The optical characterization of transparent surfaces can be also obtained by available database and software, like the application Optics developed by Lawrence Berkely National laboratory (Berkley Lab, 2019). 


\section{Luminance mapping}

Luminance mapping is possibly the most flexible tools for measuring light, see Table 6 . The monitoring team should consider including luminance mapping in the toolbox as it allows for fast, reliable, and complete monitoring. To generate a luminance map of a visual scene, i.e. images in which each pixel represents the luminance of the corresponding portion of the captured visual scene, High Dynamic Range (HDR) photography is used. HDR photography consists of capturing multiple photographs of a scene from an identical point of view with different exposures, namely Low Dynamic Range (LDR) images, and merging them to obtain an image with a higher range of brightness, namely an HDR image (Debevec et al., 2010; Inanici, 2009; Jakubiec et al., 2016b; Pierson et al., 2021).

Nowadays, there exist two main methods of generating a luminance map of a visual scene: through an absolute calibration (with a luminance camera) or through a step-by-step calibration using an automatic merging algorithm (with a photo-camera).

The absolute calibration is the one implemented by professional manufacturers in luminance cameras. This method consists of finding, for each exposure, a direct relationship between each pixel value and the luminance of the point it represents in the scene, with the relationship being applicable for all luminance levels that can be found in the field. From these relationships, the luminance validity range of each exposure can be defined, and the merging of multiple exposures into an HDR image is done accordingly (Dumortier, 2015). Generating luminance maps using a luminance camera is therefore straightforward and does not require additional manipulations or measurements.

The step-by-step calibration is less straightforward but allows to generate luminance maps using a commercially available photo-camera. A comprehensive description is provided in Annex B.2 Tutorial: Generating HDR images. The method consists of applying an automatic algorithm that merges the LDR images captured with the photocamera into an HDR image while doing a radiometric calibration, before manually adjusting the generated HDR image to calibrate it photometrically and geometrically. A detailed tutorial article, summarised below, details the step-by-step calibration method to generate luminance maps of daylit visual scenes from a sequence of LDR (jpeg) images (Pierson et al., 2021).

The step-by-step calibration method could be adapted to generate luminance maps of electrically lit visual scenes, on the condition that the following issues are taken care of:

- $\quad$ definition of the correct white balance setting of the camera for the studied lighting conditions

- potential interference of the flicker of the electric light source while the sequence of multiple exposures is being captured (need of stable lighting conditions)

- $\quad$ limited resolution of the HDR image when the size of the light source(s) being measured is very small in the visual scene, such as with current LED luminaires.

The luminance map can be used for a variety of scopes, e.g. verifying luminance ratios or measuring glare.

\subsubsection{Illumination of objects}

Cylindrical illuminance

The cylindrical illuminance (mean cylindrical illuminance), $\overline{\mathrm{E}}_{\mathrm{cl}}$, measures the volume of illumination of an object in space. It is the quantity of the total luminous flux incident at a point of a curved surface of a hypothetical cylindrical object, averaged by the total surface area. Occupants require clear visibility and usability of work areas to conduct activities where communication, recognition and interaction with other occupants are carried out (e.g. discerning facial expressions).

For office-based activities, a cylindrical illuminance of $100-150 \mathrm{Ix}$ is required with a uniformity, $\mathrm{U}_{0}$, of $0.4-0.7$ (see Table 6.26 in prEN12464-1:2019). This is measured at head height (1.2m for sitting and 1.6m for standing) with a cylindrical illuminance meter. Where a dedicated meter is not available, the cubic illuminance method can estimate the cylindrical illuminance with a standard illuminance meter (see Annex B.1 Cylindrical illuminance estimation).

The balance between directional and diffused lighting must also be considered, to avoid hard shadows caused by strong directional lighting or loss of visibility when overly diffused lighting removes contrasts and shadows. The Modelling Index refers to the balance between diffuse and directed light and is expressed as the ratio between the $\overline{\mathrm{E}}_{\mathrm{cl}}$ and the mean horizontal illuminance $\overline{\mathrm{E}}_{\mathrm{h}}$ (e.g. $500 \mathrm{lux}$ ). A ratio of 0.3 and 0.6 should be achieved. 


\subsubsection{Directionality of light}

To measure directionality, use:

- direct observations, or

- create a luminance map (luminance camera or HDR) of a diffusive white ball positioned at the head eight, located at the centre of the room or at any other significant point of interest, e.g. the teacher's position in a classroom.

Note that directionality is easier to evaluate under overcast than clear sky conditions, especially when direct sunlight meets the sphere directly. The directionality can be determined by calculating the vector-to-scalar illuminance ratio, where the vector and scalar values can be obtained from a taken HDR image. For more information on methods for directionality measurement and interpretation of the results, see Dubois, Gentile and Amorim (2016) at section "detection of shadows".

Shadows in the space may be negative or positive depending on the application. A good balance between direct and diffuse light is necessary to see the way light falls on objects. It is worthwhile to study the shadows of objects in the monitored room: the light side of an object, the shadow side, the cast shadow, and the presence of reflected light. Any abnormality or quality should be noted since it provides indication of lighting qualities. Further information on shadows may be found in Johnsen et al. (2006).

\subsubsection{Glare}

\subsubsection{Preliminary assessment of glare}

Areas at glare risk can be assessed visually for both daylight and electric lighting. To identify glare risk, refer to the procedure provided in T50 D.3 5.2.2.3 page 40 (Dubois et al., 2016).

The identification of areas at risk of glare is simpler for experienced monitoring teams. If the project is provided with a daylight model, the monitoring team can systematically identify areas at risk of glare by running an annual glare simulation with the software Climate Studio by Solemma.

Areas at risk of glare must be further tested with more specific tools, like luminance mapping.

\subsubsection{Glare from daylight}

Daylight glare is measured via Daylight Glare Probability (DGP). A luminance map is needed for measuring DGP. A luminance map accounts for a single point of view at a specific time of the year. It is responsibility of the monitoring team to identify the relevant point of view and time of the year for the measurement(s).

To measure DGP, create a luminance map following the procedure provided in this document. If the camera is provided with a 180 degrees fisheye lens, no other instruments are necessary. In other cases, the vertical illuminance at eye position should also be measured.

The resulting HDR image should be loaded in appropriate software, like the Radiance-based Evalglare. The software will provide a measure of DGP. DGP lower than 0.35 is classified as imperceptible, while DGP higher or equal to 0.45 is classified as intolerable.

\subsubsection{Glare from electric lighting}

Glare form electric lighting is measured via the Unified Glare Rating (UGR). Similarly to DGP, UGR can be measured by post-processing the HDR image in an appropriate software. The Radiance commands findglare and glarendx can be used to the scope. More information on UGR and limit values are provided in EN12464-1.

\subsubsection{Colour of the light source}

The colour of the light source for titularly white light sources is measured by the Correlated Colour Temperature (CCT). The capacity of the light source to correctly render colours of surfaces is today measured with the Color Rendering Index (CRI Ra), although other metrics have been proposed and they may supersede CRI Ra in the next future. 
In common practice, CCT is used to indicate the "warmness" of a light source. Generally, CCT below $3000 \mathrm{~K}$ are considered warm and more appropriate for home setting, CCT between $3000 \mathrm{~K}$ and $4000 \mathrm{~K}$ are considered neutral and appropriate for office settings, and CCT above $4000 \mathrm{~K}$ are considered cold and they might be used in offices or health care premises. The CCT of daylight changes continuously during day and time and it is high during the central part of the day. Recent lighting schemes (integrative lighting) introduced electric lighting changing in CCT and intensity during the day to follow daylight. It is then relevant to measure how the colour of the light source (daylight, electric light, and both) changes during the day.

$\mathrm{CRI} R a$ is measured in a scale varying between $0-100$, where 100 corresponds to rendering equal to a reference light source (daylight or incandescent lighting, depending on the CCT). High colour renderings are desirable for applications where discriminating between colours is particularly important. For office applications, $\mathrm{CRI} \mathrm{Ra}>80$ should be always pursued. Modern LEDs, even of mid-range prices, are often provided with CRI Ra $>90$. Since daylight has always $\mathrm{CRI} R a=100$, a proper integration of daylight in space will guarantee a good rendering.

Both CCT and CRI Ra depend on the spectral power distribution of the light source; therefore, the most accurate way to measure colour of the light source is by using a spectrometer.

A spectrometer can measure the spectral power of the incident light usually with 1 or $5 \mathrm{~nm}$ steps. The spectrometer is normally able to compute this information into a CCT and a CRI Ra. A spectrometer can be used for incident light, so it is handy to measure mixed daylight and electric lighting. The measured spectral power distribution can also be used to assess the circadian potential of the space, see $\S 3.4 .1$. Therefore, the tool can be used for monitoring different aspects of the integrated project.

The CCT can also be estimated using cheap colorimeter with RGB sensors. In this case, the incident light is measured only at three channels and the resulting CCT is somewhat approximate. The tool is appropriate for estimating CCT even of mixed light sources, but the results cannot be used to assess the circadian potential.

At the very minimum, the CCT and CRI Ra of electric lighting source can be retrieved from the product datasheets. This approach does not include the influence of daylight in the real space. In addition, the listed CCT and CRI Ra are nominal, and they refer to laboratory test; the sources may perform slightly differently once installed.

Finally, recent development in HDR techniques promise that luminance mapping could be successfully used even for retrieving colour information (Jung \& Inanici, 2018). However, the technique is not yet of common use.

\subsubsection{Temporal Light Modulation (TLM)}

The term "flicker" is used in everyday language to refer to variation in intensity of light over time. However, the correct term for this phenomenon is temporal light modulation, or TLM. This modulation in intensity may be periodic or non-periodic, and it can be intentional or unintentional. TLM normally refers to electric light sources and intensity variations at high frequencies, several times per second. TLM, in a strict definition, includes variations in daylight too, but TLM in daylight is usually something desirable.

In the 80's and 90's, TLM was a problem with fluorescent tubes or other discharge lamps. Then, this problem was solved by introducing electronic high frequency ballasts drivers. In the transition to LED lighting, TLM has reemerged as a problem, mostly due to low quality driver design, but also due to the use of a dimming technique called pulse width modulation (PWM) used at too low frequencies.

It is well established that TLM can have a negative effect on the human health and well-being. When the characteristics of the modulation allow (certain frequency range, waveform shapes, modulation depth, etc.) the TLM may be noticed by the human eye, seen as artefacts. These are called temporal light artefacts, or TLAs, and there are three types of these artefacts defined, induced by TLM:

- $\quad$ Flicker - Perception of unsteadiness of light intensity, with stationary environment and non-moving eyes

- Stroboscopic effects - Observation of motion patterns induced by moving objects or moving light sources, without moving the eyes

- Phantom array effect - Observation of motion patterns during the short duration of an eye movement, with otherwise stationary environment

Due to the conditions of the definition of flicker, the modulation frequency range in which flicker can be observed is below about $90 \mathrm{~Hz}$. However, both the stroboscopic and phantom array effects can be observed at much higher 
frequencies. Stroboscopic effects are not defined above $2000 \mathrm{~Hz}$, but it has been reported that phantom array effects may be observed at as high frequencies as $10000 \mathrm{~Hz}$.

Just recently, standards for measuring two of these TLAs have been developed: PstLM for flicker $(0-80 \mathrm{~Hz})$ and the stroboscopic visibility measure SVM for stroboscopic effects $(80-2000 \mathrm{~Hz}$ ) (Sekulovski et al., 2016). Both indexes consider both the characteristics of the modulation and how this is filtered and perceived by the human eye and brain. PstLM = 1 or SVM = 1 correspond to a $50 \%$ chance the effect will be perceived by a standard observer. According to EU Ecodirective regulations, starting from September 2021, the PstLM value may not exceed 1 and the SVM-value may not exceed 0.9 (expected to change to 0.4 in 2024), for light products at full load. Importantly, due to the variety of waveform frequency and complexity, old measures like Percent Flicker and Flicker Index are now obsolete.

PstLM and SVM are measured with appropriate detectors. Example of modern detectors measuring SVM are: UPRtek MK350N, LabFlicker from Viso Systems and BTS256-EF from GigaHertz Optik. The two latter also offer PstLM measurements. While performing measurement, light should be provided only by the measured light source, with other light source turned off or shielded. A SVM measurements requires 2 seconds, while a PstLM requires 180 seconds. The instrument should be kept still during this time, so it is fundamental to place the instrument on a tripod or similar.

The TLAs mentioned above are per definition visual effects. More insidious however, are the non-visual neurobiological and cognitive effects of TLM. These have been showed to induce headache, eyestrain, epilepsy, and negatively affect visual and cognitive performance, mood and comfort. These effects are especially problematic, since the people that suffers of it seldom are aware of the cause of the problems. Currently, there are no measures for these non-visual effects. Since TLM-free drivers for LED lighting is easily available, this should always be considered first When dimming is desirable, TLM due to PWM can be avoided using amplitude dimming.

\subsubsection{View out}

A good view out can compensate for both luminous and thermal deficits for example, glare from bright window openings or overheating due to direct sunlight. Occupants often accept glare and thermal discomfort to retain an enjoyable view that would otherwise be obstructed or excluded when shading devices are closed \{Markus, 1967 \#39\}.

Views of natural features (greenery, water bodies) are generally preferred over other view content, but it might not always be possible to provide natural views in densely populated and built-up environments. On the other hand, some occupants might prefer privacy over a view in context to dense urban environments, especially when a view out also allows for a view into the space. Socio-cultural conditioning likely plays a role in this. The European Standard EN 17037 takes a more objective approach. This was adopted for IEA Task 61.

The European Standard EN17037:2018 (CEN, 2018) defines three levels of recommendation for the view out criteria ('Minimum', 'Medium,' and 'High') based on three parameters: the horizontal sight angle, the outside distance of the view, and the number of horizontal layers (namely 'sky', 'landscape', and 'ground') to be seen from at least $75 \%$ of the indoor space.

The horizontal sight angle parameter defines the minimum width of view angle to be seen from any potential location within a utilized area. Thus, it is influenced by the positioning of the window(s), the width of the room, and the depth of the room. Simplified methods to verify this parameter include hand-drawn projections in architectural plans so that the minimum width of view angles is achieved for a given recommendation level. Other verification methods for the horizontal sight angle parameter include simulations that consider the building storey (that is, the elevation from the ground plane) from which the view out is assessed (Shach-Pinsly et al., 2011).

The outside distance of the view parameter defines minimum distances between the building opening and external obstructions within the field of view (for example, neighboring building facades). The outside distance parameter is closely associated with the number of horizontal layers parameter, as it helps to ensure that at least one horizontal layer is included within the view out. Simplified methods include hand-drawn projections in architectural sections, which can be used to verify both the distance of the outside view and the horizontal layers to be seen from a given position within the room. Advanced verification methods include simulations that consider the distance between the indoor occupant and the room opening (Hellinga \& Hordijk, 2014). 
The number of horizontal layers parameter is based on scholarly work suggesting that a satisfactory view out contains a layer of sky, a layer of city or landscape, and a layer of ground (Markus, 1967). Simplified methods to verify this parameter include a visual assessment of photographs, for which the European Standard EN17037 recommends the use of a fish-eye lens. More recent studies have included the use of panorama images and video recordings to capture dynamic and environmental aspects, as well as computer vision methods to classify mixed features in urban views (Rodriguez et al., 2021).

\subsection{Quantifying light as non-visual stimulus}

\subsubsection{Circadian potential}

There are two methods to quantifying light as a non-visual stimulus (Houser and Esposito, 2021), these are based on 1) spectral response of the photopigments in the rods, cones and ipRGCs, and 2) the nocturnal suppression of the hormone melatonin. There are two metrics for the first method, the Equivalent Melanopic Lux introduced by Lucas et al. (2014) and the Melanopic Equivalent Daylight illuminance (M-EDI) proposed by the CIE (CIE, 2019); and one tool for the second method, the Circadian Stimulus (CS) (Rea \& Figueiro, 2016; Rea et al., 2011; Rea et al., 2005).

The reader should consider that knowledge in the field is evolving at unprecedent pace and the information here provided may be outdated in few years. To date, the Equivalent Melanopic Lux is the most widespread metric, as it has been adopted by voluntary certification schemes (see WELL Standard). It is also the standard output for current versions of circadian lighting design software (Alfa, Lark). The M-EDI has been proposed only recently by the CIE and it is expected to become the standard in the coming future. The CS is also widely used.

For the scope of this monitoring protocol, the following measuring procedure applies to all the proposed metrics.

The non-visual stimulus must be measured for at least two (2) extreme positions in the space, one under predominantly daylighting (e.g., close to a vertical window) and the other under predominantly electric lighting (e.g., in a position deeper in the room). The measurements should be preferably repeated at different times of the day and seasons. If this is not possible, it is suggested to select an overcast day close to an equinox.

The measurement requires:

- A spectrometer or, at least, an illuminance meter,

- a toolbox to calculate the selected metric (EML, M-EDI, CS). The toolboxes are Excel files that can be freely downloaded. An online version of the CS calculator is also available. The link to the pages where they can be downloaded or consulted are indicated in the references.

The spectrometer should measure irradiance in the visible range $(380-780 \mathrm{~nm})$, generally with an interval of 1 to 5 $\mathrm{nm}$. Usually, data can be downloaded in the form of a .csv file. The advantage of using a spectrometer is that the actual irradiance is measured. The irradiance can be measured also when more light sources are providing illumination, like a mix of daylight and different electric lighting sources.

If an illuminance meter is available instead, the monitoring team should note the type(s) of light source(s) providing illumination. The toolboxes provide approximated approaches where the illuminance is converted to approximated irradiance by using standard relative spectral power distributions for the selected light source(s). The advantage of using an illuminance meter is that the device is cheap and usually available to most of monitoring teams. The disadvantages are that the resulting irradiance is only approximate, and that irradiance provided by a mix a of light sources is harder to approximate.

Note that all the measurements must be performed vertically at eye position. To perform the measurement, proceed as follow:

1. Take always note of day and time, operating conditions (shading position, electric lighting, etc) as well as weather conditions. Use photos as documentation for each of the measurements.

2. Perform an initial measurement of vertical irradiance (or, alternatively, illuminance) at the eye position of the occupant under daylight only for each of the extreme task positions. 
a. If the approximate mode is used (illuminance meter), the D65 illuminant can be used as light source

3. Perform a measurement of vertical irradiance (or, alternatively, illuminance) at the eye position of the occupant under combined daylight + electric lighting for each of the extreme task positions.

a. If particular integrated strategies are used, consider performing measurements under different scenarios, e.g. different lighting CCT or dimming levels or with shadings in different positions

b. If the approximate mode is used (illuminance meter), take note of the type of electric light source (fluorescent, LED, ...), CCT, and dimming level.

4. Perform a measurement of vertical irradiance (or, alternatively, illuminance) at the eye position of the occupant under combined electric lighting only (night time) for each of the extreme task positions.

a. If particular electric lighting strategies are used, consider performing measurements under different scenarios, e.g. different lighting CCT or dimming levels

b. If the approximate mode is used (illuminance meter), take note of the type of electric light source (fluorescent, LED, ...), CCT, and dimming level.

5. Download the data on a laptop

6. Use the appropriate toolbox for the selected metric

The following sections provide an overview of the three proposed circadian metrics (EML, Mel-EDI, CS) and their relative calculation toolboxes.

\subsubsection{Lucas Toolbox - Equivalent Melanopic Lux (EML) and M/P}

The circadian potential of a space can be estimated by quantifying the Equivalent Melanopic Lux (EML) (Enezi et al., 2011; Lucas et al., 2014). The EML values can be calculated by using the MS Excel workbook "Irradiance Toolbox" developed by Lucas et al. (2014). The workbook can be downloaded either from the article page or, currently, from the Lucas Group page on The University of Manchester website (Lucas Group \& The University of Manchester, 2020).

The toolbox provides both the photopic lux (they should be the same as measured by the illuminance meter) and the cyanopic, chloropic, erythropic, melanopic, and rhodopic lux, the first three corresponding to the three classes of cones present in the human retina, the following to the iPRGCs, and the final one to the rod photoreceptors. The reason why only the equivalent melanopic lux is used to estimate non-visual response is due to the fact that the role of each photoreceptor in circadian entrainment has not yet been precisely determined and therefore their equivalent units have not yet been integrated in the calculation of the non-visual stimulus.

The information necessary to apply the conversion are either the measured irradiance, or the measured illuminance and the spectral power distribution of the light source. In the Lucas toolbox, the measured irradiance with a spectrometer is simply copy-pasted and the illuminances are calculated. For the approximate measurement with illuminance meter, the user should type the measured photopic illuminance and select the SPD from a preset list of light sources (e.g. incandescent, daylight, narrowband, white LED, etc.).

Figure 5 illustrates in blue an example of the spectral power distribution (SPD) obtained by the relative spectral power data introduced in the toolbox. The red curve represents the melanopic sensitivity curve, peaking at $480 \mathrm{~nm}$. 


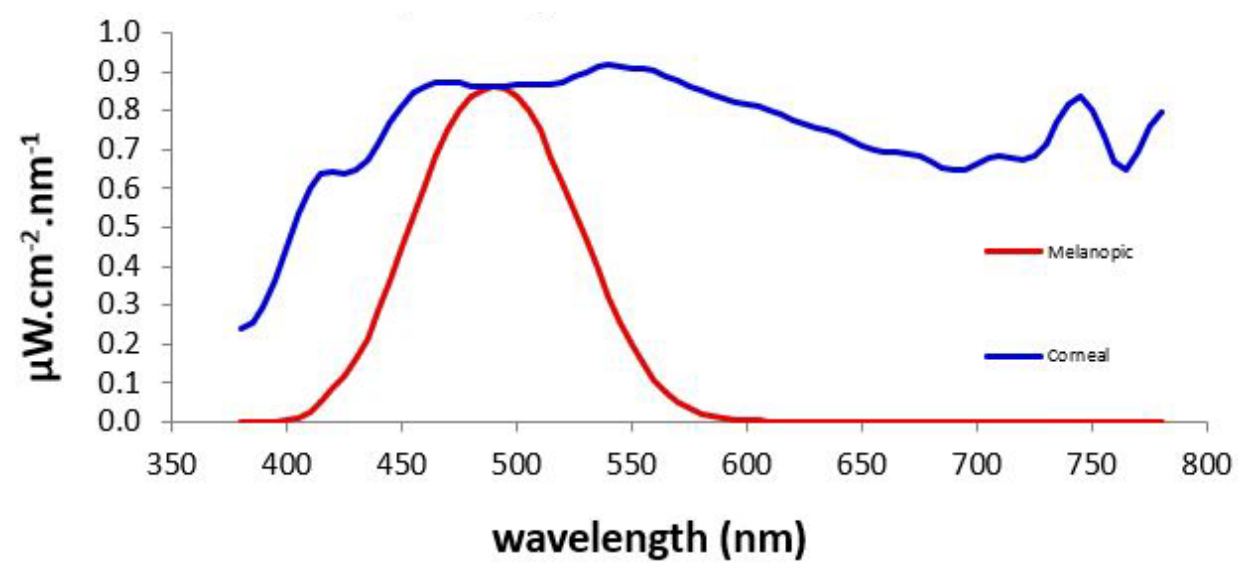

Figure 4. Spectral power distribution (Lucas et al., 2014).

The toolbox integrates the SPD curve in its calculation process and expresses its results in a table synthetizing information about the spectral sensitivity of each retinal output and the equivalent lux obtained for each photoreceptor (Figure 6). For further information on how to use the toolbox, please consult the Irradiance Toolbox User Guide provided by the Lucas Group (Lucas Group \& The University of Manchester, 2020).

It can be useful to calculate the melanopic over photopic illuminance ratio. This ratio provides a rough indication of the spectral composition of the light source. In the example of the test measurement here illustrated, the toolbox proposes for 125.48 photopic lux, a 124.01 equivalent melanopic lux. The factor of conversion is then:

$M / P=124.01 / 125.48=0.988$

The M/P ratio can be useful as rough guidance during the lighting design process. As rule of thumb, M/P $>0.9$ indicates a blue-enriched light which is recommended during daytime, while $M / P<0.35$ indicates a red-shifted light which is more appropriate during evenings.

\begin{tabular}{|c|c|c|c|c|c|c|}
\hline \multicolumn{7}{|l|}{ Photopic illuminance } \\
\hline & Photopic & Visibility & 555.0 & $\mathrm{n} / \mathrm{a}$ & $v(\lambda)$ & 125.48 \\
\hline \multicolumn{7}{|c|}{ Human retinal photopigment complement (all weighted) } \\
\hline & Prefix & Sensitivity & $\lambda_{\max }$ & $\alpha$ in $N_{\alpha}(\lambda)$ & Curve & $\alpha$-opic lux \\
\hline & Cyanopic & S cone & 419.0 & sc & $\mathrm{N}_{\mathrm{sc}}(\lambda)$ & 109.64 \\
\hline & Melanopic & Melanopsin & 480.0 & z & $\mathrm{N}_{\mathrm{z}}(\lambda)$ & 124.01 \\
\hline & Rhodopic & Rod & 496.3 & $\mathrm{r}$ & $N_{r}(\lambda)$ & 125.72 \\
\hline & Chloropic & M cone & 530.8 & $\mathrm{mc}$ & $\mathrm{N}_{\mathrm{mc}}(\lambda)$ & 126.31 \\
\hline & Erythropic & L cone & 558.4 & Ic & $\mathrm{N}_{\mathrm{lc}}(\lambda)$ & 123.76 \\
\hline
\end{tabular}

Figure 5. Photopic illuminance and equivalent illuminance for rods, cones and iPRGCs receptors (Lucas et al., 2014).

The WELL Building standard (WELL) gives recommendations for quantity design targets for circadian lighting design (M-EDI). The standard all suggests recommendations based on the temporal pattern of the light exposure (time and duration), and gives minimum values to obtained 1 or 3 points for WELL certification (see Table 9).

\subsubsection{CIE S $026 \alpha$-OPIC TOOLBOX - Melanopic equivalent daylight illuminance (mel-EDI)}

EML is expressed in units of melanopic lux (lux) which is not recognized by the international system of units (SI); as a result, the CIE (International commission of Illumination) has proposed a new quantity, the melanopic equivalent daylight illuminance (M-EDI), a new quantity that is a SI compliant unit. The M-EDI combine the sensitive of five photoreceptors (S cone, M cone, L cone, rhodopsin, melanospsin) with standard daylight (D65) 
(CIE, 2018). To calculate M-EDI the CIE has developed the "CIE S $026 \alpha$-opic toolbox", a Microsoft Excel calculator, and a user guide on how to use the toolbox, both available in the CIE web site:

- Toolbox: https://bit.ly/33YM9Rh

- $\quad$ User guide: https://bit.ly/3auN66d

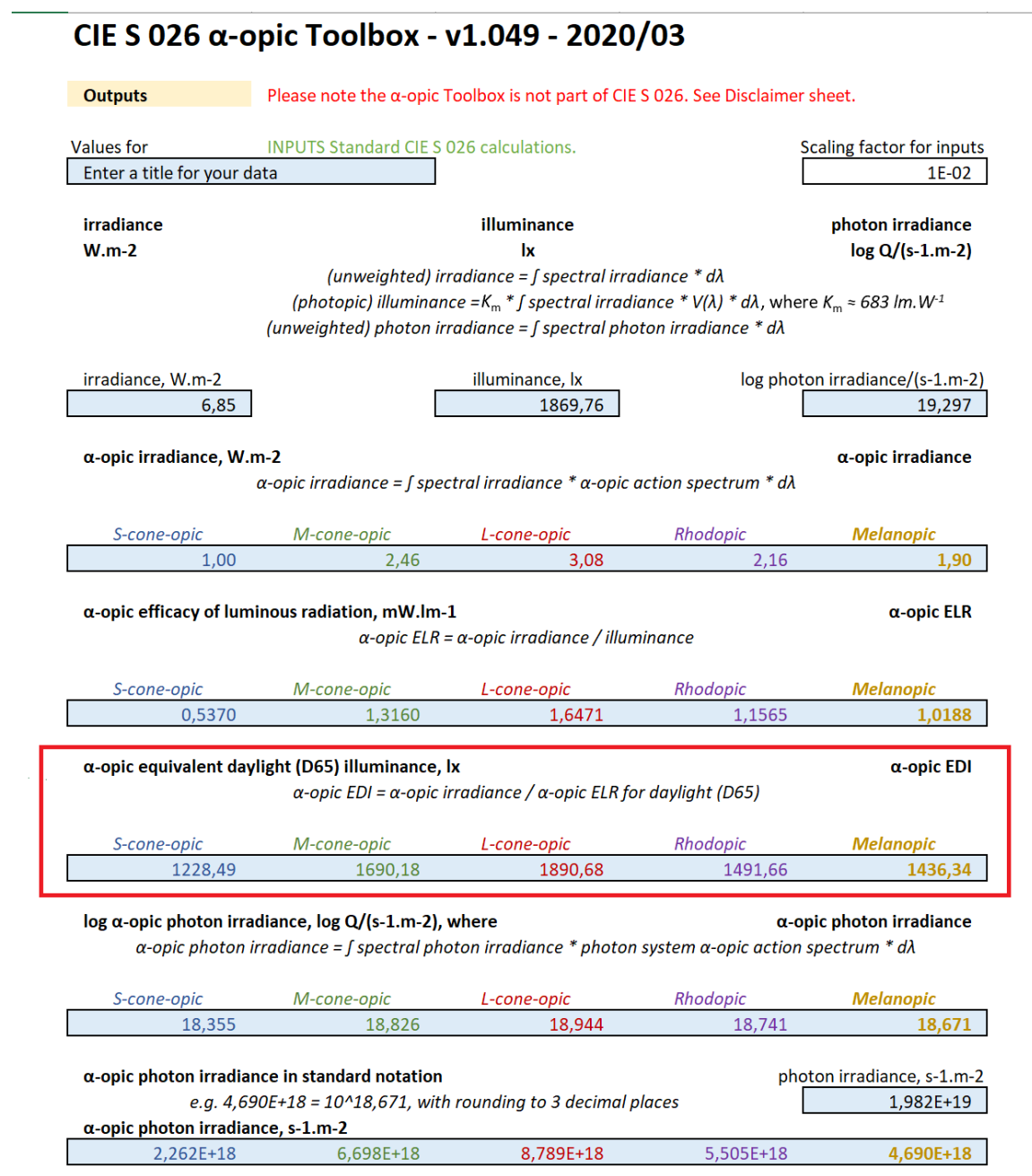

Figure 6. Outputs provided by CIE S $026 \alpha$-opic toolbox (https://bit.ly/3auN66d). Highlighted in red is the EDI= equivalent daylight (D65) illuminance

The M-EDI toolbox, as the EML toolbox, needs either the measured irradiance or a light source's spectral power distribution (SPD) and photopic illuminance at the plane of the eye. Measurements are taken at a vertical plane at $1.2 \mathrm{~m}$ heigh representing the plane of an observer's eye for sitting position. The procedure for obtaining the M-EDI from the toolbox is very similar to the one for the EML (see steps described above). The CIE S $026 \alpha$-opic toolbox outputs would provide the M-EDI (see Figure 7 in this case is 1436.34 Ix)

There exist recommendations on minimum values of for M-EDI. The WELL standard which is manly based on EML allows for compliance with M-EDI, however, Brown et al provides recommendations that are higher in quantity and longer in duration, for example WELL recommends a minimum M-EDI of 163 lux for a minimum of 4 hours, while Brown et al recommends a minimum M-EDI of 250 lux during the day. These new recommendations, articulated in an under-review publication (Brown et al., 2020), are based on an expert workshop to develop consensus on recommendations for healthy light environments. The recommendations are based on analysis of extensive data from controlled experiments. The recommended M-EDI are provided in Table 9.

\subsubsection{Circadian Stimulus Calculator - Circadian Stimulus (CS)}

The CS calculator provides a coefficient for expressing the extent to which a given light source of specific intensity and spectrum elicits circadian responses, namely the suppression of melatonin secretion. The coefficient ranges 
from 0 to 0.7 , these values ranging from no melatonin suppression (0) to maximal observed melatonin suppression (0.7), respectively (Figueiro et al., 2016). Although the output is different, the CS Calculator is similar to the Lucas toolbox in the way in which relative spectral power values imported from a .csv file (describing the spectral distribution of the light source) need to be introduced, or in the selection of a light source from a list with pre-set characteristics. The CS calculator works with wavelength increments of $2 \mathrm{~nm}$. The values can be introduced in the calculator with an increment of 1 or $5 \mathrm{~nm}$, this requiring an extrapolation of data operated by the CS Calculator, respectively, to fit its increment of $2 \mathrm{~nm}$. An important difference between the two tools is the ability of the CS Calculator to compile spectral data from several sources. For example, the SPD of a pre-codified luminaire can be combined with manually encoded data taken from a measurement. Once all light sources, combined with their respective photopic illuminance levels are encoded, the data obtained after calculation is provided in three parts together with a display of relative spectral power distribution corresponding to $2 \mathrm{~nm}$ wavelength increments. An online version of the CS Calculator exists, proposing a more didactic interface of the tool, indicating the steps to follow, facilitating the choice of a light source and the manual input of spectral data. Recommendations on CS have been provided by the emerging guidance UL DG-24480, please refer to Table 9.

Table 9. Thresholds for circadian lighting design for EML, EDI and CS, recommended by WELL v2 (IWBI, 2020), UL 24480 (UL, 2020), and Brown et al. (2020). Table adapted from Houser and Esposito (2021).

\begin{tabular}{|c|c|c|c|c|c|c|c|}
\hline \multirow{2}{*}{$\begin{array}{l}\text { Standard/Public } \\
\text { ation }\end{array}$} & \multicolumn{2}{|c|}{ Temporal pattern } & \multicolumn{4}{|c|}{ Lighting quantity (light level and spectrum) } & \multirow[t]{2}{*}{ Location } \\
\hline & $\begin{array}{l}\text { Timing of } \\
\text { exposure }\end{array}$ & $\begin{array}{l}\text { Duration of } \\
\text { the } \\
\text { exposure }\end{array}$ & $\begin{array}{l}\text { Circadian } \\
\text { stimulus } \\
\text { (CS) }\end{array}$ & $\begin{array}{l}\text { Equivalent } \\
\text { melanopic Lux } \\
(E M L)\end{array}$ & $\begin{array}{l}\text { Melanopic } \\
\text { equivalent } \\
\text { daylight } \\
\text { illuminance } \\
\text { (Melanopic EDI) } \\
\text { (Lux) }\end{array}$ & $\begin{array}{l}\text { Photopic } \\
\text { Illuminance } \\
\text { (Lux) }\end{array}$ & \\
\hline $\begin{array}{l}\text { WELL v2.0 } \\
\text { Requirements } \\
\text { for } 1 \text { point }\end{array}$ & $\begin{array}{l}\text { Between } \\
\text { 9am to } 1 \mathrm{pm} . \\
\text { Light levels } \\
\text { may be } \\
\text { lowered } \\
\text { after 8pm }\end{array}$ & $\begin{array}{l}\text { Minimum of } \\
4 \text { hours }\end{array}$ & $\begin{array}{l}\geq 0.30 \text { (if } \\
\text { electric } \\
\text { light only) }\end{array}$ & $\begin{array}{l}\geq 150 \text { (if electric } \\
\text { light only) } \\
\geq 120 \text { from electric } \\
\text { lighting (if certain } \\
\text { daylighting criteria } \\
\text { are met) }\end{array}$ & $\begin{array}{l}\geq 136 \text { (if electric } \\
\text { light only) } \\
\geq 109 \text { from electric } \\
\text { lighting (if certain } \\
\text { daylighting criteria } \\
\text { are met) }\end{array}$ & $\mathrm{N} / \mathrm{A}$ & $\begin{array}{l}\text { Vertical } \\
\text { plane at } \\
\text { eye level }\end{array}$ \\
\hline $\begin{array}{l}\text { WELL v2.0 } \\
\text { Requirements } \\
\text { for } 3 \text { points }\end{array}$ & $\begin{array}{l}\text { Between } \\
\text { 9am to } 1 \mathrm{pm} . \\
\text { Light levels } \\
\text { may be } \\
\text { lowered } \\
\text { after 8pm }\end{array}$ & $\begin{array}{l}\text { Minimum of } \\
4 \text { hours }\end{array}$ & $\mathrm{N} / \mathrm{A}$ & $\begin{array}{l}\geq 240 \text { (if electric } \\
\text { lighting only) } \\
\geq 180 \text { from electric } \\
\text { lighting (if certain } \\
\text { daylighting criteria } \\
\text { are met) }\end{array}$ & $\begin{array}{l}\geq 218 \text { (if electric } \\
\text { lighting only) } \\
\geq 163 \text { from electric } \\
\text { lighting (if certain } \\
\text { daylighting criteria } \\
\text { are met) }\end{array}$ & $\mathrm{N} / \mathrm{A}$ & $\begin{array}{l}\text { Vertical } \\
\text { plane at } \\
\text { eye level }\end{array}$ \\
\hline \multirow[t]{3}{*}{ UL 24480} & $7 \mathrm{am}$ to $4 \mathrm{pm}$ & $\begin{array}{l}\text { Minimum of } \\
2 \text { hours, } \\
\text { morning if } \\
\text { not full } \\
\text { period }\end{array}$ & $\geq 0.30$ & $\begin{array}{l}\text { Comply with WELL } \\
\text { criteria listed above } \\
\text { to achieve } 1 \text { point } \\
\text { or } 3 \text { points }\end{array}$ & $\mathrm{N} / \mathrm{A}$ & $\geq 500$ & \multirow[t]{3}{*}{$\begin{array}{l}\text { Vertical } \\
\text { plane at } \\
\text { eye leve }\end{array}$} \\
\hline & $5 \mathrm{pm}$ to $7 \mathrm{pm}$ & $\begin{array}{l}\text { During full } \\
\text { period }\end{array}$ & $\geq 0.20$ & & $\mathrm{~N} / \mathrm{A}$ & $\mathrm{N} / \mathrm{A}$ & \\
\hline & After 8pm & $\begin{array}{l}\text { During full } \\
\text { period }\end{array}$ & $\geq 0.10$ & & $\mathrm{~N} / \mathrm{A}$ & $\mathrm{N} / \mathrm{A}$ & \\
\hline Brown et al. & $\begin{array}{l}\text { Through the } \\
\text { day } \\
\text { 6am to } 7 \mathrm{pm}\end{array}$ & $\begin{array}{l}\text { During the } \\
\text { full period }\end{array}$ & $\mathrm{N} / \mathrm{A}$ & & $\geq 250$ & & $\begin{array}{l}\text { Vertical } \\
\text { plane at } \\
\text { eye level }\end{array}$ \\
\hline
\end{tabular}




\begin{tabular}{|l|l|l|l|l|l|l|l|}
\hline & $\begin{array}{l}3 \text { hours } \\
\text { before bed } \\
7 \mathrm{pm} \text { to } \\
10 \mathrm{pm}\end{array}$ & $\begin{array}{l}\text { During the } \\
\text { full period }\end{array}$ & N/A & & $\leq 10$ & & \\
\cline { 1 - 4 } & $\begin{array}{l}\text { Night time } \\
\text { (sleep } \\
\text { environment } \\
\text { s) after } \\
10 \mathrm{pm}\end{array}$ & $\begin{array}{l}\text { During the } \\
\text { full period }\end{array}$ & N/A & & $\leq 1$ & & \\
\hline
\end{tabular}

\subsubsection{Circadian lighting design software}

\section{ALFA}

A way for evaluating the efficiency of a light input in terms of their circadian potential is to run simulations through software tools such as ALFA. The software was developed by the Solemma team, an international group of designers, building scientists, educators, and environmental performance consultants based at the MIT (Massachusetts Institute of Technology), working since 2012 on environmental analysis tools. The team has developed other tools such as DIVA (Design Iterate Validate Adapt) and Climate Studio that can provide environmental performance evaluation of individual buildings and urban landscapes.

Developed in 2018, ALFA, standing for Adaptive Lighting for Alertness, allows simulation of lighting conditions based on a 3D Rhino model. Once the 3D model is imported from Rhino, ALFA proposes several settings (e.g., luminaires, sky type, materials, etc.), all featuring detailed spectral power distribution data resulting from tests and measurements. The software requires to complete four tabs before running the simulation:

1) Identify the sky proprieties, intrinsic to a selected location, timing, and external conditions: the location allows to choose a city or to manually insert geographic coordinates; the timing data depends on the simulation that needs to be run (e.g., point-in-time); and the external conditions propose a clear, hazy, overcast, or heavy rain cloudy sky. The orientation of the building must be fixed in the $X Y$ plane of the Rhino model, the $Y$ direction (green axis) indicating North.

2) Define materials for each layer drawn in the Rhino model from a large catalogue of materials with pre-set information. Opaque materials can be chosen based on their melanopic and photopic reflectance, their melanopic ratio, and specularity. The glazing materials can also be sorted according to their melanopic and photopic reflectance and transmittance, and their melanopic ratio.

3) Set the luminaires into the different spaces. The software proposes some pre-set luminaires that can be selected based on their shape (e.g., Circular, Bulb, Linear suspended, etc.) and spectrum (e.g., LED 0.45, LED 0.57, LED 0.87, etc.). Each luminaire can be introduced in the Rhino model and positioned based on needs.

4) Select two reference planes where the measurements need to be taken. A few settings allow to set the horizontal distance between measure points (analysis grid) along with the directions they are facing (e.g., vertical or horizontal). To evaluate the luminous potential of a space, and include the factor of mobility of individuals, the measure points can face different direction. Photopic illuminance levels measures, to be used also to estimate the circadian potential, are made on a vertical plane, in the direction of view. Workplane illuminance represents the amount of light reaching the workplane and is therefore measured on the horizontal plane.

Each point has a flexible view plane and work plane height, these being by default 1200 and 760 $\mathrm{mm}$ respectively, for vertical and horizontal measurements. 


\section{Choose Location}
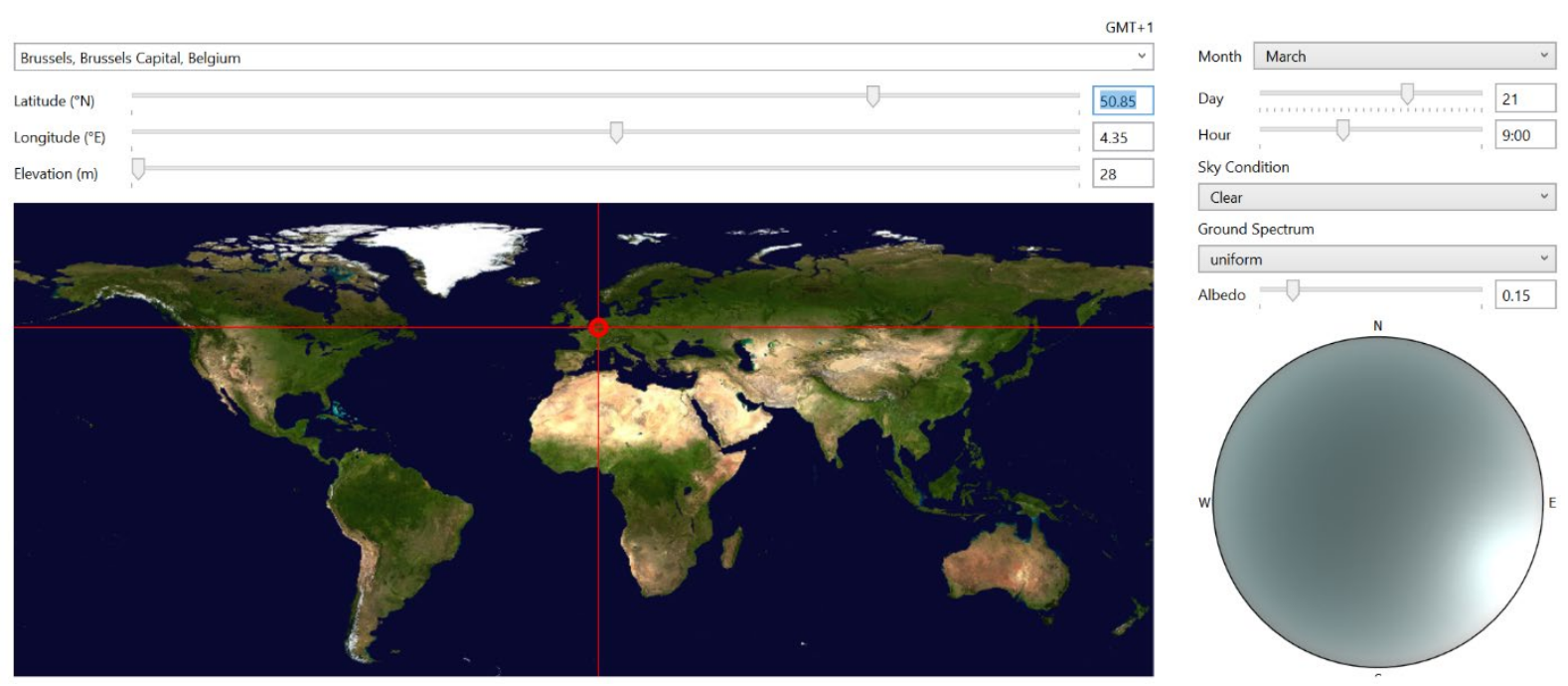

Figure 7. Choose location, ALFA.

\section{Assign Materials by Layer}

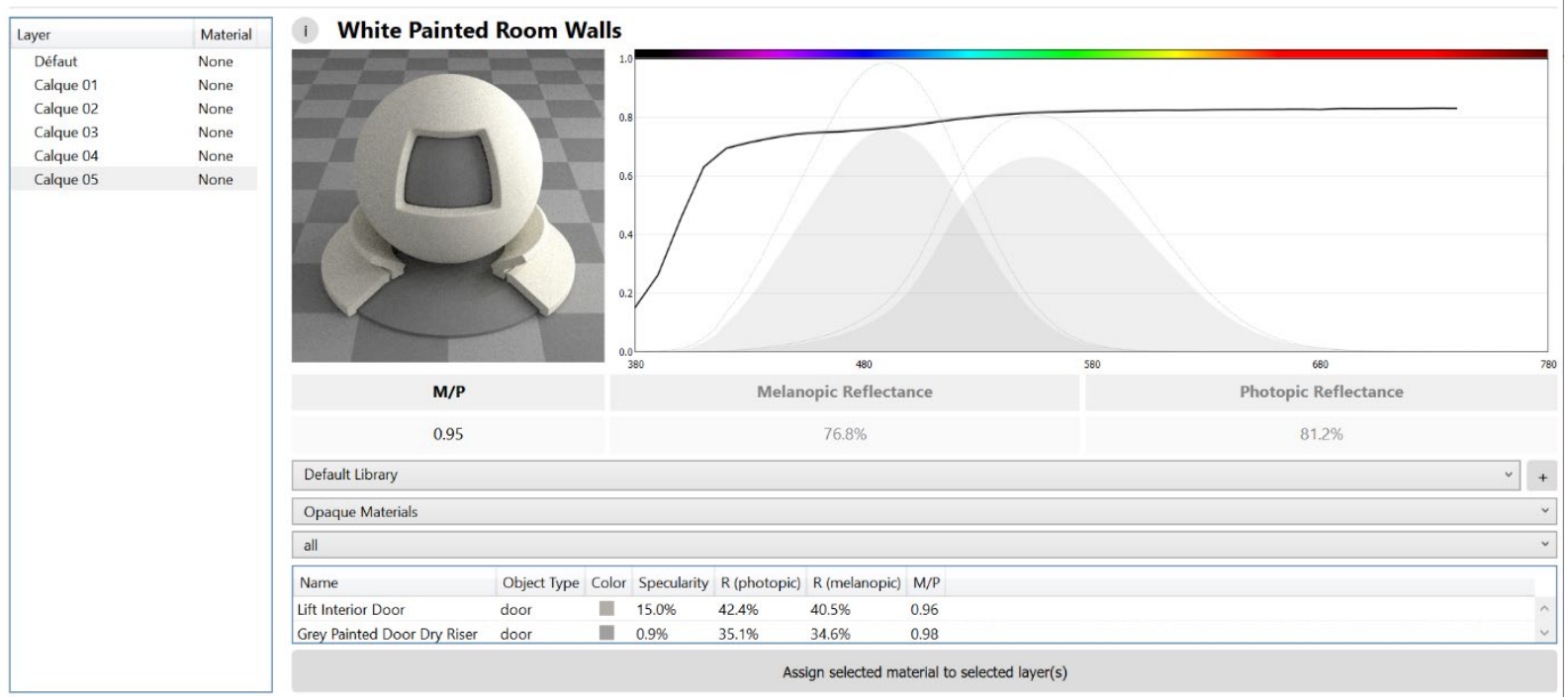

Figure 8. Assign materials, ALFA. 


\section{Create Luminaires}
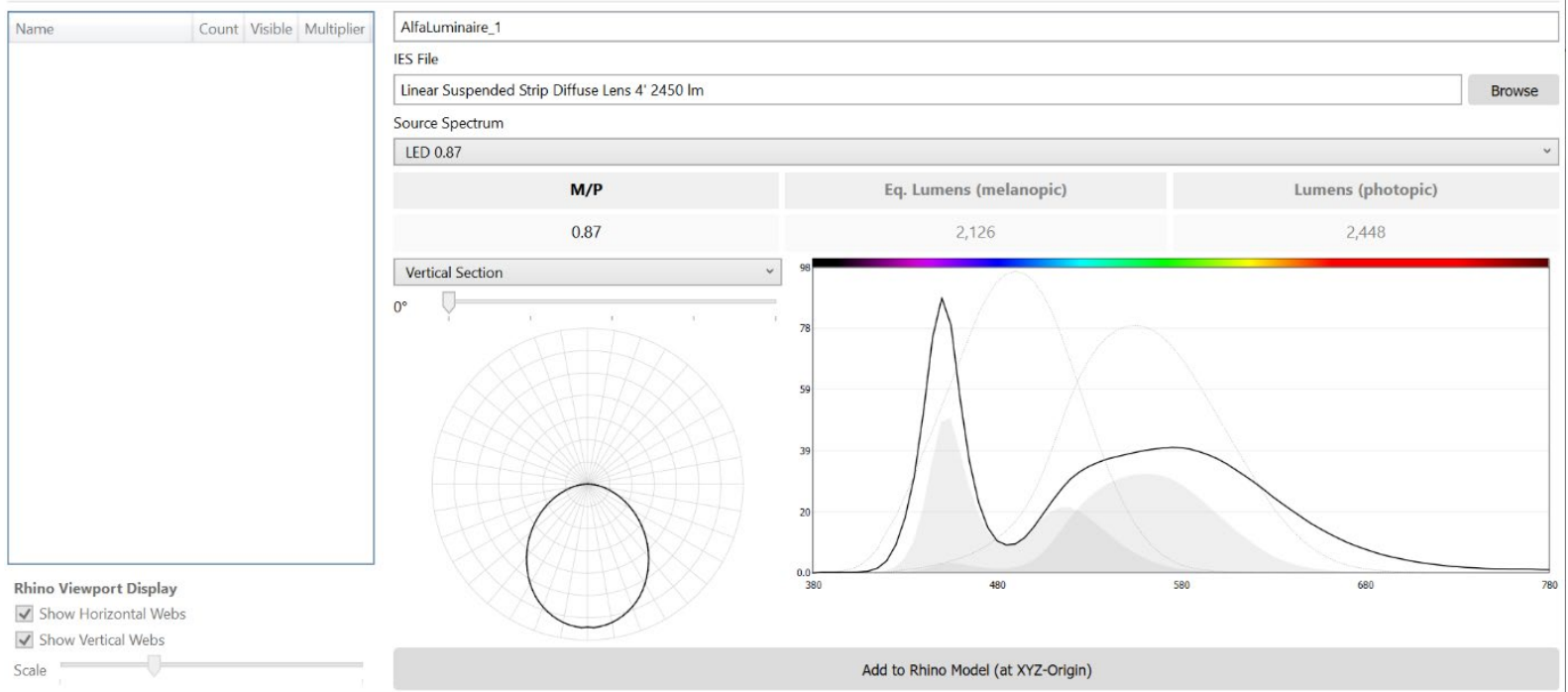

Figure 9. Create luminaires, ALFA.

Once these steps are completed, the model is ready to be launched for simulation.

Four types of results are proposed by ALFA (Figure 11): A) the spectral distribution of the light source; B) an interactive rendering, allowing the computer mouse to browse the image and obtain detailed spectral power distribution curve for each position within the space; C) a list of numerical results, distinguished in three categories, Alertness, Visual Comfort, and Workplane Illuminance. The Alertness category is itself divided in two parts; D) a .csv file displaying numerical information separately for each position and view direction. Results 3 ) and 4) are furtherly detailed in the following paragraphs.

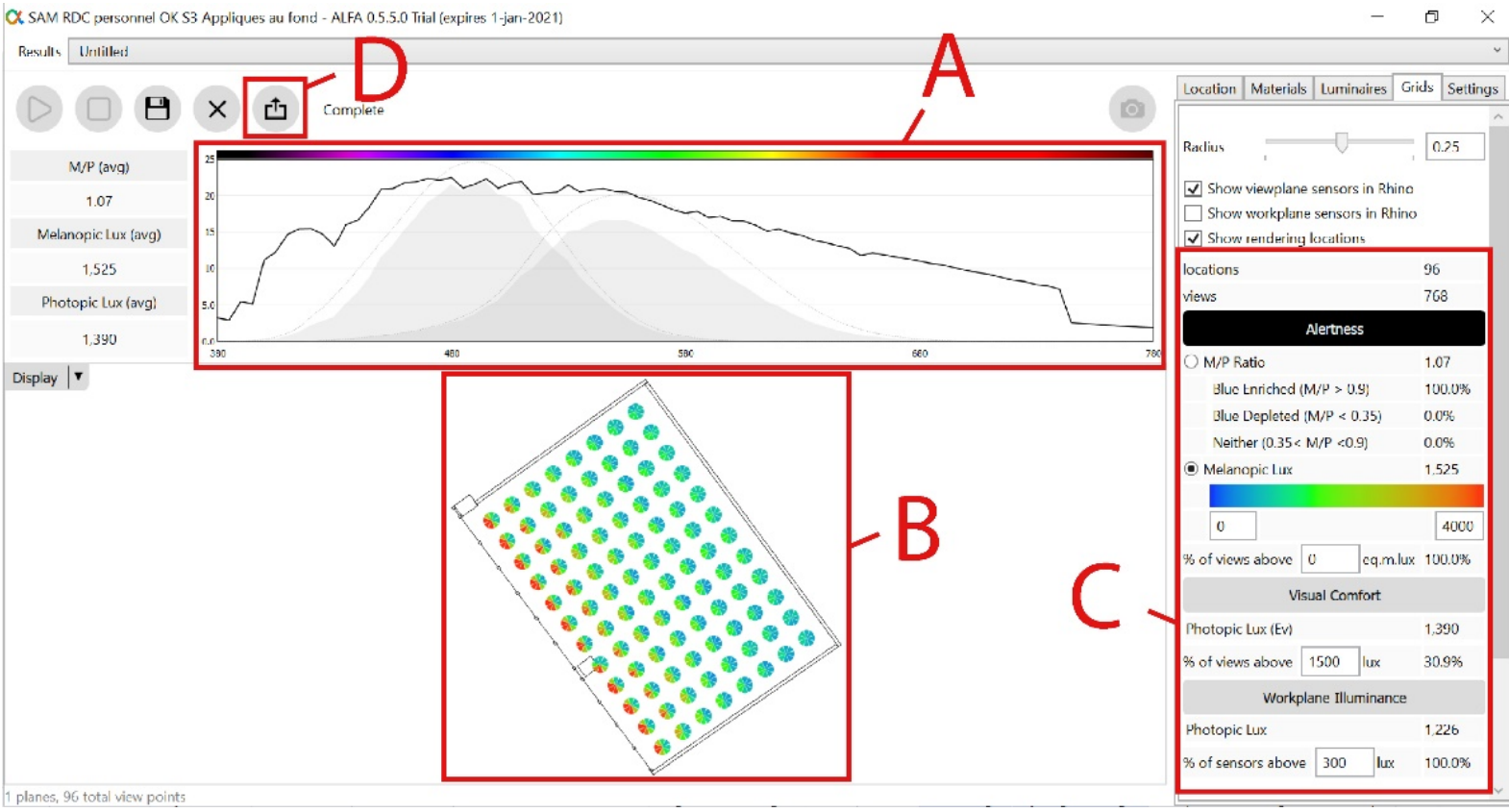

Figure 10. Display of results proposed by ALFA.

The Alertness category data is directly linked to the efficiency of the lighting conditions to entrain the circadian systems and features information related to the Melanopic Lux and the M/P Ratio. The Melanopic Lux (Figure 12) is directly provided by ALFA, which operates the conversion from Photopic lux. 


\begin{tabular}{ll} 
M/P Ratio & 1.07 \\
Blue Enriched $(\mathrm{M} / \mathrm{P}>0.9)$ & $100.0 \%$ \\
Blue Depleted $(\mathrm{M} / \mathrm{P}<0.35)$ & $0.0 \%$ \\
Neither $(0.35<\mathrm{M} / \mathrm{P}<0.9)$ & $0.0 \%$ \\
\hline Melanopic Lux & 1,486 \\
\hline 0 & 4000 \\
\hline
\end{tabular}

Figure 11. Melanopic Illuminance caption, ALFA.

The M/P Ratio, that is the ratio of melanopic illuminance to photopic illuminance, expresses the circadian efficacy of a given lighting condition. For two sources emitting the same visual brightness, the source with the greater M/P Ratio delivers a greater circadian stimulation (Konis, 2018). ALFA proposes two thresholds -0.35 and $0.9-$ under, above, or between which, the lighting condition can be respectively considered blue-depleted, blueenriched, or neither.

\begin{tabular}{|ll|}
\hline \multicolumn{2}{|c|}{ Alertness } \\
\hline M/P Ratio & 1.07 \\
Blue Enriched (M/P > 0.9) & $100.0 \%$ \\
Blue Depleted (M/P < 0.35) & $0.0 \%$ \\
Neither $(0.35<\mathrm{M} / \mathrm{P}<0.9)$ & $0.0 \%$ \\
Melanopic Lux & 1,486 \\
\% of views above 0 & $100.0 \%$
\end{tabular}

Figure 12. M/P Ratio caption, ALFA.

The Visual Comfort category displays the Photopic Lux (Ev) measured vertically at a chosen height, by default $1200 \mathrm{~mm}$, and in a certain number of directions (in the example above, a single view direction per viewing position was selected) and view angle, perpendicular to the vertical plane.

\section{Visual Comfort}

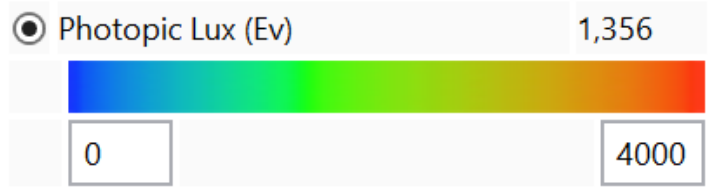

Figure 13. Visual comfort caption, ALFA

The Workplane Illuminance is expressed with the same unit of measure (photopic lux) as the previous category, but it is measured on the horizontal plane. The workplane is by default at a height of $760 \mathrm{~mm}$, but can be adjusted based on specific requirements. 


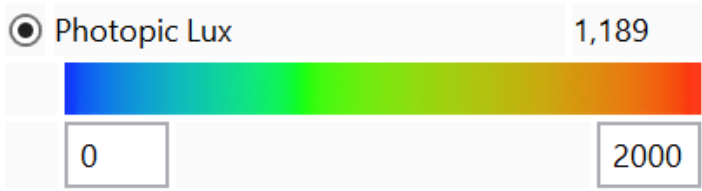

Figure 14. Workplan illuminance caption, ALFA.

In the four different figures (Figure 7 to 10), the numerical figure indicated in the first line is an average value calculated between the exposures received by the three individuals that occupy the room in the example. The caption of the M/P Ratio displays the percentage of pie charts receiving a light source that is categorised, respectively, as blue-depleted, blue-enriched, or neither. All outputs can be easily visualised via a colour chart (colours can be manually modified). The percentage of pie charts exceeding a certain entered value is also provided.

Although the visualisation only shows the average values for the room, all data are recorded on a .csv file available from the simulation. The file displays the information separately for each position and view direction (Figure 16).

\begin{tabular}{|c|c|c|c|c|c|c|c|c|c|c|c|}
\hline \multicolumn{12}{|c|}{ WORKPLANE SENSORS } \\
\hline $\mathrm{ptX}$ & ptY & ptz & $\operatorname{dir} X$ & $\operatorname{dirY}$ & $\operatorname{dir} Z$ & EML & Lux & $M / P$ & 380 & 385 & 390 \\
\hline-1.381439 & -0.9593401 & 1.07 & 0 & 0 & 1 & 4152.583 & 4711.88 & 0.8813006 & 0.00287776 & 0.0028827 & 0.00582642 \\
\hline-7.640189 & 6.680847 & 1.07 & 0 & 0 & 1 & 2497.738 & 2713.267 & 0.9205645 & 0.00273352 & 0.00257128 & 0.00492282 \\
\hline & & & & & & & & & & & \\
\hline \multicolumn{12}{|l|}{ VIEW SENSORS } \\
\hline $\mathrm{ptX}$ & ptY & ptZ & $\operatorname{dir} X$ & $\operatorname{dir} Y$ & $\operatorname{dir} Z$ & EML & Lux & $M / P$ & 380 & 385 & 390 \\
\hline-1.381439 & -0.9593401 & 1.07 & 0.8007314 & 0.5990236 & 0 & 2302.796 & 2718.055 & 0.847222 & 0.00049154 & 0.00063787 & 0.00152525 \\
\hline-7.640189 & 6.680847 & 1.07 & -0.6819984 & -0.7313537 & 0 & 3818.139 & 3822.427 & 0.9988783 & 0.0072122 & 0.00653922 & 0.01211633 \\
\hline
\end{tabular}

Figure 15. *.csv file regrouping the simulation results, ALFA

The data provides, for both the workplane and viewplane sensors, and for each location and direction, the relative spectral power value for every $5 \mathrm{~nm}$ wavelength, ranging from 380 to $780 \mathrm{~nm}$, the photopic lux and equivalent melanopic lux, and the M/P Ratio. The relative spectral power data can be introduced in the converters described in the previous sections (i.e., Lucas toolbox and Circadian Stimulus Calculator) to, respectively, verify the photopic lux conversion in EML the Circadian Stimulus of the lighting sources.

Lark

Lark spectral lighting is a plugin for the visual programming environment Grasshopper for Rhinoceros 3D (Inanici \& ZGF Architects, 2021). It was developed by Inanici and ZGF Architects to allow architects, lighting designers and researchers to calculate circadian light metrics in a workflow that takes into consideration the spectral properties of daylight and materials. An innovation of the tool is that it divides the visible light spectrum into nine color channels, in contrast to the conventional light simulation tools that use only three-color channels (RGB). This increased spectral resolution allows for more accurate simulations of circadian metrics, although Lark can also perform the standard RGB simulations that are faster. Lark is a free simulation tool, available to anyone that has access to Rhinoceros. Its code is open-source, which means that anyone with knowledge of python can inspect it and make modifications to it. More information on the methods that Lark uses can be found in a publication by Inanici et al. (2015)

The use of the tool requires basic knowledge of Grasshopper. The user of Lark needs to define opaque and transparent materials, generate a sky, run the simulation, and interpret the results. The materials are defined by their measured spectral reflectance or transmittance. The sky is generated based on inputs of spectral power distribution, location, time, sky type (sunny, intermediate or overcast) and exterior global horizontal illuminance (or direct and diffuse irradiance) which can be measured or simulated. Next, the Honeybee plugin for Grasshopper (www.ladybug.tools) is used to run either an image-based radiance or a grid-based irradiance simulation. Finally, the radiance or irradiance results are weighted with sensitivity curves from Lucas (EML) or Rea (CS) to calculate "circadian" radiance or irradiance (Figure 17). 


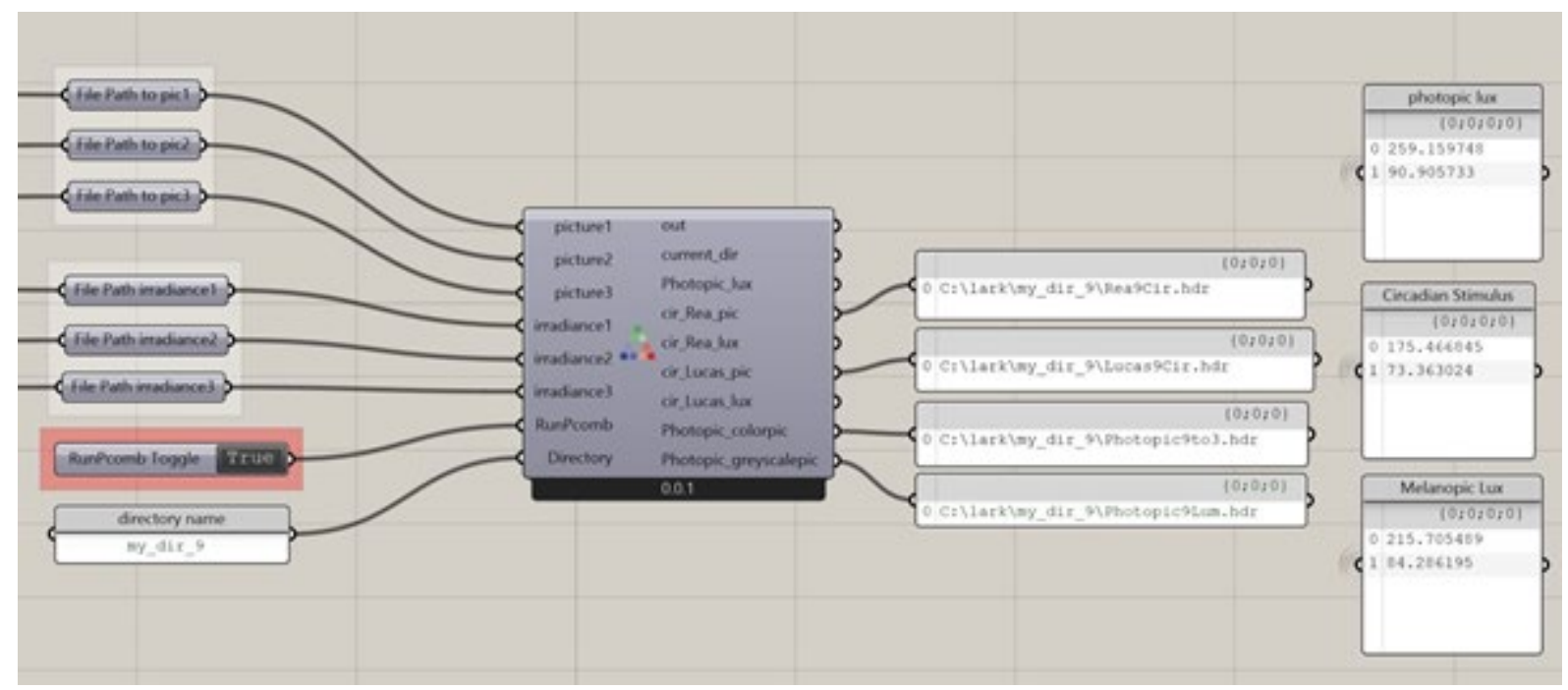

Figure 16. Nine-channel simulation with Lark spectral lighting for calculating radiance or irradiance weighted by the sensitivity curves of Rea or Lucas.

In case measured data are lacking, a useful database of realistic spectral opaque materials is spectraldb.com (Jakubiec, 2016). For transparent materials, spectral data can be extracted using the Optics software of Berkeley Laboratory (Berkley Lab, 2019). If measurements are lacking for the SPD of the sky, standard CIE illuminants can be used.

Lark in its current version (0.0.1) is able to perform daylight simulations, but since it is open-source and implemented in a flexible parametric workflow, it could be possible to modify it for electric lighting simulations. This would require an experienced user in Grasshopper, Lark, Honeybee and Python.

\subsubsection{Extra tools}

\subsubsection{Wearable lighting logging devices for individual light intake}

Wearable light logging devices (also called light dosimeters) are portable sensors that can track personal light exposure. They are often used in field studies that aim to connect the daily light dose received by a person with some physiological or psychological response (e.g. alertness, sleep quality). During the day, a person is exposed to a variety of light conditions, daylight and electric, that cannot be adequately measured by static light measurements in indoor spaces. Wearable light loggers allow for dynamic measurements over a period of time, connected with a specific person. Often, the use of wearable light loggers is combined with the use of questionnaires, activity trackers and sleep diaries. Several wearables are now available commercially, but there is a large variety in what light metrics they can measure, where on the body they are worn, accuracy and cost.

The most common output metric of wearable light loggers is illuminance. Some of the devices available on the market provide CCT and three distinct colour channels (red, green and blue or RGB), but a very limited number of commercial devices gives an SPD as an output. Although illuminance is a useful output, it is now not considered to be the appropriate metric for physiological responses to light and it cannot be directly converted to EML, CS or melEDI. We should note that RGB data are not equivalent to spectral data. In order to calculate circadian metrics, measurements of the full visible spectrum are needed (e.g. every $5 \mathrm{~nm}$ ). Wearable devices that provide spectral data with a high resolution have started to become available, although still at a high cost.

The location of the device on the body is important. Ideally, they should be located as close to the eye as possible with the sensor at a vertical position, since it is the eye that mediates the response of humans to light. However, several devices are wrist-worn. One study found that large deviations exist between wearing a device on the wrist and vertically at eye-level (Aarts et al., 2017). The study suggests that from an accuracy point of view, the best location for a wearable would be on the temple next to the eye (e.g. attached on glasses), but the annoyance of the participants needs to be considered. Another study showed that wrist worn devices were the least obstructive for the people wearing them (van Duijnhoven et al., 2017). Therefore, deciding what location on the body is more suitable depends on the priorities of the use, in terms of whether reliable data are needed or a more qualitative evaluation. 
Calibration of the wearable devices against a trusted cosine-corrected sensor might be necessary before using them in the field. In case of using multiple wearable devices, it is advisable to calibrate all of them, since large differences can be observed among devices of even the same brand. This was demonstrated by a study that tested 48 devices of the same manufacturer and found differences of up to $60 \%$ among them (Markvart et al., 2015). The calibration also needs to be light source specific, because the SPD plays a role. For testing the accuracy of photometers ISO and CIE defined 12 quality indices (ISO/CIE, 2014). However, studies that tested wearable dosimeters with some of these indices found that they are not always performing well (Aarts et al., 2017; Figueiro et al., 2012). For testing the quality of wearable sensors, the reader is referred to the ISO/CIE document, while here we mention a few of the important indices: the general $V(\lambda)$ mismatch index $f_{1}{ }^{\prime}$, the directional response index $f_{2}$, the linearity index $f_{3}$ and the temperature index $f_{6, T}$. The $f_{1}$ ' measures the spectral match between the sensor and the photopic luminous efficiency curve $V(\lambda)$. The $f_{2}$ index is the cosine match of the sensor, which describes the influence of angle of incidence. The $f_{3}$ index tests if the output of a sensor increases linearly with the increase of the light source output. The $f_{6, T}$ refers to the influence of ambient temperature on the performance of the sensor.

Practical issues also need to be considered, such as the capacity of the device in terms of data logging, data extraction and the duration of the battery. The ability to log and download a time series of light measurements should be provided, which sometimes comes at an additional cost. Data might need to be downloaded with wired or wireless connection, using a phone app or a computer software. It is useful to test in advance how the data is extracted to avoid data loss afterwards. The sampling rate of the device affects the number of data points that can be stored on it, therefore it is necessary to select it based on the specific needs of the application. In addition, before using a device it is beneficial to know how often it needs to be charged and for long-term measurements instruct the participants to charge them.

Providing clear instructions to the participants is vital. Before starting data collection, it needs to be understood by the users when and where to wear the device and to which direction it should face. The users need to know what to do with the devices when going outdoors or during sleep. For example, devices that are placed on the wrist or on clothes might be covered when a user is putting on a coat, and therefore extra care is needed. A suggestion would be to combine the use of wearable light sensors with journals or log books, where participants can indicate the activities they are performing, and whether they wear the device or not. Generally, the quality of the measured data depends on the quality of the sensor, but also on the way the participant uses it.

\subsubsection{Considering ageing}

The following tool applies the both the visual and non-visual aspects considered for this monitoring framework.

The International Commission on Illumination (CIE) published a position statement in 2018 based on existing literature studies focusing on ipRGCs-influenced responses to light (CIE, 2019). One of the points that the CIE addressed in their position statement is focused on the age-related changes in the human lens that modify the transmission of light within the ocular system. To this aim, the CIE proposed a correction factor that must be applied to the light spectrum to account for the different sensitivities of observers of various ages.

The correction factor to apply to the luminous stimulus is provided across the various wavelengths of the visible spectrum, from 380 to $780 \mathrm{~nm}$. Each curve corresponds to a different age, ranging from 1 to 90 years old. The value of the correction factor is higher for shorter wavelengths and is expressed relative to a 32-year old individual, for which the curve remains flat and the index of correction is consistently 1 . For example, the correction factor to apply to melanopic quantities having a wavelength of $480 \mathrm{~nm}$, for a CIE standard illuminant D65 is 1.052 for a 25 -year- old person, 1 for a 32-year old, 0.835 for a 50 -year old and 0.457 for a 90 -year old individual. The age of 32 years old was chosen since the conventional photopic sensitivity function $\mathrm{V}($ lambda) conventionally utilised in the scientific lighting literature is normalised against an individual of this age .

The decrease of light transmission with age implies that the current thresholds proposed to guarantee a response to visual and non-visual needs must be modified based on the age of the observer. A tool created by the LIPID team at the EPFL of Lausanne, SpeKtro (EPFL-LIPID, 2015) provides, among other features, an interactive dashboard for exploring non-visual responses to light, with the possibility to set the age of the observer between 0 and 100 years old. The tool allows to choose a specific light source, or import relative spectral power distribution values, and set the desired effect of the light stimulus on circadian entrainment from 0 to $100 \%$. For example, as illustrated in Figure 4, to achieve a $68 \%$ effect on circadian stimulation, producing an approximated $2 \mathrm{~h}$ phase shift, 247 equivalent melanopic lux from a CIE F11 light source are necessary. 

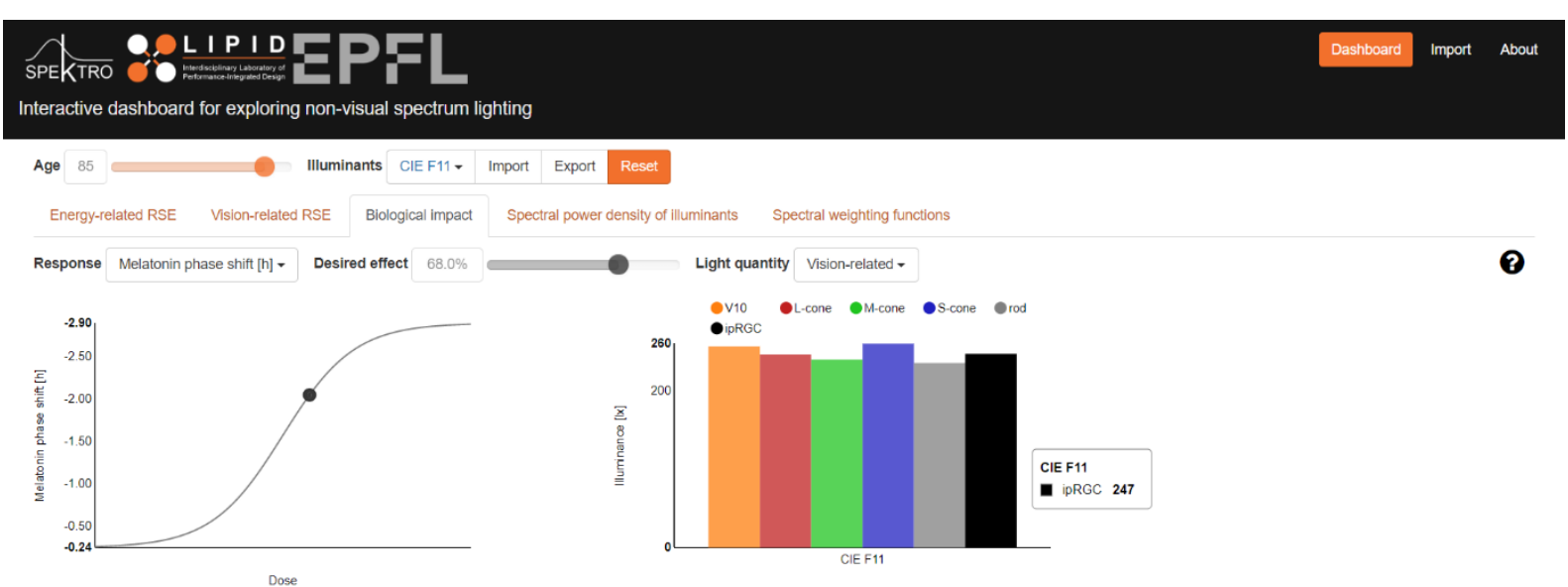

Figure 17. Dose response curve for an 85 years old individual, with a CIE F11 light source and a $68 \%$ desired effect on circadian resetting (EPFL-LIPID, 2015).

\subsection{User}

The evaluation of daylighting and lighting integrated projects based only on technical instruments would be difficult and resource consuming. Technical Environmental Assessments (TEAs) may be also difficult to be interpreted, especially in real occupied buildings, where it is difficult to control the environmental conditions. Finally, while it is recommendable to set-up a long-term continuous monitoring to understand a dynamic light source as daylight, this is impossible to put into practice for most of real occupied buildings. In this perspective, observer-based environmental assessment (OBEA) provides an excellent completion to TEAs, forming a complete post-occupancy evaluation (POE). OBEAs can enrich the understanding of space and user's opinion and behaviour, especially when few point-in-times TEAs are available.

This chapter guides the investigators through the design, application, and analysis of OBEAs for their specific daylighting and lighting integrated project in the context of POE. In this IEA SHC Task 61 project, the main role of the OBEA - combined with the technical assessments TEAs - is to verify that the project achieved its design goals considering both objective measurements and user's opinion.

Some examples are provided; they have been used in some of the IEA SHC Task 61 Case studies and they can also be used in other projects. However, the here presented examples should be seen only as some of the available tools.

\subsubsection{Design of the user monitoring}

\subsubsection{Goal(s) of the monitoring and relevant users}

The first step should be to verify that specific goal(s) of the daylighting and lighting integrated project are met. The assessment is done for relevant users of the space (or building).

Therefore, the design must start by identifying the goal(s) of the monitoring. Abundant time and reflections should be allocated for this phase. The identification of the goal(s) is central for both determining the relevant users and choosing type of surveys.

There might be more than one general goal for an integrated project and, therefore, for the monitoring. For example, the goal(s) a project aims at providing both a comfortable visual environment and circadian entrainment. One general goal of the project might be breaking down to smaller and more specific goals for the monitoring. For example, the monitoring of a project that aims at providing a comfortable visual environment might check uniformity, glare, degree of control over light, etc. The monitoring of a project using a new type of lighting or shading control might address goals like acceptance of the technology, user behaviour towards the control, etc. 
Once the goals are clearly identified, it will be relatively straightforward to select the relevant users of the space are. Those are usually:

1. the actual users of the space, and/or

2. the building manager or a responsible person.

More in general, the relevant users are those that are more affected by the monitored environment or those that are well acquainted with it. Examples are full time employees for an office, or a selection of them, or patients and nurses in health care. However, it is always the goal(s) of the monitoring that supports the selection. For example, the case study IKEA Kaarst in IEA SHC Task 61 aimed at both improving the shopping experience via daylighting and triggering circadian response via an integrative lighting system. In this case, customers and store manager were identified as relevant users for a shopping experience POE, while employees, all of whom spend many hours in the shop - were selected as relevant users for the POE about the integrative lighting system.

\subsubsection{When and how to survey the users}

In the context of this IEA SHC Task, OBEAs are seen as a complement to TEAs in a general POE. As general rule, the OBEA should capture information that cannot be measured via TEAs. When and how to survey the users depend on the goals of the monitoring. The following steps are to identify the suitable survey method (questionnaires, interviews, ...) and the actual survey instrument (like a specific set of questions), which is always the very last step.

\subsubsection{Long-term and point-in-time}

Both TEAs and OBEAs may assess the situation in a specific moment and condition (right here and right now), or for a more general long-term condition, e.g. throughout the year.

It is often the case that TEAs for (day)lighting can be performed only at selected points in time. In such circumstances, the POE becomes central as it bears most of the information. Extra care should be used when defining goals of the monitoring and when selecting the survey instrument. If the POE consist of questionnaires, the investigators should strive to obtain as many respondents as possible. It is a good habit to repeat the POE in different seasons/conditions (longitudinal approach) as users may have different perception of the integrated projects at different time of the year, even when the questions are posed in a long-term "fashion".

In other cases, the goal of the monitoring could be to test a specific lighting condition. Ordinary photometric measurements may not capture the user experience of lighting and point-in-time surveys can be useful. Semantic differential scales (cold-warm, diffuse-focused, etc.) or likert scales (strongly agree - strongly disagree, etc.) are often used in this case. This type of surveys should be designed in coordination with the TEAs so that the specific lighting condition can be measured both with TEAs and with the survey. Point-in-time surveys can be seen as any ordinary measuring instrument; however, while there is a well-established metrology for technical measurements, like the International System of Units (SI), the measuring system for point-in-time POEs is still young and an agreed list of units and metrics is not yet existing, and several instruments are available in literature.

Point-in-time surveys can also be used to describe behavioural intention or actual behaviours. The lighting diary described in this chapter is an example of point-in-time survey describe self-reported behaviour.

\subsubsection{Survey types}

Surveys can have a quantitative or qualitative research design. Quantitative research is generally considered more objective, but the robustness of findings depends on how the survey has been designed and submitted. Qualitative research requires more experienced investigators, as the collection and interpretation of results can be difficult, time-consuming, and partially subjective. When designing simple POEs for daylighting and lighting projects in real occupied building, the investigator may consider the general recommendations in Table 10. 
Table 10. Some of the pros and cons of quantitative and qualitative research design.

\begin{tabular}{|l|l|}
\hline Quantitative design is better... & Qualitative design is better... \\
\hline $\begin{array}{l}\text { if the goal of the monitoring is well-defined and very specific } \\
\text { for bigger sample size - at least } 15 \text { to } 20 \text { individuals }\end{array}$ & $\begin{array}{l}\text { if the goals of the monitoring are broader } \\
\text { for smaller sample size } \\
\text { if the surveyed individuals share similar background/roles/use } \\
\text { if the surveyed individuals represent a group } \\
\text { of other individuals or have an overall grasp } \\
\text { on the space, like building managers. }\end{array}$ \\
$\begin{array}{l}\text { if TEAs predicting the expected outcome are planned (e.g. } \\
\text { luminance ratios in the field of view are measured and } \\
\text { quantitative closed-end questions on glare perception are } \\
\text { used) } \\
\text { if only few confounding factors are expected for the case study } \\
\text { or if confounding factors can be isolated (controlling the } \\
\text { environment or with appropriate survey) }\end{array}$ & $\begin{array}{l}\text { to the in thestigator has lower control on } \\
\text { possible confounding factors or if these } \\
\text { cannot be isolated }\end{array}$ \\
\hline
\end{tabular}

Generally, quantitative design includes questionnaires with closed-ended questions. Qualitative design relies mainly on interviews, focus groups, or the like; the questions are open-ended. The investigators are recommended to provide space for open reflections even when designing quantitative research with closed-ended questions. This is particularly important in real occupied buildings, where the environment cannot be controlled; open comments can warn for confounding factors or provide additional insights.

When designing a qualitative study for a case study building, the investigators may consider the following:

- use informal unstructured interviews if the goals of the monitoring are very loose and there are not specific thematic areas that should be investigated;

- use semi-structured interviews if the goals of the monitoring are broad, but there are defined thematic areas that needs to be investigated;

- $\quad$ use individual interviews if there are few subjects, indicatively up to ten;

- opt for focus groups if there are more subjects.

In any case, all the recommendations above should be seen as general advices. The investigators are always invited to explore the wide available literature on the topic.

\subsubsection{Data analysis}

The data analysis depends on the type of survey. For quantitative surveys, some statistical analysis can be performed. Frequencies and descriptive statistics can be generally performed on the data. These types of analysis can be conducted even with ordinary office software, like Microsoft Excel. The interpretation of the results is left to the investigators. Because of the intrinsic nature of surveys, it is usually not possible to provide benchmarks.

For qualitative data, the process is more complex. Literature provides instruments to support unbiased and replicable results, but a degree of subjectivity should always be accounted for. In case of informal interviews, the investigators may consider analyzing the content and define thematic areas; this process can be quite long when aiming for robust analysis. In some cases, the themes can be quite self-evident; in such cases, a "streamlined" analysis process is generally acceptable for the monitoring of real buildings. In case of semi-structured interviews, the analysis is easier since the thematic areas used for the interviews template can be used also as analysis matrix for organizing the findings. In some case is possible to generate quantitative information from qualitative results (e.g. analyzing the recurrence of some key-words during an interview), but this type of analysis requires expertise.

\subsubsection{Example of surveys}

This section provides four examples of instruments: the first is a generic questionnaire for office spaces, suitable for long-term with quite generic goals for the monitoring. The following two are point-in-time bipolar semantic differential scales assessing the light experience via perceived qualities; they are best used in retrofit projects, or, more in general, when there are two situations to compare. The fourth one is a self-reported diary which can be used to monitor the behaviour at individual level and for short period of times, as complement or in substitution of occupancy and environmental sensors. 


\subsubsection{Questionnaire on integrated daylighting and lighting projects}

The questionnaire here presented was developed by the experts in IEA SHC Task 61 Subtask D and used in selected case studies. The questionnaire can be used to retrieve general information about the appreciation of the integrated project. It is suitable for surveying employees in office spaces, preferably if the survey sample is large. However, space for open comments is provided; open comments are particularly useful when the survey sample is small. It is a long-term POEs. If possible, it is suggested to submit the survey at least two times in a year, at each solstice; a further submission during equinoxes is also welcome. The questionnaire works best if submitted to many individuals, at least 15-20, and if the sample of individuals is homogenous (background, professional roles, working space, but even age and gender). Heterogenous groups may require more individuals to provide robust results. The data analysis may consist of frequency and descriptive statistics.

The questionnaire is based on existing surveys, but it is not validated. The questionnaire consists of five sections and it is modular; it is suggested that sections 1-3 are always included. Questions 43-45 are used only when integrative lighting is provided. Sections $4-5$ are used in case of surveying the acceptance of new (day)lighting technologies or in case of retrofit projects.

1. Background data

2. Social and physical environment

3. User experience of lighting

4. User acceptance of (new) technologies

5. Retrofit

\section{Sources}

\section{Background data}

The questions on personal background data were picked from different questionnaires used by the Environmental Psychology group in Lund. They were originally in Swedish and then translated in English.

The questions on sitting position, type of space, etc. are from "Post occupancy evaluation of daylight in buildings" of IEA Task 21 (Hygge \& Löfberg, 1999).

\section{Social and physical environment}

Questions 13-20 are taken from the Copenhagen Psychosocial Questionnaire (Kristensen et al., 2005; Pejtersen et al., 2009), which is widely used in companies. The whole questionnaire assess psychosocial working conditions, health and well-being, but we kept only four questions. Questions 13-16 relate to "sensorial demands" and they may mediate the user experience of light. Questions 17-18 relate to the "vitality" and they may link to circadian rhythms.

The occupants' appraisal of different aspects of the room (questions 21-31) are from the IEA SHC Task 50 monitoring protocol (Dubois et al., 2016; Gentile et al., 2016). Questions 21-22,27,30 are used as 'control' for more specific answers on Section 3.

At the end of section 2, for the first time in the document, the surveyed person can express an open opinion. There are more of these boxes later in the document, since they provided quite valuable information in Task 50.

\section{User experience of lighting}

The user experience of light is the central part of the survey. The user experience of light section is based mainly on two sources:

1. §3.1, the "Post occupancy evaluation of daylight in buildings" of IEA Task 21 (Hygge \& Löfberg, 1999);

2. $\S 3.2$ and $\S 3.3$, the "right-now" survey by (Altomonte et al., 2017), which has been adapted to fit the cross-sectional nature of this questionnaire.

Please note that, differently from the original surveys, the word "electric lighting" replaces "artificial lighting" and the word "daylighting" replaces "natural lighting". Based on the investigated case study, not relevant questions may be simply removed.

\section{User acceptance of (new) technologies}

Section 4 is thought for case studies focusing on a new technology/control. An example could be a new control system based on remote control, or a system linked to a light dosimeter. The questionnaire is based on the well spread Unified Theory of Acceptance and Use of Technology updated version (UTUAT2) (Venkatesh et al., 2003; 
Venkatesh et al., 2012). Only few items are selected from the original scale. The scope is not to assess the behavioural intention as described by the UTUAT2, rather to have a general understanding of what could or could not affect the behavioural intention.

When using the questionnaire, please replace the word "control device" with the name of the device you are going to use (e.g. "remote control for shading").

\section{Retrofit}

Section 5 is based on kind contribution of Peter Fuhrmann, Signify. It includes few questions evaluating daylelectric lighting retrofits. Therefore, it should be included only in case studies consisting in actual retrofits.

The questionnaire

The questionnaire is provided in Annex C.1 IEA SHC Task 61 Questionnaire.

\subsubsection{Experiencing light - semantic differential scales}

Here two semantic differential scales consisting of pair of opposite adjectives are proposed. Both scales should be used as point-in-time survey and always in combination with TEAs. The first scale, called room appraisal questionnaire, has been developed at Bartenbach and used in the case study of Bartenbach headquarter in Aldrans, Austria. The second scale is called PILQ (Perceived Indoor Lighting Quality) has been developed at Lund University. The first version of the PILQ dates back 1993, when Rikard Küller developed a first semantic scale. The scale has been modified during the years until reaching the current form with sixteen items; it has been used in many field and laboratory studies (Gentile et al., 2018; Kuller \& Laike, 1998). Factor analysis revealed two strong factors, one dealing with the general perception of lighting quality (Perceived Comfort Quality, PCQ) and one representing the perceived strength of lighting (Perceived Strength Quality, PSQ). The scale has also been used for outdoor lighting, revealing similar factors (Johansson et al., 2014).

It should be noted that the two scales have been developed in German and Swedish respectively and reported in English in this report. Being semantic scales, it is important that the scale are translated in the mother tongue. Even in this case, the questionnaire works best if submitted to many individuals, at least 15-20, and if the sample of individuals is homogenous (background, professional roles, working space, but even age and gender). Heterogenous groups may require more individuals to provide robust results.

The data analysis may consist of frequency and descriptive statistics. For the PILQ scale, the items can be grouped in the known factors PCQ and PSQ.

The semantic differential scale used at Bartenbach

The semantic differential scale developed by Bartenbach can be used to obtain a rating of the room atmosphere as experienced by the user. It helps to analyse the influence of the integrated lighting system on the overall room appearance and the resulting user perception of the room. The scale is provided in Annex C.2 User rating of the room atmosphere.

For a basic evaluation the answers are divided into two groups by joining the responses very/quite/rather on both sides to obtain a binary assessment.

\section{PILQ - Perceived Indoor Lighting Quality}

The PILQ is a semantic differential scale developed at Lund University during the early ' 90 s. The scale has been used in several research studies and case studies monitoring. The scale has been validated for outdoor lighting and it is currently being validated for indoor lighting. The scale is provided in Annex C.3 PILQ.

\subsubsection{The lighting diary - an instrument to capture behaviour}

Investigators are often interested in capturing the behaviour of users in respect to a lighting system. This section illustrates the lighting diary, an instrument to record the self-reported use of office lighting. A rationale and a validation for the instrument is provided in Maleetipwan-Mattsson et al. (2013). The diary is easy to understand and use, but it should be used only for short period of times, since it can generate burden to participants, resulting in high risk for drop-out. The reliability of the data on self-reported behaviour decreases over time. The lighting diary is provided in Annex C.4 The lighting diary. 
Table 11. Pros and cons of using the self-reported lighting diary.

\begin{tabular}{|c|c|}
\hline Pros & Cons \\
\hline $\begin{array}{l}\text { 1. It captures all kind of behavior - does not } \\
\text { rely on poorly formulated questions. } \\
\text { 2. The subject does not need to think to the } \\
\text { behavior as "energy"-related. } \\
\text { 3. The participants do not need to reflect when } \\
\text { marking their behavior }\end{array}$ & $\begin{array}{l}\text { 1. Burden for participants - risk of drop-out } \\
\text { 2. Subjectivity - people document what they } \\
\text { think is relevant. } \\
\text { 3. Time-consuming for the researcher - } \\
\text { preparation, instructions, coding }\end{array}$ \\
\hline
\end{tabular}

The diary method has its root in the time-geographical research from the $60 \mathrm{~s}$. The aim was to better understand temporal and spatial processes, including people's activities (Ellegård \& Svedin, 2012). Over the year the method have been used in a multitude of different settings such as transportation and energy-related behavior (Palm \& Ellegård, 2011). The advantages of the method are that it includes all kinds of behaviours and do not need to rely on questionnaires. Furthermore, the participants don't need to reflect when marking their behavior. The drawbacks are that the method is a large burden for the participant and it is also quite time-consuming for the researcher regarding preparations, instructions and coding. However, it seems that the advantages are important and that it is a cheap and easy way to get information about behavior.

Concerning the use of lighting and daylight a diary was developed by Maleetipwan-Mattsson et al. (2013). This method was investigated regarding its reliability and validity. The aim of the method was to be able to examine relationships between occupant-behaviors, occupancy, and light on time. The results showed that there was a quite good correlation between the self-reported and logged data, $r=.65$ for activities regulating ceiling luminaires; $r=.66$ for occupancy vs. vacancy. This method has been used in the present study.

The participants were asked to report both movements and activities, Movements included: (i) coming into the room, (ii) sitting in the room, (iii) leaving the room but staying in the building, and (iv) going outside the building.

Activities that should be recorded were:

- $\quad$ regulation of a ceiling luminaire: (i) switch on, (ii) switch off, and (iii) do nothing (additionally, if relevant: (iv) increase and (v) lowering of lighting level with manual dimmers);

- $\quad$ regulation of a desk lamp: (i) switch on, (ii) switch off, and (iii) do nothing;

- $\quad$ adjustment of window blinds and/or curtains to block daylight from the office's windows: (i) $100 \%$ blocked, (ii) $75 \%$ percent blocked, (iii) $50 \%$ percent blocked and $0 \%$ percent blocked.

- Each time a new movement or activity was performed, a new row on the diary was used, starting with the registration of time. The time required for the data collection was 1 day at two different occasions.

\subsubsection{Example of guide for semi-structured interviews}

The example here proposed is a generic template for semi-structured interviews (Table 11). It can be customized based on themes and goals for the monitoring. Examples questions should be proposed as a guidance. The questions should be preferably open, not very direct, and allowing for articulate answers (avoid yes/no answers, if possible). The example questions can be used to prompt the discussion, but it can be that they are covered autonomously by the interviewed person.

It is suggested that interviews are recorded and transcribed. The verbatim can be analysed by using a thematic coding approach. The coding can use the themes and goals in the template.

Table 12. Example of guiding template for semi-structured interviews.

\begin{tabular}{|c|c|c|c|}
\hline THEME & $\begin{array}{c}\text { GENERAL } \\
\text { GOAL }\end{array}$ & SPECIFIC GOALS & EXAMPLE OF QUESTIONS \\
\hline $\begin{array}{l}\text { Patterns } \\
\text { of use }\end{array}$ & $\begin{array}{l}\text { Understanding } \\
\text { determinants } \\
\text { of users' } \\
\text { behaviour }\end{array}$ & $\begin{array}{l}\text { - Check the usage of the } \\
\text { room during the week. } \\
\text { Identify the tasks } \\
\text { performed. } \\
\text { - Understand the usual } \\
\text { sitting positions }\end{array}$ & $\begin{array}{l}\text { - How often have you been in the office during the past } \\
\text { two weeks? Have you had many meetings, lectures, } \\
\text { travels, ...? } \\
\text { Did it was a "normal" week? } \\
\text { o Did you work with the laptop for writing, } \\
\text { simulate, ...? } \\
\text { o Have you read papers or reviewed } \\
\quad \text { articles? }\end{array}$ \\
\hline
\end{tabular}




\begin{tabular}{|c|c|c|c|}
\hline THEME & $\begin{array}{c}\text { GENERAL } \\
\text { GOAL }\end{array}$ & SPECIFIC GOALS & EXAMPLE OF QUESTIONS \\
\hline $\begin{array}{l}\text { Light } \\
\text { Environ } \\
\text { ment }\end{array}$ & $\begin{array}{l}\text { Characterizati } \\
\text { on of the } \\
\text { general } \\
\text { lighting } \\
\text { experience }\end{array}$ & $\begin{array}{l}\text { - General level of } \\
\text { satisfaction with the light } \\
\text { environment } \\
\text { - Understand how much } \\
\text { the environmental light } \\
\text { influences the quality of } \\
\text { task lighting. } \\
\text { - Identify possible glaring } \\
\text { situations. } \\
\text { Use of the screens' }\end{array}$ & $\begin{array}{l}\text { - How would you describe the light in your room? } \\
\text { o Do you think you room was too dark? } \\
\quad \text { Too bright? } \\
\text { Do you think that the light was too direct } \\
\text { on the working space? Too diffuse? Did } \\
\text { you find it sharp? ... }\end{array}$ \\
\hline $\begin{array}{l}\text { Control } \\
\text { System }\end{array}$ & $\begin{array}{l}\text { Characterizati } \\
\text { on of the } \\
\text { appreciation of } \\
\text { the control } \\
\text { system }\end{array}$ & $\begin{array}{l}\text { - LCS capability in } \\
\text { matching the light } \\
\text { requirements. } \\
\text { - User-friendliness of the } \\
\text { LCS } \\
\text { - Users' preferences in } \\
\text { automatic/manual } \\
\text { controls }\end{array}$ & $\begin{array}{l}\text { - What is your opinion about the system? } \\
\text { o } \begin{array}{c}\text { Do you think that the system worked } \\
\text { properly? }\end{array} \\
\text { o } \quad \text { Did you find the system easy to use? } \\
\text { o Would you like to have more "control" on } \\
\text { the system? E.g., decide when turn } \\
\text { on/off, decide the dimming level, ... } \\
\text { o Starting from this kind of system, do you } \\
\text { think there are improvable aspects? } \\
\text { E.g., deactivate the absence sensor, } \\
\text { change the type of manual switch, ... }\end{array}$ \\
\hline $\begin{array}{c}\text { Eye } \\
\text { Sympto } \\
\text { ms }\end{array}$ & $\begin{array}{c}\text { Check } \\
\text { contingents } \\
\text { eye symptoms } \\
\text { due to } \\
\text { over/under-lit } \\
\text { environment, } \\
\text { flickering, ... }\end{array}$ & $\begin{array}{l}\text { - Confirm relation } \\
\text { between flickering and } \\
\text { eye symptoms. } \\
\text { - Check issues related to } \\
\text { low lighted environment } \\
\text { (task lamp) }\end{array}$ & $\begin{array}{c}\text { - Did you have any health problems during the use of this } \\
\text { lighting control system? } \\
\text { o Headache } \\
\quad \begin{array}{ll}\quad \text { If yes, do you think that this } \\
\text { problem is related to the }\end{array} \\
\text { lighting situation? } \\
\text { o } \quad \begin{array}{l}\text { Eye symptoms (pain, eye itching, } \\
\text { photosensitivity, redness, tears, }\end{array} \\
\text { dryness) } \\
\text { o } \quad \begin{array}{l}\text { Other? } \\
\text { How often did they occur? }\end{array}\end{array}$ \\
\hline
\end{tabular}

\subsubsection{Use of personas}

The method of developing personas stems from IT system development during the late 1990s where researchers had begun reflecting on how you could best communicate an understanding of the users. Various concepts emerged, such as user archetypes, user models, lifestyle snapshots, and model users.

In 1999, Alan Cooper published his successful book, The Inmates are Running the Asylum, where he, as the first person ever, described personas as a method we can use to describe fictitious users. There are a vast number of articles and books about personas, however a unified understanding of one single way to apply the method doesn't exist, nor does a definition of what a persona description should contain exactly.

Personas are fictional characters. You create personas based on your research to help you understand your users' needs, experiences, behaviours, and goals. In this context, a persona represents just a user group.

The representation of user behavior will be finalized in form of so-called personas, that is, reliable and realistic representations of the user groups. In general, an effective persona describes a real person with her background, goals, and values. This person represents one of the major user groups, expresses the major needs of the group and gives a clear picture of their expectations; it also shows how the members of the group are likely to use the systems and/or solutions. Personas can be created using various tools, like the lighting diary, interviews, or surveys. More detailed information can be found in Matusiak et al. (2021). Personas have been also used for the monitoring of the Elderly residence "The Stephenson Garden" in Brussels, one of the case studies of IEA SHC Task 61. 


\section{References}

Aarts, M. P. J., van Duijnhoven, J., Aries, M. B. C., \& Rosemann, A. L. P. (2017). Performance of personally worn dosimeters to study non-image forming effects of light: Assessment methods. Building and Environment, 117, 60-72. https://doi.org/https://doi.org/10.1016/j.buildenv.2017.03.002

Aktuna, B., Bueno, B., Darula, S., Deneyer, A., Diakite, A., Fuhrmann, P., Geisler-Moroder, D., Hubschneider, C., Johnsen, K., \& Kostro, A. (2016). Daylighting and electric lighting retrofit solutions. Universitätsverlag der TU Berlin.

Altomonte, S., Saadouni, S., Kent, M. G., \& Schiavon, S. (2017). Satisfaction with indoor environmental quality in BREEAM and non-BREEAM certified office buildings. Architectural Science Review, 60(4), 343-355.

Baumann, T. F., M. Khaintatzi-Masouti, M., \& Osterhaus, W. (2021, 21-24 March 2021). Luminance maps for investigation of lighting in indoor environments from HDR images with the use of a Raspberry $\mathrm{Pi}$ computer. Proc. LICHT 2021, Bamberg.

Berkley Lab. (2019). Windows \& Daylighting. https://windows.lbl.gov/software/optics

Brown, T., Brainard, G., Cajochen, C., Czeisler, C., Hanifin, J., Lockley, S., Lucas, R., Munch, M., O'Hagan, J., Peirson, S., Price, L., Roenneberg, T., Schlangen, L., Skene, D., Spitschan, M., Vetter, C., Zee, P., \& Wright Jr, K. (2020). https://doi.org/10.20944/preprints202012.0037.v1

Campama Pizarro, R. (2019). Daylighting and Electric Lighting Integration in the Retail Sector Lund University ]. http://lup.lub.lu.se/student-papers/record/8999762

CEN. (2017a). EN15193-1 Energy performance of buildings - energy requirements for lighting - Part 1: specifications, module M9. In: Comite Europeen de Normalisation.

CEN. (2017b). EN 15193-2 Energy performance of buildings - Energy requirements

for lighting - Part 2: Explanation and justification, Module M9. In.

CEN. (2018). EN 17037:2018 Daylight in Buildings. In.

CIE. (2018). CIE System for Metrology of Optical Radiation for ipRGC-Influenced Responses to Light. In. Vienna, Austria: CIE Central Bureau.

CIE. (2019). Position Statement - Proper Light at the Proper Time https://cie.co.at/publications/cie-systemmetrology-optical-radiation-iprgc-influenced-responses-light-0

Debevec, P., Reinhard, E., Heidrich, W., Ward, G., Myszkowski, K., \& Pattanaik, S. (2010). High Dynamic Range Imaging: Acquisition, Display, and Image-Based Lighting. Elsevier Science.

Delvaeye, R. (2017). Lighting Energy Numeric Indicator (LENI) Version 2.0. Retrieved March 2 from https://www.cstc.be/homepage/index.cfm?cat=tools\&sub=calculator\&pag=leni

Design for Climate \& Comfort Lab. (2021). Spectral materials database. http://spectraldb.com/

Dubois, M.-C., Gentile, N., Amorim, C. N. D., Geisler-Moroder, D., Jakobiak, R., Matusiak, B., Osterhaus, K. E. W., \& Stoffer, S. (2016). Monitoring protocol for lighting and daylighting retrofits (IEA SHC Task 50: Advanced Lighting Solutions for Retrofitting Buildings, Issue. http://task50.ieashc.org/data/sites/1/publications/Technical Report T50 D3 final.pdf

Dumortier, D. (2015). PHOTOLUX: a new luminance mapping system based on Nikon Coolpix digital cameras.Proceedings of Lux Europa 2015 Berlin, Germany.

Ellegård, K., \& Svedin, U. (2012). Torsten Hägerstrand's time-geography as the cradle of the activity approach in transport geography. Journal of Transport Geography, 23, 17-25.

https://doi.org/https://doi.org/10.1016/j.jtrangeo.2012.03.023

Enezi, J., Revell, V., Brown, T., Wynne, J., Schlangen, L., \& Lucas, R. (2011). A "melanopic" spectral efficiency function predicts the sensitivity of melanopsin photoreceptors to polychromatic lights. J Biol Rhythms, 26(4), 314-323. https://doi.org/10.1177/0748730411409719

EPFL-LIPID. (2015). SpeKtro, Interactive dashboard for exploring non- visual spectrum lighting [online]. Retrieved 22 May from http://spektro.epfl.ch/

Figueiro, M. G., Gonzales, K., \& PeDLer, D. (2016). Designing with circadian stimulus. Ld+ a, 8, 30-34.

Figueiro, M. G., Hamner, R., Bierman, A., \& Rea, M. S. (2012). Comparisons of three practical field devices used to measure personal light exposures and activity levels. Lighting Research \& Technology, 45(4), 421434. https://doi.org/10.1177/1477153512450453

Gentile, N., Dubois, M.-C., Osterhaus, W., Stoffer, S., Amorim, C. N. D., Geisler-Moroder, D., \& Jakobiak, R. (2016). A toolbox to evaluate non-residential lighting and daylighting retrofit in practice. Energy and Buildings, 123, 151-161. https://doi.org/10.1016/j.enbuild.2016.04.026 
Gentile, N., Goven, T., Laike, T., \& Sjoberg, K. (2018). A field study of fluorescent and LED classroom lighting. Lighting Research \& Technology, 50(4), 631-650. https://doi.org/10.1177/1477153516675911

Gifford, R. (2007). Environmental psychology: Principles and practice. Optimal books Colville, WA.

Hellinga, H., \& Hordijk, T. (2014). The D\&V analysis method: A method for the analysis of daylight access and view quality. Building and Environment, 79, 101-114. https://doi.org/https://doi.org/10.1016/j.buildenv.2014.04.032

Houser, K. W., \& Esposito, T. (2021). Human-Centric Lighting: Foundational Considerations and a Five-Step Design Process. Frontiers in Neurology, 12. https://doi.org/10.3389/fneur.2021.630553

Hygge, S., \& Löfberg, H. (1999). IEA SHC Task 21 Post occupancy evaluation of daylight in buildings (Center for the Built Environment, Sweden, for IEA Solar and Heating Program Task, Issue.

Inanici, M. (2006). Evaluation of high dynamic range photography as a luminance data acquisition system. Lighting Research \& Technology, 38(2), 123-134. https://doi.org/10.1191/1365782806li164oa

Inanici, M. (2009). Introduction to high dynamic range photography. https://www.radianceonline.org/community/workshops/2009-boston-ma/Presentations/inanici HDR-2009.pdf

Inanici, M., Brennan, M., \& Clark, E. (2015). Spectral daylighting simulations: computing circadian light. Buiding Simulation 2015, Hyderabad, India.

Inanici, M., \& ZGF Architects, L. (2021). Lark spectral lighting. https://faculty.washington.edu/inanici/Lark/Lark home page.html

ISO/CIE. (2014). Characterization of the Performance of Illuminance Meters and Luminance Meters. In. Vienna, Austria.: ISO.

IWBI. (2020). WELL v2 Circadian Lighting Design. In.

Jakubiec, J. A. (2016). Building a database of opaque materials for lighting simulation. PLEA 2016-Cities, Buildings, People: Towards Regenerative Environments, Proceedings of the 32nd International Conference on Passive and Low Energy Architecture,

Jakubiec, J. A., Van Den Wymelenberg, K., Inanici, M., \& Mahic, A. (2016a). Accurate measurement of daylit interior scenes using high dynamic range photography. Proceedings of the CIE 2016 Lighting Quality and Energy Efficiency Conference,

Jakubiec, J. A., Van Den Wymelenberg, K., Inanici, M., \& Mahic, A. (2016b). Improving the accuracy of measurements in daylit interior scenes using high dynamic range photography. Proceedings of the $32 \mathrm{nd}$ PLEA Conference, Los Angeles, CA, USA,

Johansson, M., Pedersen, E., Maleetipwan-Mattsson, P., Kuhn, L., \& Laike, T. (2014). Perceived outdoor lighting quality (POLQ): A lighting assessment tool. Journal of Environmental Psychology, 39, 14-21. https://doi.org/10.1016/j.jenvp.2013.12.002

Johnsen, K., Dubois, M.-C., \& Sørensen, K. G. (2006). Assessment of daylight quality in simple rooms: Impact of three window configurations on daylight conditions, Phase 2. SBI forlag.

Jung, B., \& Inanici, M. (2018). Measuring circadian lighting through high dynamic range photography. Lighting Research \& Technology, 51(5), 742-763. https://doi.org/10.1177/1477153518792597

Knoop, M. (2016). Daylighting and electric lighting retrofit solutions (A source book of IEA SHC Task 50 'Advanced lighting for retrofitting buildings', Issue. https://depositonce.tu-berlin.de/handle/11303/5494

Konis, K. (2018). Field evaluation of the circadian stimulus potential of daylit and non-daylit spaces in dementia care facilities. Building and Environment, 135, 112-123. https://doi.org/10.1016/j.buildenv.2018.03.007

Kristensen, T. S., Hannerz, H., Høgh, A., \& Borg, V. (2005). The Copenhagen Psychosocial Questionnaire-a tool for the assessment and improvement of the psychosocial work environment. Scandinavian journal of work, environment \& health, 438-449.

Kruisselbrink, T., Dangol, R., \& Rosemann, A. (2018). Photometric measurements of lighting quality: An overview. Building and Environment, 138, 42-52. https://doi.org/10.1016/j.buildenv.2018.04.028

Kruisselbrink, T. W., Dangol, R., \& van Loenen, E. J. (2020). Feasibility of ceiling-based luminance distribution measurements. Building and Environment, 172, 106699.

Kuller, R., \& Laike, T. (1998). The impact of flicker from fluorescent lighting on well-being, performance and physiological arousal. Ergonomics, 41(4), 433-447. https://doi.org/10.1080/001401398186928

Ladybug Tools LLC. (2021). Ladybug Tools. https://www.ladybug.tools/about.html

Liu, R., Zhou, X., Lochhead, S. J., Zhong, Z., Huynh, C. V., \& Maxwell, G. M. (2017). Low-energy LED lighting heat gain distribution in buildings, part II: LED luminaire selection and test results. Science and Technology for the Built Environment, 23(4), 688-708. https://doi.org/10.1080/23744731.2016.1250563

Lucas Group, \& The University of Manchester. (2020). Lucas Toolbox [online]. Retrieved 2 March from http://lucasgroup.lab.manchester.ac.uk/research/measuringmelanopicilluminance/

Lucas, R. J., Peirson, S. N., Berson, D. M., Brown, T. M., Cooper, H. M., Czeisler, C. A., Figueiro, M. G., Gamlin, P. D., Lockley, S. W., O'Hagan, J. B., Price, L. L., Provencio, I., Skene, D. J., \& Brainard, G. C. (2014). 
Measuring and using light in the melanopsin age. Trends Neurosci, 37(1), 1-9.

https://doi.org/10.1016/j.tins.2013.10.004

Lys og udsyn (§ 377- § 384). (2018). https://bygningsreglementet.dk/Tekniske-bestemmelser/18/Krav

Maleetipwan-Mattsson, P., Laike, T., \& Johansson, M. (2013). Self-Report Diary: A Method to Measure Use of Office Lighting. Leukos, 9(4), 291-306. https://doi.org/10.1582/LEUKOS.2013.09.04.004

Mardaljevic, J., Andersen, M., Roy, N., \& Christoffersen, J. (2012). Daylighting, Artificial Lighting and Non-Visual Effects Study for a Residential Building.

Markus, T. A. (1967). The function of windows-A reappraisal. Building Science, 2(2), 97-121. https://doi.org/https://doi.org/10.1016/0007-3628(67)90012-6

Markvart, J., Hansen, A.. M., \& Christoffersen, J. (2015). Comparison and Correction of the Light Sensor Output from 48 Wearable Light Exposure Devices by Using a Side-by-Side Field Calibration Method. Leukos, 11(3), 155-171. https://doi.org/10.1080/15502724.2015.1020948

Matusiak, B., Martyniuk-Pęczek, J., Sibilio, S., Amorim, C. N. D., Scorpio, M., Nazari, M., \& Sokol, N. (2021). User perspective and requirements. Personas. (A Technical Report of IEA SHC Task 61/ EBC Annex 77. Integrated solutions for Daylighting and Electric Lighting, Issue.

Meir, I. A., Garb, Y., Jiao, D., \& Cicelsky, A. (2009). Post-Occupancy Evaluation: An Inevitable Step Toward Sustainability. Advances in Building Energy Research, 3(1), 189-219.

https://doi.org/10.3763/aber.2009.0307

Nabil, A., \& Mardaljevic, J. (2006). Useful daylight illuminances: A replacement for daylight factors. Energy and Buildings, 38(7), 905-913. https://doi.org/10.1016/i.enbuild.2006.03.013

Palm, J., \& Ellegård, K. (2011). Visualizing energy consumption activities as a tool for developing effective policy. International Journal of Consumer Studies, 35(2), 171-179.

Pejtersen, J. H., Kristensen, T. S., Borg, V., \& Bjorner, J. B. (2009). The second version of the Copenhagen Psychosocial Questionnaire. Scandinavian Journal of Public Health, 38(3_suppl), 8-24. https://doi.org/10.1177/1403494809349858

Pham, K., Garcia-Hansen, V., Isoardi, G., \& Allan, A. (Manuscript in submitted, 2021). Open-source hardware and software for in-situ measurements in real contexts: a use case scenario of its usability for lighting research.

Pierson, C., Cauwerts, C., Bodart, M., \& Wienold, J. (2021). Tutorial: luminance maps for daylighting studies from high dynamic range photography. Leukos, 17(2), 140-169.

Pierson, C., Jacobs, A., Wienold, J., \& Bodart, M. (2017). Luminance maps from High Dynamic Range imaging: photometric, radiometric and geometric calibrations. Lux Europa 2017,

Preiser, W. F., White, E., \& Rabinowitz, H. (2015). Post-Occupancy Evaluation (Routledge Revivals). Routledge.

Rea, M. S., \& Figueiro, M. G. (2016). Light as a circadian stimulus for architectural lighting. Lighting Research \& Technology, 50(4), 497-510. https://doi.org/10.1177/1477153516682368

Rea, M. S., Figueiro, M. G., Bierman, A., \& Hamner, R. (2011). Modelling the spectral sensitivity of the human circadian system. Lighting Research \& Technology, 44(4), 386-396. https://doi.org/10.1177/1477153511430474

Rea, M. S., Figueiro, M. G., Bullough, J. D., \& Bierman, A. (2005). A model of phototransduction by the human circadian system. Brain Research Reviews, 50(2), 213-228. https://doi.org/10.1016/j.brainresrev.2005.07.002

Robertson, M. A., Borman, S., \& Stevenson, R. L. (1999). Dynamic range improvement through multiple exposures. Proceedings 1999 International Conference on Image Processing (Cat. 99CH36348),

Rodriguez, F., Garcia-Hansen, V., Allan, A., \& Isoardi, G. (2021). Subjective responses toward daylight changes in window views: Assessing dynamic environmental attributes in an immersive experiment. Building and Environment, 195, 107720. https://doi.org/https://doi.org/10.1016/j.buildenv.2021.107720

Sekulovski, D., Poplawski, M., Vogels, I., Whitehead, L., Wilkins, A., Perz, M., \& Pong, B.-J. (2016). CIE TN 006:2016: Visual Aspects of Time-Modulated Lighting Systems-Definitions and Measurement Models. Commission International de l'Éclairage Retrieved from http://files.cie.co.at/883 CIE TN 006-2016.pdf

Shach-Pinsly, D., Fisher-Gewirtzman, D., \& Burt, M. (2011). Visual Exposure and Visual Openness: An Integrated Approach and Comparative Evaluation. Journal of Urban Design, 16(2), 233-256.

https://doi.org/10.1080/13574809.2011.548979

UL. (2020). Design Guideline for Promoting Circadian Entrainment with Light for Day-Active People. In.

van Duijnhoven, J., Aarts, M. P. J., Aries, M. B. C., Böhmer, M. N., \& Rosemann, A. L. P. (2017).

Recommendations for measuring non-image-forming effects of light: A practical method to apply on cognitive impaired and unaffected participants. Technology and Health Care, 25, 171-186.

https://doi.org/10.3233/THC-161258 
Veitch, J. A., \& Newsham, G. R. (1998). Determinants of Lighting Quality I: State of the Science. Journal of the Illuminating Engineering Society, 27(1), 92-106. https://doi.org/10.1080/00994480.1998.10748215

Venkatesh, V., Morris, M. G., Davis, G. B., \& Davis, F. D. (2003). User acceptance of information technology: Toward a unified view. MIS quarterly, 425-478.

Venkatesh, V., Thong, J. Y., \& Xu, X. (2012). Consumer acceptance and use of information technology: extending the unified theory of acceptance and use of technology. MIS quarterly, 157-178.

Wang, Y., Pandharipande, A., \& Fuhrmann, P. (2018). Energy data analytics for nonintrusive lighting asset monitoring and energy disaggregation. IEEE Sensors Journal, 18(7), 2934-2943.

Wienold, J., \& Christoffersen, J. (2005). Towards a new daylight glare rating. Lux Europa, Berlin, 157-161.

Zeifman, M., \& Roth, K. (2011). Nonintrusive appliance load monitoring: Review and outlook. IEEE transactions on Consumer Electronics, 57(1), 76-84. 


\section{Annex A Calculated method for energy use}

Calculation of the energy use by deriving the LENI value via the comprehensive method is in accordance with EN15193-1:2017 M7 and EN15193-2:2017. It is important to note, that the LENI value does not indicate the efficiency of the electrical lighting system but only the expected energy use.

The required input information will depend on the size of the area (floor area in $\mathrm{m}^{2}$ ), the number of luminaires and the type of luminaires, the number of emergency luminaires and the type of emergency luminaires, control systems (e.g. dimming or occupancy linked sensors), fenestration and shading type, occupancy periods and maintenance schedule. This can be added into the excel spreadsheet developed by Delvaeye (2017).

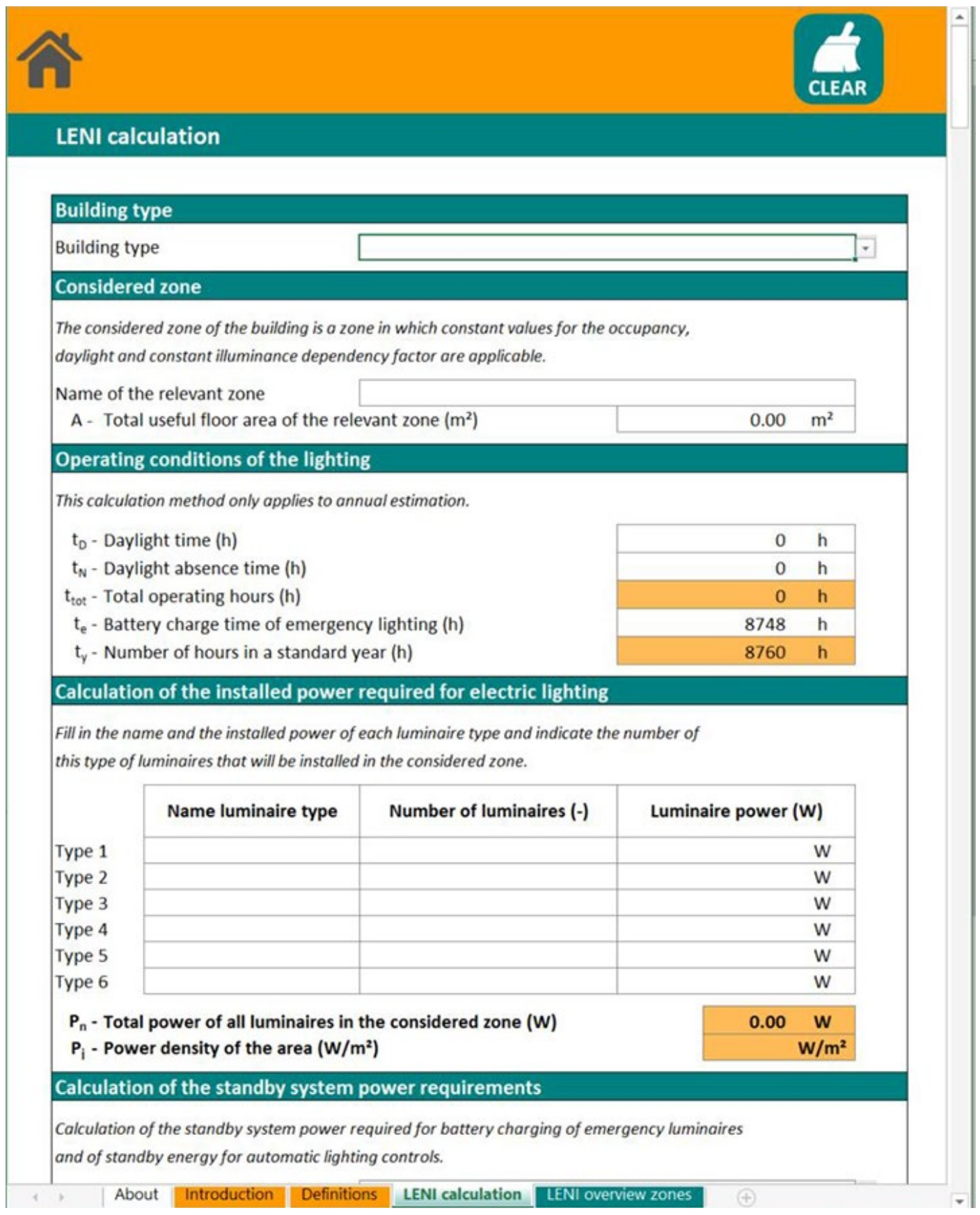




\subsection{An Example from Denmark}

In the Danish Building Regulations("Lys og udsyn (§ 377- § 384)," 2018), it is prescribed in §382 pc. 3 that workplaces and common spaces/hallways need to be fitted with automatic daylight-depended control, if there is sufficient daylight. For spaces that are only used intermittently, a motion sensor needs to be installed. EN15193-1 is used for determining the energy saving contributions from the daylight-dependent control system and the motion sensor.

An Excel Spreadsheet developed by Inger Erhardtsen of IVE Consulting can be used for the calculations. The spreadsheet was developed based on the methods and formulas published in EN15193-1. The spreadsheet is currently not available publicly. In two of the Danish case studies conducted as part of IEA Task 61, electric lighting settings change on the basis of circadian lighting schedules. This requires additional steps to ensure that the energy use is appropriately described and attributed. Method 2 of EN 15193-1 is used for calculations of the energy requirements for lighting in cases for which comprehensive lighting system designs have not been performed as part of the current process.

The different steps in the calculations process are stated below and are further described below in this Annex.

- Specification of the luminaires used and their relevant technical data as well as the different settings in the daily (circadian) lighting schedule.

- Number of hours used in the existing/refurbished buildings for each setting (e.g. 5,500K for 3.5 hours per day

- Determination of adjusted hours according to the default values used in a standard reference room. This is helpful when trying to establish baseline values for comparison.

- Determination of the numbers of light sources.

- Determination of the power consumption of a luminaire incl. driver for different settings.

- Determination of the cost savings for using daylight-linked control system.

- Determination of the cost savings for using a motion sensor.

- $\quad$ Calculation of the Annual Lighting Energy Numeric Indicator (LENI)

- Calculate the Total Annual Energy Use during the day and during the night

- Calculate the Total Annual Energy Use

- Comparison of the energy use values for the actual building and a standard reference case.

\subsection{Specification of the lighting system}

Every effort should be made to determine as much detail of the installed lighting system as possible. This includes data on the light sources or luminaires, as well as the control systems in different modes of operation (e.g. in stand-by). In addition, documentation is needed for the operating schedule of the lighting systems. In two of the Danish case studies, correlated colour temperature (CCT) and light levels are changing according to the desired circadian settings to support the non-visual effects of light.

\subsubsection{Burning hours}

Default values for $t_{D}$ (hours during the day) and $t_{N}$ (hours during the night) are provided in EN 15193-1, Annex B, Table B.2. These values can be used for a standard reference case. 
Table 5.1. Sample of annual operating hours of buildings from EN 15193 (Table B.2).

\begin{tabular}{|l|l|l|l|}
\hline \multicolumn{1}{|c|}{ Building type } & \multicolumn{3}{c|}{ Default annual operating hours } \\
\hline & \multicolumn{1}{|c|}{$t_{D}$} & \multicolumn{1}{c|}{$t_{N}$} & \multicolumn{1}{c|}{$t_{\text {tot }}$} \\
\hline Offices & 2250 & 250 & 2500 \\
\hline $\begin{array}{l}\text { Wholesale and retail } \\
\text { services }\end{array}$ & 3000 & 2000 & 5000 \\
\hline$\ldots$ & $\ldots$ & $\ldots$ & $\ldots$ \\
\hline
\end{tabular}

Adjustments need to be made to reflect the actual operating hours of the installed light sources and luminaires. Alternatively, operating hours for lighting might be calculated for minimum and maximum numbers of hours and a range can provided for the energy use calculations. If it is possible to observe the lighting use on site or get more detailed information from the facility manager, users or user groups, this is highly recommended. This is particularly useful when lighting can be controlled by an individual user of a room.

\subsubsection{Installed power}

Information for the number of light sources and luminaires, as well as the luminaire power used for the different settings needs to be collected. The data can be provided by the manufacturer(s) or determined by measurements/experiments on site or in a laboratory.

As an example, in the Danish case study for the Vikærgården Rehabilitation Center in Aarhus, technical staff members of the luminaire manufacturer were on site for a few days to complete some work. These staff members were asked to take measurements of the connected power of individual luminaires for the different spectral power distribution (SPD) and dimming/illuminance settings.

\subsection{The cost savings for using daylight-linked control systems}

\subsubsection{Daylight dependency factor $\left(\mathrm{FD}_{\mathrm{D}}\right)$}

\subsubsection{Daylight factor (D)}

The daylight factor is often a parameter, which is typically measured during the monitoring. The daylight factor can also be determined through simulation tools.

For the energy calculations, the daylight factor is determined at the middle of the room.

\subsubsection{Orientation}

The orientation of the building and use of shading devices need to be stated (North, South (shaded or nonshaded), East, West).

\subsubsection{Daylight supply factor ( $\left.F_{\mathrm{DS}, \mathrm{SNA}}\right)$}

Using method 2 in EN 15193-1, the daylight supply factor for situations with solar/glare protection $\left(F_{D S, S N A}\right)$ is given in Annex B, Table B.3 of the standard. Here, the daylight factor (D) as percentage needs to be specified.

When $F_{D S, S N A}$ is determined, it is possible to determine the $F_{D, S} F_{D, S}$ depends on the orientation and use of shading. For south facing facades with shading or glare protection, Formula (28) from EN 15193-1 applies.

$F_{D, S}=0,65 \cdot F_{D, S, S N A}+0,07$

For a south facing façade without shading or glare protection, or for east, west and north facing façades formula (29) applies:

$F_{D, S}=0,65 \cdot F_{D S, S N A}+0,25$ 


\subsection{The cost savings for using a motion sensor}

\subsubsection{Occupancy dependency factor ( $F \circ)$}

The $F_{O}$ value estimation can be rewritten as a single expression as formula:

$$
F_{O}=\min \left\{\begin{array}{c}
1-\frac{\left(1-F_{O C}\right) * F_{A}}{0,2} \\
F_{O C}+0,2-F_{A} \\
\left(7-\left(10 * F_{O C}\right)\right) *\left(F_{A}-1\right)
\end{array}\right.
$$

\subsubsection{Absence factor $\left(F_{A}\right)$}

The Absence factor $\left(F_{A}\right)$ can be determined from EN 15193-1, Annex E, Table E.2.

\subsubsection{Control function factor ( $\left.F_{\circ c}\right)$}

The control function factor $\left(F_{\text {oc }}\right)$ can be determined from EN 15193-1, Annex E, Table E.1

\subsection{Calculate Annual Lighting Energy Numeric Indicator (LENI)}

The total annual energy is first calculated separately for the different settings, e.g. night light and lighting during the day and perhaps also for different settings according to a changing circadian schedules. Energy Use, Day or Night depends on the luminaires used, their burning hours and the calculated $F_{O}$ and $F_{D}$ :

Energy Use $[\mathrm{kWh}]$

$=\frac{(\text { number of luminiares } * \text { light sources pr luminaire } * \text { Power Use pr luminiare }[\text { Watt }]) * \text { hours }[h] * F_{o}[\%] * F_{D}[\%]}{1000}$ 1000

Annual Total Energy Use (W) is the total of all the separately calculated energy use values for different settings.

$W=$ Energy $_{\text {use }}$ Day + Energy use $_{\text {Night }}$

LENI for the building is calculated using:

LENI $\left(\frac{k W h}{m^{2}}\right)=\frac{W \text { (the total annual energy required for lighting for the building }[\mathrm{kWh}])}{A(\text { the total useful floor area of the building })\left[\mathrm{m}^{2}\right]}$

\subsection{References}

Bygningsreglementet. (2018). Lys og udsyn (§ 377- § 384). Retrieved November 30., 2020, from https://bygningsreglementet.dk/Tekniske-bestemmelser/18/Krav

CEN. (2017). EN 15193-1:2017 Energy performance of buildings- Energy requirements for lighting - Part 2: Explanation and justification of EN 15193 Module M9. Nordhavn: Danish Standards Foundations. 


\section{Annex B.1 Cylindrical illuminance estimation}

Where a dedicated cylindrical illuminance meter is not available, the cubic illuminance method can estimate the cylindrical illuminance with a standard illuminance meter and a physically constructed cube positioned at $1.2 \mathrm{~m}$ for sitting or $1.6 \mathrm{~m}$ for standing (see Figure 19).

Obtain the lux values by mounting the illuminance meter on each facet of the cube, such that the detector head is facing away from the cube to capture lux values for facet $E_{x}, E_{y}, E_{z}, E_{-x}, E_{-y}$ and $E_{-z}$ as the resultant vectors and symmetric components. Using the equation by Cuttle (1997), the cylindrical illuminance, $E_{c l}$, is derived:

$$
E_{c l}=\frac{|E| e \cdot e_{(x, y)}}{\pi}+\frac{\left(\sim E_{(x)}+\sim E_{(y)}\right)}{2}
$$

\begin{tabular}{|c|c|}
\hline${ }^{\prime} E_{(x, y, z)}=\left({ }^{\prime} E_{(x)},{ }^{\prime} E_{(y)},{ }^{\prime} E_{z}\right)$ & (1) \\
\hline${ }^{\prime} E_{(x)}=E_{(+x)}-{ }^{\prime} E_{(-x)}$ & (2) \\
\hline${ }^{\prime} E_{(y)}=E_{(+y)}-E_{(-y)}$ & (3) \\
\hline${ }^{\prime} E_{(z)}=E_{(+z)}-E_{(-z)}$ & (4) \\
\hline$\sim E_{(x, y, z)}=\left(\sim E_{(x)}, \sim E_{(y)}, \sim E_{z}\right)$ & (5) \\
\hline$\sim E_{(x)}=\min \left(E_{(+x)}, E_{(-x)}\right)$ & (6) \\
\hline$\sim E_{(y)}=\min \left(E_{(+y)}, E_{(-y)}\right)$ & (7) \\
\hline$\sim E_{(z)}=\min \left(E_{(+z)}, E_{(-z)}\right)$ & (8) \\
\hline$\left|E_{(x, y, z)}\right|=\left({ }^{\prime} E_{(x)}{ }^{2}+{ }^{\prime} E_{(y)}{ }^{2}+{ }^{\prime} E_{(z)}{ }^{2}\right)^{0.5}$ & (9) \\
\hline$e_{(x)}=\frac{{ }^{\prime} E_{(x)}}{\left|E_{(x, y, z)}\right|}$ & (10) \\
\hline$e_{(y)}=\frac{{ }^{\prime} E_{(y)}}{\left|E_{(x, y, z)}\right|}$ & (11) \\
\hline$e_{(z)}=\frac{{ }^{\prime} E_{(z)}}{\left|E_{(x, y, z)}\right|}$ & (12) \\
\hline$e_{(c y l)}=\frac{|E| e \cdot e_{x, y}}{\pi}+\frac{\left(\sim E_{(x)}+\sim E_{(y)}\right)}{2}$ & (13) \\
\hline
\end{tabular}

\subsection{References}

Rizki A. Mangkuto (2020) Uncertainty Analysis of Cylindrical Illuminance Approximation, LEUKOS, 16:4, 267-278, DOI: $10.1080 / 15502724.2019 .1619574$ 


\section{Annex B.2 Tutorial: Generating HDR images}

The following tutorial was kindly provided by Clotilde Pierson, PhD. An extensive version and the rationale are published elsewhere (Pierson et al., 2020). Please cite the original publication in future works.

The method consists of applying an automatic algorithm that merges the LDR images captured with the photocamera into an HDR image while doing a radiometric calibration, before manually adjusting the generated HDR image to calibrate it photometrically and geometrically. A detailed tutorial article, summarised below, details the step-by-step calibration method to generate luminance maps of daylit visual scenes from a sequence of LDR (jpeg) images (Pierson et al., 2020).

The step-by-step calibration method could be adapted to generate luminance maps of electrically lit visual scenes, on the condition that the following issues are taken care of:

- Definition of the correct white balance setting of the camera for the studied lighting conditions;

- Potential interference of the flicker of the electric light source while the sequence of multiple exposures is being captured (need of stable lighting conditions); and

- $\quad$ Limited resolution of the HDR image when the size of the light source(s) being measured is very small in the visual scene, such as with current LED luminaires.

\subsection{Step-by-step calibration using an automatic merging algorithm}

The complete procedure to generate a luminance map of a visual scene with daylight consists of multiple steps, some of which are based on predefined calibration material. The predefined calibration material, such as the camera response function or the vignetting curves, has to be derived only once for a specific equipment during the one-time setup. The predefined calibration material can be used afterwards for each luminance map of a daylit scene generated with the same equipment.

\section{Equipment}

The equipment required for the one-time setup should only be available once. The rest of the equipment will always be needed for the generation of a luminance map.

\section{Basic equipment}

A Digital Single-Lens Reflex (DSLR) photo-camera, with the settings configured as recommended in the literature (Inanici, 2009), see Table 13.

- A circular fisheye lens which is compatible with the camera (a normal (non-fisheye) lens can also be used, on condition that this lens is not a zoom lens or that the zoom is fixed to ensure that the lens is in the exact same position during the entire calibration procedure and for all following captures of LDR images)

- A tripod on which to set the camera to ensure that the camera does not move during the sequence of multiple exposures, namely the capture of multiple LDR images

- A computer to remotely control the camera and process the images, equipped with qDslrDashboard to remotely control the camera; the Radiance suite of programs and the command tool hdrgen to process the images; and Photosphere to apply the photometric adjustment (these are freely accessible software on which this tutorial is based, although other software could be used)

- A calibrated spot luminance meter and a middle grey target to make the photometric adjustment

- A calibrated illuminance meter to check the validity of the calibrated HDR fisheye image

- A Neutral Density (ND) filter could be needed if the sun or a very bright surface is in the FOV

Table 13. Camera setting set-up for the DSLR photo-camera.

\begin{tabular}{|l|l|}
\hline Setting & Value \\
\hline Film speed & ISO 100 \\
\hline White balance & Daylight (5200K) \\
\hline Exposure mode & Manual \\
\hline
\end{tabular}




\begin{tabular}{|l|l|}
\hline Light metering mode & Insignificant \\
\hline Focus mode & Manual \\
\hline Focus value & Infinite \\
\hline Image quality & Largest \\
\hline Image type & JPEG or RAW \\
\hline Picture style & Neutral \\
\hline Peripheral illumination correction & Disabled \\
\hline Colour space & SRGB \\
\hline
\end{tabular}

\section{One-time setup equipment}

- A colour chart;

- a panoramic rotation unit and a sliding plate to move the camera on the tripod; and

- a stable and bright light source (e.g. a halogen spotlight) in a dark room, or a stable overcast sky simulator (e.g. a mirror box) with a semi-circular platform

\subsection{One-time set-up}

The steps required for the one-time setup are summarised below. More details on how to practically execute these steps can be found in the tutorial article (Pierson et al., 2020).

A. Determination of the no-parallax point, namely the point of the lens at which the rays entering the lens should converge, the real viewing angle, which most of the time does not equal exactly $180^{\circ}$ for a fisheye lens, and the view coordinates, since the center of the view might not be exactly at the center of the image;

B. Determination of the luminous range of the camera, which is characterized by the minimal and maximal luminance values that the camera/lens combination can measure through HDR photography (Jakubiec et al., 2016);

C. Determination of the response function of the camera, which relates radiance values from the scene $\left(\mathrm{W} / \mathrm{m}^{2} \mathrm{sr}\right)$ to pixel values (0-255) for the RGB channels, and is specific for each camera;

D. Determination of the projection function of the lens, namely how the $3 D$ scenes is projected on a 2D image, and its corresponding distortion function, namely the function establishing the displacement that should be applied to a pixel according to its original position to get another projection, such as an equidistant one, in an HDR image;

E. Determination of the vignetting curves, namely the curves representing the brightness decrease that can be observed from the center of a picture towards its periphery, especially when a fisheye lens is used (Reinhard et al., 2006).

F. Determination of the ND filter correction function if a ND filter was used during the capture of LDR images to prevent pixel overflow, namely pixels reaching their limited charge capacity and propagating the extra charge to surrounding pixels.

\section{Generation of a luminance map with the step-by-step calibration}

1. Capture of a sequence of around 15 multiple exposures (LDR images) of the visual scene through automatic bracketing, accompanied by at least one spot luminance measurement and one vertical illuminance measurement.

2. (optional) Selection of the useful exposures in order to accelerate the HDR generation process and make it more stable.

3. Merging of the exposures to generate the HDR image by using the predefined camera response function and an automatic merging algorithm such as hdrgen.

4. Nullification of exposure value, i.e. inclusion of the exposure value directly in the pixel values.

5. Cropping and resizing the HDR image by using the predefined fisheye view coordinates to facilitate the future manipulations applied to the HDR image

6. Adjustment of the projection of the HDR image by using the predefined distortion function, since in applications for which the geometry of the visual scene is relevant, it is often preferred to have an HDR image with one the two most common theoretical projections (i.e. equidistant or orthographic).

7. Correction of the vignetting of the HDR image by using the predefined vignetting curves

8. Correction of the alterations of the HDR image due to the ND filter if one was used, by using the predefined ND correction function 
9. Adjustment of the photometry of the HDR image by using the measured spot luminance value, since HDR photography captures relative luminance values that have to be adjusted to retrieve the absolute luminance values of the scene.

10. Editing of the HDR image header, namely the location where the settings and parameters of the image are stored, by using the predefined projection type and real viewing angle to provide correct information for post-analyses.

11. Check of the validity of the HDR image as a luminance map by using the measured vertical illuminance, and if needed the predefined luminous range 


\section{Annex C.1 IEA SHC Task 61 Questionnaire}

\subsection{Section 1: Background data}

1. Date

. 2. Time

4. Gender $\bigcirc$ Female

Male

Prefer not to answer
5. Age

(years)
3. Type of work

7. Do you wear glasses or contact lenses when you work?
Yes, always
Yes, sometimes
No, never

If yes, please specify the vision correction type of your lenses

8. At what time do you usually start working at your workstation?

9. At what time do you usually finish working at your workstation?

10. How many days per week do you usually work at your usual workstation?

11. Do you mostly work in front of a monitor or with paper? $\bigcirc$ Computer Screen $\bigcirc$ Paper

12. Please read all the categories and then mark the type of workspace you are in (only one alternative).

Enclosed office, private

Enclosed office, shared with other people

Cubicles with high partitions (higher than $1.5 \mathrm{~m}$ approximately)

$\bigcirc \quad$ Cubicles with low partitions (lower than $1.5 \mathrm{~m}$ approximately)

Workspace in open workspace with no partitions (just desks)

13. How many people share your current room or work space?

It's just me $\quad$ Two people $\quad 3-4$ persons $\quad$ 5-10 persons $\quad$ More than 10

\subsection{Section 2: Social and physical climate}

Never

Always

Prefer not to answer

14. Does your work demand a great deal of concentration?

15. How often do you interact with your colleagues while you work?

16. How much of the time during the past 4 weeks did you feel tired?

$\begin{array}{ccccc}0 & 0 & 0 & 0 & 0 \\ 0 & 0 & 0 & 0 & 0 \\ 0 & 0 & 0 & 0 & 0\end{array}$


I wish to explain more about my work or why I feel tired/energetic

Are you satisfied with the following aspects of the workspace?

$\begin{array}{cccccc}\begin{array}{c}\text { Very } \\ \text { dissatisfied }\end{array} & & & \begin{array}{c}\text { Very } \\ \text { satisfied }\end{array} & \begin{array}{c}\text { Prefer } \\ \text { not to } \\ \text { answer }\end{array} \\ 0 & 0 & 0 & 0 & 0 & 0 \\ 0 & 0 & 0 & 0 & 0 & 0 \\ 0 & 0 & 0 & 0 & 0 & 0 \\ 0 & 0 & 0 & 0 & 0 & 0 \\ 0 & 0 & 0 & 0 & 0 & 0 \\ 0 & 0 & 0 & 0 & 0 & 0 \\ 0 & 0 & 0 & 0 & 0 & 0 \\ 0 & 0 & 0 & 0 & 0 & 0 \\ 0 & 0 & 0 & 0 & 0 & 0 \\ 0 & 0 & 0 & 0 & 0 & 0 \\ 0 & 0 & 0 & 0 & 0 & 0\end{array}$

I wish to say more

\subsection{Section 3: User experience of lighting} DAYLIGHTING

28. How best would you describe the amount of daylight that you typically get at your workspace?

O

$\bigcirc$

$\bigcirc \bigcirc$

Far too much 
29. What is the degree of control (e.g. use of shading) that you have over the daylighting at your workspace?

$$
\text { No control } \bigcirc \bigcirc \bigcirc \bigcirc \bigcirc \text { High control }
$$

30. Do you typically experience discomfort with daylighting at our workspace?

$$
\text { No discomfort } \bigcirc \bigcirc \bigcirc \bigcirc \text { A lot of discomfort }
$$

If you are experiencing discomfort with daylighting in your workspace, please provide some more information

\section{ARTIFICIAL LIGHTING}

31. How best would you describe the amount of artificial light in your workspace?
Far too little
$\bigcirc$
$\bigcirc \bigcirc$
Far too much

32. What is the degree of control that you have over the artificial lighting in your workspace?

$$
\text { No control } \bigcirc \bigcirc \bigcirc \bigcirc \text { High control }
$$

33. Do you typically experience discomfort with artificial lighting in your workspace?
No discomfort
$\bigcirc$
O
A lot of discomfort

If you are experiencing discomfort with artificial lighting in your workspace, please describe where 


\section{DAYLIGHTING AND ARTIFICIAL LIGHTING INTEGRATION}

34. Do you prefer working in daylight, artificial light or a combination of daylight and artificial?

Prefer daylight $\quad \bigcirc$ Prefer artificial $\bigcirc$ Prefer combination

35. Do you ever work using only the light from the windows?
Often
$\bigcirc$
$\bigcirc \quad$ Never
Prefer not to answer

In general, how do you rate the amount of light, artificial and daylight combined?

\begin{tabular}{|c|c|c|c|c|c|c|}
\hline & $\begin{array}{l}\text { Too } \\
\text { little }\end{array}$ & & & & $\begin{array}{l}\text { Too } \\
\text { much }\end{array}$ & $\begin{array}{l}\text { Prefer not } \\
\text { to answer }\end{array}$ \\
\hline 36. At the workplace (e.g. desk) & $\bigcirc$ & $\bigcirc$ & $\bigcirc$ & $\bigcirc$ & $\bigcirc$ & $\bigcirc$ \\
\hline 37. In the room in general & $\bigcirc$ & $\bigcirc$ & $\bigcirc$ & $\bigcirc$ & $\bigcirc$ & $\bigcirc$ \\
\hline
\end{tabular}

Do you perceive reflections on your computer screen or desk surface?

\begin{tabular}{|c|c|c|c|c|c|c|}
\hline & $\mathrm{Nev}$ & & & & Often & $\begin{array}{l}\text { Prefer not } \\
\text { to answer }\end{array}$ \\
\hline 38. From the ceiling lighting & $\bigcirc$ & $\bigcirc$ & $\mathrm{O}$ & $\mathrm{O}$ & $\mathrm{O}$ & $\bigcirc$ \\
\hline 39. From the task lighting & $\bigcirc$ & $\bigcirc$ & $\bigcirc$ & $\bigcirc$ & $\bigcirc$ & $\bigcirc$ \\
\hline 40. From the daylight & $\bigcirc$ & $\bigcirc$ & $\bigcirc$ & $\bigcirc$ & $\bigcirc$ & $\bigcirc$ \\
\hline
\end{tabular}

Do you perceive glare (i.e., distracting, flickering, shiny reflective surfaces, etc.)"?

Often Never $\begin{aligned} & \text { Prefer not } \\ & \text { to answer }\end{aligned}$
41. From artificial lighting
42. From daylight

Overall, how satisfied are you with the following aspects of the lighting at your work space? $\bigcirc$

$\bigcirc$
Prefer not to answer
43. The light intensity changes over the day
44. The light tone changes over the day
45. The lighting control options

$$
\begin{aligned}
& \text { Very } \\
& \text { dissatisfied }
\end{aligned}
$$

$\begin{array}{llll}0 & 0 & 0 & \bigcirc \\ \bigcirc & \bigcirc & \bigcirc & 0 \\ \bigcirc & \bigcirc & \bigcirc & 0\end{array}$

If you have remarks on the dynamic lighting, please add your comments in the box below 


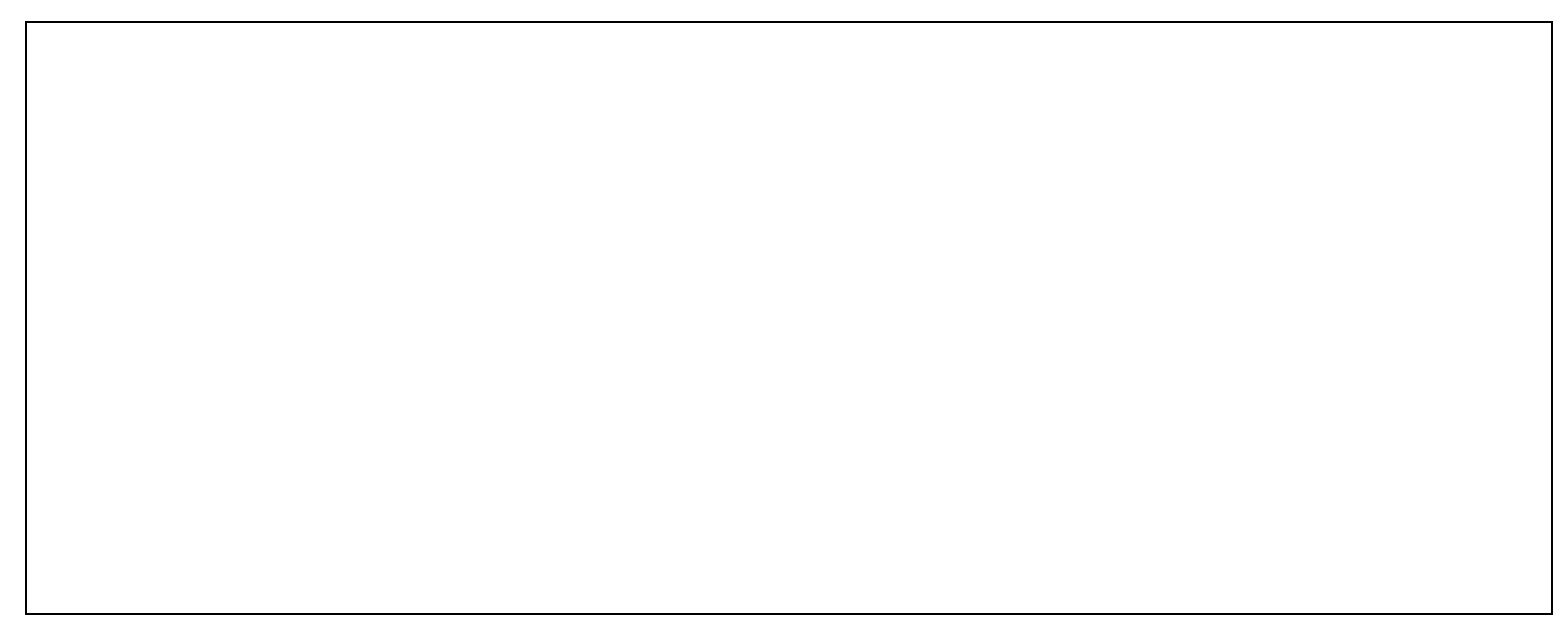




\subsection{Section 4: User acceptance of (new) technologies}

46. I find the control device useful in my daily life.

47. Using the control device increases my productivity.

48. I find the control device easy to use.

49. People whose opinions that I value prefer that I use the control device.

50. I have the knowledge necessary to use the control device.

51. I can get help from others when I have difficulties using the control device.

52. Using the control device has become habit for me.

53. I plan to continue to use the control device frequently.

$\begin{array}{llllll}0 & 0 & 0 & 0 & 0 & 0 \\ 0 & 0 & 0 & 0 & 0 & 0 \\ 0 & 0 & 0 & 0 & 0 & 0 \\ 0 & 0 & 0 & 0 & 0 & 0 \\ 0 & 0 & 0 & 0 & 0 & 0 \\ 0 & 0 & 0 & 0 & 0 & 0 \\ 0 & 0 & 0 & 0 & 0 & 0 \\ 0 & 0 & 0 & 0 & 0 & 0\end{array}$

What kind of better/ideal user interface could you imagine?

\subsection{Section 5: Retrofit}

54. Did you observe any difference in lighting conditions on your workspace, as compared to the previous situation?
O Yes
O No
O Prefer not to answer

55. If yes, do you think the present situation is better or worse as compared to the previous one?
Worse
$\bigcirc$
O Better
Prefer not to answer 


\section{Annex C.2 User rating of the room atmosphere}

The following semantic differential can be used to obtain a rating of the room atmosphere as experienced by the user. It helps to analyse the influence of the integrated lighting system on the overall room appearance and the resulting user perception of the room.

For a basic evaluation the answers are divided into two groups by joining the responses very/quite/rather on both sides to obtain a binary assessment.

Please rate the room atmosphere by marking your particular assessment.

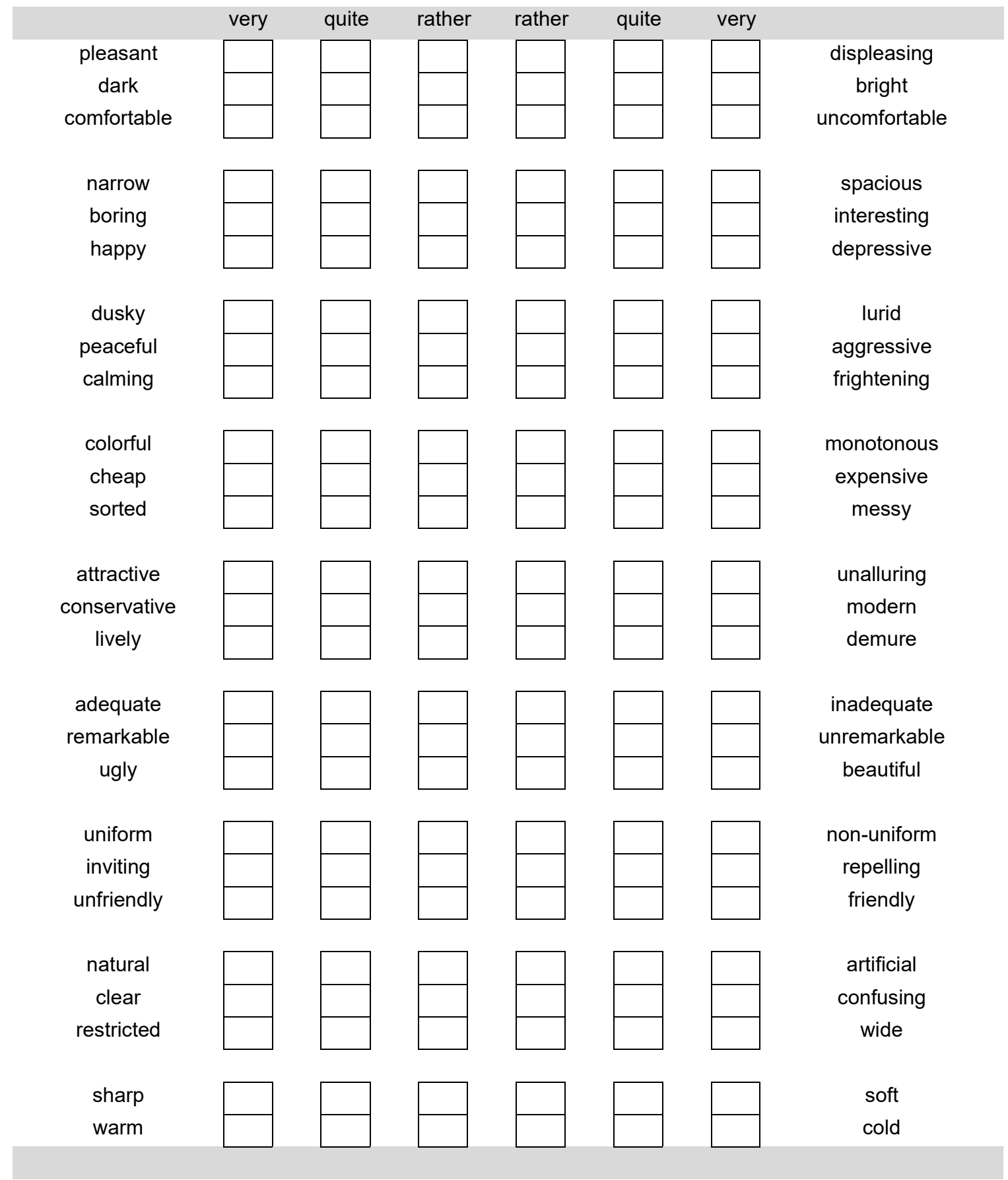




\section{Annex C.3 PILQ}

How do you perceive the lighting conditions in this room

Mark by ticking the scales below

\begin{tabular}{|c|c|c|c|c|c|c|c|c|}
\hline dark & $\square$ & $\square$ & $\square$ & $\square$ & $\square$ & $\square$ & $\square$ & light \\
\hline pleasant & $\square$ & $\square$ & $\square$ & $\square$ & $\square$ & $\square$ & $\square$ & unpleasant \\
\hline uncoloured & $\square$ & $\square$ & $\square$ & $\square$ & $\square$ & $\square$ & $\square$ & coloured \\
\hline strong & $\square$ & $\square$ & $\square$ & $\square$ & $\square$ & $\square$ & $\square$ & weak \\
\hline scattered & $\square$ & $\square$ & $\square$ & $\square$ & $\square$ & $\square$ & $\square$ & concentrated \\
\hline warm & $\square$ & $\square$ & $\square$ & $\square$ & $\square$ & $\square$ & $\square$ & cool \\
\hline unevenly distributed & $\square$ & $\square$ & $\square$ & $\square$ & $\square$ & $\square$ & $\square$ & evenly distributed \\
\hline hard & $\square$ & $\square$ & $\square$ & $\square$ & $\square$ & $\square$ & $\square$ & soft \\
\hline unfocused & $\square$ & $\square$ & $\square$ & $\square$ & $\square$ & $\square$ & $\square$ & focused \\
\hline natural & $\square$ & $\square$ & $\square$ & $\square$ & $\square$ & $\square$ & $\square$ & unnatural \\
\hline flicker & $\square$ & $\square$ & $\square$ & $\square$ & $\square$ & $\square$ & $\square$ & no flicker \\
\hline clear & $\square$ & $\square$ & $\square$ & $\square$ & $\square$ & $\square$ & $\square$ & drab \\
\hline varied & $\square$ & $\square$ & $\square$ & $\square$ & $\square$ & $\square$ & $\square$ & monotonous \\
\hline mild & $\square$ & $\square$ & $\square$ & $\square$ & $\square$ & $\square$ & $\square$ & sharp \\
\hline glaring & $\square$ & $\square$ & $\square$ & $\square$ & $\square$ & $\square$ & $\square$ & shaded \\
\hline subdued & $\square$ & $\square$ & $\square$ & $\square$ & $\square$ & $\square$ & $\square$ & brilliant \\
\hline
\end{tabular}

How well do you think you could see in these lighting conditions?

\begin{tabular}{|r|l|l|l|l|l|l|l|l|l|l|}
\hline very bad & & $\square$ & $\square$ & $\square$ & $\square$ & $\square$ & $\square$ & $\square$ & & very good \\
\hline
\end{tabular}

\section{For data analysis - how to combine items in factors:}

Leftmost value is assigned with "1", rightmost is assigned with "7", e.g.

\begin{tabular}{|r|l|l|l|l|l|l|l|l|l|l|}
\hline glaring & & $\square$ & $\mathrm{X}$ & $\square$ & $\square$ & $\square$ & $\square$ & $\square$ & & shaded \\
\hline
\end{tabular}

is assigned Score $_{\text {shaded }}=2$

The factors below are as measured in Gentile et al. (2018) :

- $\quad \mathrm{PCQ}=\left[\right.$ Score $_{\text {soft }}+$ Score $_{\text {shaded }}+$ Scoreno_flicker $+(8-$ Score unpleasant $)+$ Score evenly_distributed $_{+}+\left(8-\right.$ Score $\left.\left._{\text {sharp }}\right)\right]$ 16

$-\quad \mathrm{PSQ}=\left[\right.$ Score $_{\text {brilliant }}+$ Score $_{\text {light }}+\left(8-\right.$ Score $\left._{\text {drab }}\right)+\left(8-\right.$ Score $\left.\left._{\text {weak }}\right)\right] / 4$ 


\section{Annex C.4 The lighting diary}

Subject \#

\section{LIGHTING DIARY}

\section{Subject \# :}

Date:

\section{$\square$ Morning}

\section{$\square$ Afternoon}

\section{INSTRUCTIONS}

An important part of our research is to investigate how we behave in our local environment. The diary contains a number of measures you take when you enter your office room when you stay there and when you leave the room.

Please fill out a form this morning and a form in the afternoon. Do not forget to check your trial number at the top right and fill in if it is morning or afternoon.

Please fill in an action on each line and indicate at what time it occurred. For example, when you entered the room and lit the desk lamp or you activated the sun shade in the room.

When leaving the room, leave the form, but fill in your destination, if you stay in the department, stay in the building or leave the building. When you come back you fill in this on a new line "sitting in my office" and then you fill in if you take any action.

At lunch you put the form in the enclosed envelope, and after lunch you use a new form.

If you have any questions, contact us 


\section{HOW I USE LIGHTING IN MY OFFICE WHEN I WORK}

\section{Fill in all lighting-use-related activities and movements to and from your office}

\begin{tabular}{|c|c|c|c|c|c|}
\hline & \multicolumn{4}{|c|}{ Activity } & Movement \\
\hline Time & \multicolumn{2}{|c|}{ Ceiling lamp } & Desk lamp & Sun shade & Location \\
\hline & $\square$ Switch on & $\square$ Increase lighting level & $\square$ Switch on & $\square 100 \%$ & $\square$ Sitting in my office \\
\hline & $\square$ Switch off & & Switch off & $50 \%$ & Leaving the office room but in dept. \\
\hline & $\square$ Do nothing & $\square$ Decrease lighting level & Do nothing & $25 \%$ & Leaving for another department \\
\hline & & & & $0 \%$ & Leaving the building \\
\hline & $\square$ Switch on & $\square$ Increase lighting level & Switch on & $100 \%$ & Sitting in my office \\
\hline & $\square$ Switch off & & Switch off & $50 \%$ & $\square$ Leaving the office room but in dept. \\
\hline & $\square$ Do nothing & $\square$ Increase lighting level & Do nothing & $25 \%$ & $\square$ Leaving for another department \\
\hline & & & & $0 \%$ & $\square$ Leaving the building \\
\hline & $\square$ Switch on & Increase lighting level & Switch on & $100 \%$ & Sitting in my office \\
\hline & $\square$ Switch off & & Switch off & $\square 50 \%$ & Leaving the office room but in dept. \\
\hline & $\square$ Do nothing & $\square$ Increase lighting level & Do nothing & $\square 25 \%$ & Leaving for another department \\
\hline & & & & $0 \%$ & Leaving the building \\
\hline & $\square$ Switch on & Increase lighting level & Switch on & $100 \%$ & Sitting in my office \\
\hline & $\square$ Switch off & & Switch off & $\square 50 \%$ & Leaving the office room but in dept. \\
\hline & $\square$ Do nothing & $\square$ Increase lighting level & Do nothing & $\square 25 \%$ & Leaving for another department \\
\hline & & & & $0 \%$ & Leaving the building \\
\hline & $\square$ Switch on & Increase lighting level & $\square$ Switch on & $\square 100 \%$ & Sitting in my office \\
\hline & $\square$ Switch off & & $\square$ Switch off & $\square 50 \%$ & $\square$ Leaving the office room but in dept. \\
\hline & $\square$ Do nothing & $\square$ Increase lighting level & $\square$ Do nothing & $25 \%$ & Leaving for another department \\
\hline & & & & $0 \%$ & Leaving the building \\
\hline & $\square$ Switch on & Increase lighting level & Switch on & $100 \%$ & Sitting in my office \\
\hline & $\square$ Switch off & & Switch off & $50 \%$ & Leaving the office room but in dept. \\
\hline & $\square$ Do nothing & $\square$ Increase lighting level & $\square$ Do nothing & $\square 25 \%$ & Leaving for another department \\
\hline & & & & $\square 0 \%$ & Leaving the building \\
\hline
\end{tabular}




\section{Annex D List of equipment}

Table 14. Selection of the necessary equipment needed to monitor daylighting and lighting projects. Depending on needs, monitoring teams may select only some of these tools. Aspects: $E=$ Energy, $V=$ Visual, $N V=$ Non-Visual, $U=$ User.

\begin{tabular}{|c|c|c|c|c|c|}
\hline Aspect & Tool & $\begin{array}{l}\text { Price } \\
\text { range }\end{array}$ & $\begin{array}{l}\text { Experience } \\
\text { needed }\end{array}$ & Can be used for & Notes \\
\hline$E$ & Energy meter & $€$ & 太放访 & $\begin{array}{l}\text { Annual energy use for } \\
\text { lighting }\end{array}$ & \\
\hline$E$ & Smart meter & $€ €$ & 太为访 & $\begin{array}{l}\text { Annual energy use for } \\
\text { lighting }\end{array}$ & \\
\hline$E, V$ & $\begin{array}{l}\text { Stand-alone } \\
\text { light logger }\end{array}$ & $€$ & $\star \star \star 认$ & $\begin{array}{l}\text { Patterns of lighting use (to } \\
\text { estimate annual energy } \\
\text { use) }\end{array}$ & \\
\hline E & $\begin{array}{l}\text { EN15193-1 } \\
\text { Excel sheet }\end{array}$ & free & 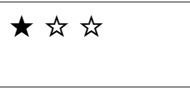 & $\begin{array}{l}\text { Annual energy use for } \\
\text { lighting }\end{array}$ & $\underline{\text { Link }}$ \\
\hline $\mathrm{V}, \mathrm{NV}$ & $\begin{array}{l}\text { Illuminance } \\
\text { meter }\end{array}$ & $€ €$ & 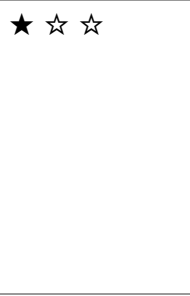 & $\begin{array}{l}\text { Grid-based measurements } \\
\text { (not climate-based), } \\
\text { uniformity ratios, } \\
\text { transmittance of glazing, } \\
\text { circadian stimulus (via } \\
\text { approximate method). } \\
\text { At least } 2 \text { pcs are required. }\end{array}$ & $\begin{array}{l}\text { Must be a calibrated and } \\
\text { cosine corrected } \\
\text { instruments. Avoid cheap } \\
\text { illuminance meter or app- } \\
\text { based meters. }\end{array}$ \\
\hline \multirow[t]{2}{*}{$\mathbf{v}$} & $\begin{array}{l}\text { Cylindrical } \\
\text { illuminance } \\
\text { meter }\end{array}$ & $€ €$ & 太为柁 & Illumination of objects & \\
\hline & $\begin{array}{l}\text { WiFi Cubic } \\
\text { illuminance } \\
\text { meters }\end{array}$ & $€$ & $\star \star \star$ & $\begin{array}{l}\text { All illuminance-based } \\
\text { measurements under } \\
\text { Chapters 3.3.1, 3.3.2, } \\
\text { 3.3.3 }\end{array}$ & $\begin{array}{l}\text { Not commercially } \\
\text { available, under } \\
\text { development }\end{array}$ \\
\hline $\mathbf{v}$ & $\begin{array}{l}\text { Spot luminance } \\
\text { meter }\end{array}$ & $€ €$ & 太为柁 & $\begin{array}{l}\text { Spot luminance, luminance } \\
\text { ratio, reflectance of } \\
\text { Lambertian surfaces } \\
\text { (together with plate of } \\
\text { known reflectance) }\end{array}$ & \\
\hline V, NV & $\begin{array}{l}\text { RPi camera } \\
\text { with fisheye for } \\
\text { HDR }\end{array}$ & $€$ & $\star \star \star$ & $\begin{array}{l}\text { Climate-based metrics } \\
\text { (potentially). May be } \\
\text { disclosed for glare } \\
\text { analysis, shading and } \\
\text { lighting usage analysis, } \\
\text { spectral analysis, .... }\end{array}$ & $\begin{array}{l}\text { Requires experience to } \\
\text { assemble components } \\
\text { and to perform calibration, } \\
\text { but flexible to use. Open } \\
\text { source code }\end{array}$ \\
\hline $\mathbf{V}, \mathbf{N V}$ & $\begin{array}{l}\text { Calibrated HDR } \\
\text { camera }\end{array}$ & $€ € €$ & 太为柁 & $\begin{array}{l}\text { Glare analysis, luminance } \\
\text { based analysis, and - } \\
\text { potentially - circadian } \\
\text { analysis (under } \\
\text { development) }\end{array}$ & \\
\hline V, NV & $\begin{array}{l}\text { DSLR camera } \\
\text { for HDR }\end{array}$ & $€ €$ & 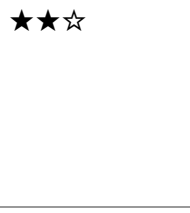 & $\begin{array}{l}\text { Glare analysis, luminance } \\
\text { based analysis, and - } \\
\text { potentially - circadian } \\
\text { analysis (under } \\
\text { development) }\end{array}$ & $\begin{array}{l}\text { Requires expert } \\
\text { calibration before use }\end{array}$ \\
\hline $\mathbf{V}, \mathbf{N V}$ & Spectrometer & $€ €$ & 太放谈 & $\begin{array}{l}\text { Illuminance based } \\
\text { measurements, colour of } \\
\text { the light source, accurate }\end{array}$ & \\
\hline
\end{tabular}




\begin{tabular}{|c|c|c|c|c|c|}
\hline Aspect & Tool & $\begin{array}{l}\text { Price } \\
\text { range }\end{array}$ & $\begin{array}{l}\text { Experience } \\
\text { needed }\end{array}$ & Can be used for & Notes \\
\hline & & & & $\begin{array}{l}\text { methods for circadian } \\
\text { potential (all metrics) }\end{array}$ & \\
\hline V, NV & $\begin{array}{l}\text { Wearable } \\
\text { devices }\end{array}$ & $€ €$ & 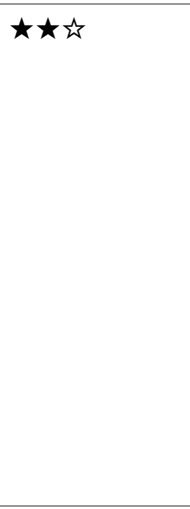 & $\begin{array}{l}\text { Illuminance at individual } \\
\text { level, patterns of light } \\
\text { intake, approximate } \\
\text { circadian potential (based } \\
\text { on RGB sensors only) }\end{array}$ & $\begin{array}{l}\text { Can generate } \\
\text { overwhelming amount of } \\
\text { data, thus needing careful } \\
\text { planning of } \\
\text { measurements. } \\
\text { Some wearables do not } \\
\text { allow for access to raw } \\
\text { data. } \\
\text { Ethical concerns } \\
\text { (personal data) must be } \\
\text { considered if used for } \\
\text { research. }\end{array}$ \\
\hline $\mathbf{v}$ & $\begin{array}{l}\text { PstLM and } \\
\text { SVM }\end{array}$ & $€ €$ & 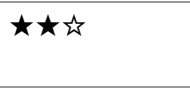 & TLM & $\begin{array}{l}\text { Require some experience } \\
\text { for correct use. }\end{array}$ \\
\hline$E, V$ & $\begin{array}{l}\text { Daylighting / } \\
\text { lighting design } \\
\text { software }\end{array}$ & variable & 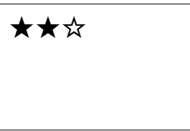 & $\begin{array}{l}\text { Almost any of the } \\
\text { metrics/indicator in } 3.3\end{array}$ & $\begin{array}{l}\text { Open source and/or free } \\
\text { sources software are } \\
\text { available }\end{array}$ \\
\hline V, NV & $\begin{array}{l}\text { Circadian } \\
\text { lighting } \\
\text { software }\end{array}$ & variable & 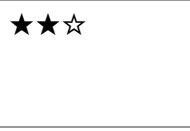 & All indicators in 3.4 & $\begin{array}{l}\text { ALFA (paid license), Lark } \\
\text { (open, but work on paid } \\
\text { 3D modelling software). }\end{array}$ \\
\hline $\mathrm{V}, \mathrm{NV}$ & Excel toolboxes & free & 太方访 & M-EDI, EML, CS & $\begin{array}{l}\text { Check report for } \\
\text { specifications }\end{array}$ \\
\hline $\mathbf{U}$ & $\begin{array}{l}\text { Quantitative } \\
\text { observations } \\
\text { (questionnaires, } \\
\text { etc) }\end{array}$ & $€$ & $\star \star \hbar$ 拧 & $\begin{array}{l}\text { Almost all in } 3.5 \text {, see } \\
\text { chapter for guidance }\end{array}$ & $\begin{array}{l}\text { Data are easier to collect, } \\
\text { but meaningful } \\
\text { questionnaires are hard to } \\
\text { be built. May require } \\
\text { statistics software. }\end{array}$ \\
\hline $\mathbf{U}$ & $\begin{array}{l}\text { Qualitative } \\
\text { observations } \\
\text { (interviews, etc) }\end{array}$ & $€ € €$ & $\star \star \star$ & $\begin{array}{l}\text { Almost all in } 3.5 \text {, see } \\
\text { chapter for guidance }\end{array}$ & $\begin{array}{l}\text { High cost in terms of time, } \\
\text { experience is needed to } \\
\text { collect and analyse data }\end{array}$ \\
\hline
\end{tabular}

